NASA/TM-2010-216087

AIAA-2009-4816

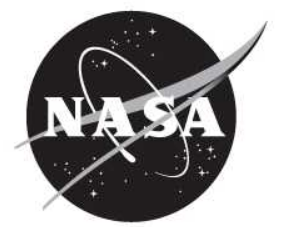

\title{
NEXT Single String Integration Test Results
}

George C. Soulas, Michael J. Patterson, and Luis Pinero

Glenn Research Center, Cleveland, Ohio

Daniel A. Herman

ASRC Aerospace Corporation, Cleveland, Ohio

John Steven Snyder

Jet Propulsion Laboratory, Pasadena, California 


\section{NASA STI Program . . . in Pro le}

Since its founding, NASA has been dedicated to the advancement of aeronautics and space science. The NASA Scienti $c$ and Technical Information (STI) program plays a key part in helping NASA maintain this important role.

The NASA STI Program operates under the auspices of the Agency Chief Information Of cer. It collects, organizes, provides for archiving, and disseminates NASA's STI. The NASA STI program provides access to the NASA Aeronautics and Space Database and its public interface, the NASA Technical Reports Server, thus providing one of the largest collections of aeronautical and space science STI in the world. Results are published in both non-NASA channels and by NASA in the NASA STI Report Series, which includes the following report types:

- TECHNICAL PUBLICATION. Reports of completed research or a major signi cant phase of research that present the results of NASA programs and include extensive data or theoretical analysis. Includes compilations of signi cant scienti $\mathrm{c}$ and technical data and information deemed to be of continuing reference value. NASA counterpart of peer-reviewed formal professional papers but has less stringent limitations on manuscript length and extent of graphic presentations.

- TECHNICAL MEMORANDUM. Scienti c and technical ndings that are preliminary or of specialized interest, e.g., quick release reports, working papers, and bibliographies that contain minimal annotation. Does not contain extensive analysis.

- CONTRACTOR REPORT. Scienti c and technical ndings by NASA-sponsored contractors and grantees.
- CONFERENCE PUBLICATION. Collected papers from scienti $\mathrm{c}$ and technical conferences, symposia, seminars, or other meetings sponsored or cosponsored by NASA.

- SPECIAL PUBLICATION. Scienti c, technical, or historical information from NASA programs, projects, and missions, often concerned with subjects having substantial public interest.

- TECHNICAL TRANSLATION. Englishlanguage translations of foreign scienti $\mathrm{c}$ and technical material pertinent to NASA's mission.

Specialized services also include creating custom thesauri, building customized databases, organizing and publishing research results.

For more information about the NASA STI program, see the following:

- Access the NASA STI program home page at http://www.sti.nasa.gov

- E-mail your question via the Internet to help@ sti.nasa.gov

- Fax your question to the NASA STI Help Desk at 443-757-5803

- Telephone the NASA STI Help Desk at 443-757-5802

- Write to: NASA Center for AeroSpace Information (CASI) 7115 Standard Drive Hanover, MD 21076-1320 
NASA/TM-2010-216087

AIAA-2009-4816

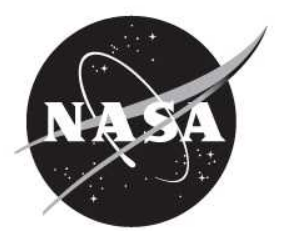

\section{NEXT Single String Integration Test Results}

George C. Soulas, Michael J. Patterson, and Luis Pinero

Glenn Research Center, Cleveland, Ohio

Daniel A. Herman

ASRC Aerospace Corporation, Cleveland, Ohio

John Steven Snyder

Jet Propulsion Laboratory, Pasadena, California

Prepared for the

45th Joint Propulsion Conference and Exhibit

cosponsored by the AIAA, ASME, SAE, and ASEE

Denver, Colorado, August 2-5, 2009

National Aeronautics and

Space Administration

Glenn Research Center

Cleveland, Ohio 44135 


\section{Acknowledgments}

A portion of the work described in this paper was carried out by the Jet Propulsion Laboratory, California Institute of Technology, under a contract with the National Aeronautics and Space Administration, funded by the In-Space Propulsion Technology project.

This report contains preliminary ndings, subject to revision as analysis proceeds.

Level of Review: This material has been technically reviewed by technical management.

Available from

NASA Center for Aerospace Information 7115 Standard Drive

Hanover, MD 21076-1320
National Technical Information Service 5285 Port Royal Road Spring eld, VA 22161

Available electronically at http://gltrs.grc.nasa.gov 


\title{
NEXT Single String Integration Test Results
}

\author{
George C. Soulas, Michael J. Patterson, and Luis Pinero \\ National Aeronautics and Space Administration \\ Glenn Research Center \\ Cleveland, Ohio 44135 \\ Daniel A. Herman \\ ASRC Aerospace Corporation \\ Cleveland, Ohio 44135 \\ John Steven Snyder \\ National Aeronautics and Space Administration \\ Jet Propulsion Laboratory \\ Pasadena, California 91109
}

\begin{abstract}
As a critical part of NASA's Evolutionary Xenon Thruster (NEXT) test validation process, a single string integration test was performed on the NEXT ion propulsion system. The objectives of this test were to verify that an integrated system of major NEXT ion propulsion system elements meets project requirements, to demonstrate that the integrated system is functional across the entire power processor and xenon propellant management system input ranges, and to demonstrate to potential users that the NEXT propulsion system is ready for transition to flight. Propulsion system elements included in this system integration test were an engineering model ion thruster, an engineering model propellant management system, an engineering model power processor unit, and a digital control interface unit simulator that acted as a test console. Project requirements that were verified during this system integration test included individual element requirements, integrated system requirements, and fault handling. This paper will present the results of these tests, which include: integrated ion propulsion system demonstrations of performance, functionality and fault handling; a thruster reperformance acceptance test to establish baseline performance; a risk-reduction PMS-thruster integration test; and propellant management system calibration checks.
\end{abstract}

\section{Nomenclature}

$\begin{array}{ll}\text { BOB } & \text { breakout box } \\ \text { DCIU } & \begin{array}{l}\text { digital control interface unit } \\ \text { end of life }\end{array} \\ \text { EOL } & \text { flow control device } \\ \text { FCD } & \text { NASA Glenn Research Center } \\ \text { GRC } & \text { high pressure assembly } \\ \text { HPA } & \text { high power bus } \\ \text { HPB } & \text { NASA Jet Propulsion Laboratory } \\ \text { JPL } & \text { low pressure assembly } \\ \text { LPA } & \text { low power bus } \\ \text { LPB } & \text { mass flow controller } \\ \text { MFC } & \text { NASA's Evolutionary Xenon Thruster } \\ \text { NEXT } & \text { NASA's Solar Electric Propulsion Technology Application Readiness } \\ \text { NSTAR } & \text { performance acceptance test } \\ \text { PAT } & \text { proportional flow control valve } \\ \text { PFCV } & \end{array}$




$\begin{array}{ll}\text { PM } & \text { prototype model } \\ \text { PMS } & \text { propellant management system } \\ \text { PPU } & \text { power processor unit } \\ \text { RePAT } & \text { reperformance acceptance test } \\ \text { RTD } & \text { resistance temperature detector } \\ \text { SSIT } & \text { single string integration test } \\ \text { TRL } & \text { technology readiness level } \\ \text { VF } & \text { vacuum facility } \\ \text { XFSE } & \text { xenon feed support equipment }\end{array}$

\section{Introduction}

The NASA Glenn Research Center (GRC) is responsible for the development of NASA's Evolutionary Xenon Thruster (NEXT) ion propulsion system (Ref. 1). The NEXT system is a next generation ion propulsion system to follow the successful NSTAR (NASA's Solar Electric Propulsion Technology Applications Readiness) ion propulsion system that propelled NASA's Deep Space 1 spacecraft and is presently propelling the Dawn spacecraft (Refs. 2 and 3). The objective of the NEXT project is to advance this next generation ion propulsion technology to NASA Technology Readiness Level (TRL) 5, with significant progress towards TRL 6, to support NASA Science Mission Directorate missions (Ref. 4). Propulsion system elements under development by the NEXT program include a high performance, $7 \mathrm{~kW}$ ion thruster; a modular, high-efficiency $7 \mathrm{~kW}$ power processor unit; a highly flexible advanced xenon propellant management system; and a compact, light-weight thruster gimbal. This design approach was selected to provide future NASA science missions with the greatest value in mission performance benefit at a low total development cost (Ref. 1).

As a critical part of the NEXT test validation process, a single string integration test (SSIT) was performed on the NEXT propulsion system. The objectives of this test were to verify that an integrated system of major NEXT propulsion system elements meets project requirements, to demonstrate that the integrated system is functional across the entire power processor and propellant management system input ranges, and to demonstrate to potential users that the NEXT propulsion system is ready for transition to flight. Project requirements that were verified during this system integration test included individual element requirements, integrated system requirements, and fault handling. Although an earlier system integration test had already been performed on the NEXT system, this earlier test utilized hardware at a brassboard model level (Refs. 4 to 6). Engineering model hardware (i.e., hardware designed for the mechanical and thermal environments anticipated for launch and spaceflight) was predominantly used for the system integration test reported herein (Ref. 6). Propulsion system elements included in this system integration test were:

- An engineering model ion thruster, labeled PM1R, that was manufactured by the NEXT program's industrial partner Aerojet and successfully completed environmental testing at qualification levels (Refs. 7 and 8)

- An engineering model propellant management system (PMS) that was designed and manufactured by the NEXT program's industrial partner Aerojet and successfully completed environmental testing at qualification levels (Refs. 9 and 10)

- An engineering model power processor unit (PPU) manufactured by the NEXT program's industrial partner L-3 Communication Electron Technologies, Inc. (Ref. 11) and

- A breadboard model digital control interface unit (DCIU) that acted as a test console for performing ground-based testing of the propulsion system, and was designed and manufactured by the NEXT program's industrial partner Aerojet (Ref. 10)

This paper will present some of the test results of the NEXT single string integration test. Both propulsion element and system level-performance test results will be presented that bound the NEXT 
throttling envelope. Test results will include all tests associated with propulsion system demonstration of performance and demonstrations of various PMS operating modes including fault mode. Some system demonstrations of PMS and PPU functionality will also be presented. The verification and validation of some requirements will be presented.

\section{Propulsion System Element Descriptions}

The following sections describe the propulsion system elements tested during the single string integration test. They include the ion thruster, the propellant management system, the power processor unit, and the DCIU simulator. Also included in a separate section is a description of the propulsion system interfaces.

\section{Ion Thruster}

The engineering model thruster (previously labeled prototype model, or PM) used in the integration test is labeled PM1R, and is shown in Figure 1. The thruster was developed by GRC, and the technology was transferred to Aerojet, who designed and built this flight-like thruster. The PM thruster design is functionally identical to the thruster developed by NASA (Ref. 12). The PM design improved upon the GRC thruster design with emphasis on surviving vibration and thermal environments and on reduced thruster mass. Manufacturability was also improved with this new design. The PM thruster design included innovative coatings to increase emissivity for enhanced thermal margin, more uniform ion optics aperture diameters with much shallower cusps, a $36 \mathrm{~cm}$ beam extraction diameter to reduce edge aperture erosion, and graphite discharge cathode keeper to mitigate keeper erosion. A more detailed discussion of the PM thruster design can be found in Reference 7.

The PM1R thruster mass, including the cable harnesses, is $13.5 \mathrm{~kg}$ and fits into a $58.0 \mathrm{~cm}$ diam by $43.5 \mathrm{~cm}$ long cylindrical envelope. The thruster input power throttling range is 0.5 to $6.9 \mathrm{~kW}$, with thrust and specific impulse ranges of 26 to $236 \mathrm{mN}$ and 1400 to $4200 \mathrm{~s}$, respectively.

The PM1R thruster is a reworked version of the PM1 thruster that was initially performance tested in the summer of 2006 (Ref. 13). Subsequent environmental tests uncovered deficiencies in the thruster design (Ref. 14). These design deficiencies were resolved and the reworked thruster, now labeled PM1R, was successfully performance acceptance tested during the summer of 2007. This performance test included testing at seven throttle levels that bound the throttle table, and measurements of overall and major subassembly performances. Following that test, PM1R was used for a thruster-PPU integration test (described later). The thruster was then environmentally tested to qualification levels at JPL (Ref. 8). Environmental testing included vibration and thermal vacuum testing with thruster functional tests following each test to assess thruster functionality. Vibration testing included three random vibration tests

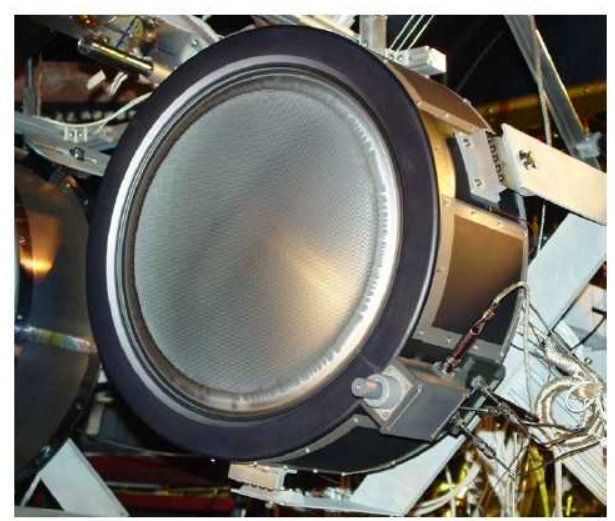

Figure 1. Photograph of the NEXT PM1R ion thruster. 
to 10.0 grms in each axis for 2 min each while mounted on a NEXT gimbal (Ref. 15). Sinusoidal vibrations sweeps were conducted before and after each test to assess thruster health. Thermal vacuum testing included three full thermal cycles from -120 to $215^{\circ} \mathrm{C}$, with three cold and three hot thruster startups demonstrated, and with a $24 \mathrm{hr}$ of accumulated operation at $215^{\circ} \mathrm{C}$. The PM1R thruster successfully completed environmental testing and detailed results can be found in Reference 8 .

\section{Propellant Management System}

The propellant management system used for the system integration test was an engineering model system. The overall design approach was developed by a NEXT integrated product team led by NEXT program's industrial partner Aerojet, who designed and manufactured the engineering model hardware. A schematic of the PMS is shown in Figure 2. The PMS is composed of High Pressure Assembly (HPA) and Low Pressure Assembly (LPA). The HPA reduces xenon tank pressure from a maximum expected operating inlet pressure of $18,600 \mathrm{kPa}(2700 \mathrm{psia})$ to a regulated outlet pressure of $240 \mathrm{kPa}(35 \mathrm{psia})$. The outlet pressure is regulated with proportional flow control valve (PFCV) using an outlet pressure transducer for feedback. The HPA includes a redundant PFCV and outlet pressure transducer for fault tolerance. A single HPA can provide flow to multiple LPAs for systems utilizing multiple thrusters.

The LPA provides independent flow control to each of the three thruster propellant inputs, labeled neutralizer, cathode, and main in Figure 2. During normal operation, each LPA branch flow rate is set by regulating the pressure to a heated porous plug, or thermal throttle, with a separate PFCV and pressure transducer. Thermal throttle temperature is controlled using a sheathed heater with a temperature sensor for feedback. As with the HPA, thermal throttle inlet pressure is regulated with a PFCV using a pressure transducer for feedback. The thermal throttle temperature is typically set to $75{ }^{\circ} \mathrm{C}$ and thermal throttle inlet pressures range from 77.9 to $189 \mathrm{kPa}$ (11.3 to $27.4 \mathrm{psia})$ to achieve the commanded flow rates. To support fault tolerance in the design, the LPA design includes latch valves between the three branches of the LPA and the thermal throttle was designed for operation up to $400{ }^{\circ} \mathrm{C}$. If a branch's PFCV were to fail closed or pressure transducer not operate, for example, the failed branch's latch valve would be opened. The working PFCV of the coupled branches would then regulate pressure to both branches to a constant level, and xenon flow rate would be varied by changing thermal throttle temperatures. The thermal throttle design also incorporated redundant a heater and temperature sensor for fault tolerance.

Photographs of the NEXT engineering model HPA and LPA are shown in Figure 3 and Figure 4, respectively. The HPA's redundant PFCV and outlet pressure transducer were mass model mock-ups to reduce assembly cost. The LPA main flow branch can output a xenon flow rate of up to $50 \mathrm{sccm}$, while the cathode and neutralizer branches can output up to $6 \mathrm{sccm}$ each. The HPA and LPA weigh 1.9 and $3.1 \mathrm{~kg}$, respectively. These masses include each assembly's mounting plate, connectors, and component heaters used for the system integration test.

The engineering model HPA and LPA have completed environmental testing at qualification levels. Vibration testing was conducted in April of 2005 and included three random vibration tests to $14.1 \mathrm{grms}$ in each axis for $2 \mathrm{~min}$ each. Sinusoidal vibrations sweeps were conducted before and after each test to assess PMS health. Thermal vacuum testing was conducted in May of 2007 and included three full thermal cycles from 12 to $70^{\circ} \mathrm{C}$ with $2 \mathrm{hr}$ dwell times at each temperature, followed by two separate $24 \mathrm{hr}$ dwell times at each temperature. Flow calibration checks were conducted prior to and following the vibration test and throughout the thermal vacuum test. Proof pressure tests, leakage checks, and electrical checks were conducted on the HPA and LPA prior to and following the vibration and thermal vacuum tests. The PMS successfully completed environmental testing, and the results of these tests can be found in References 16 and 17. 

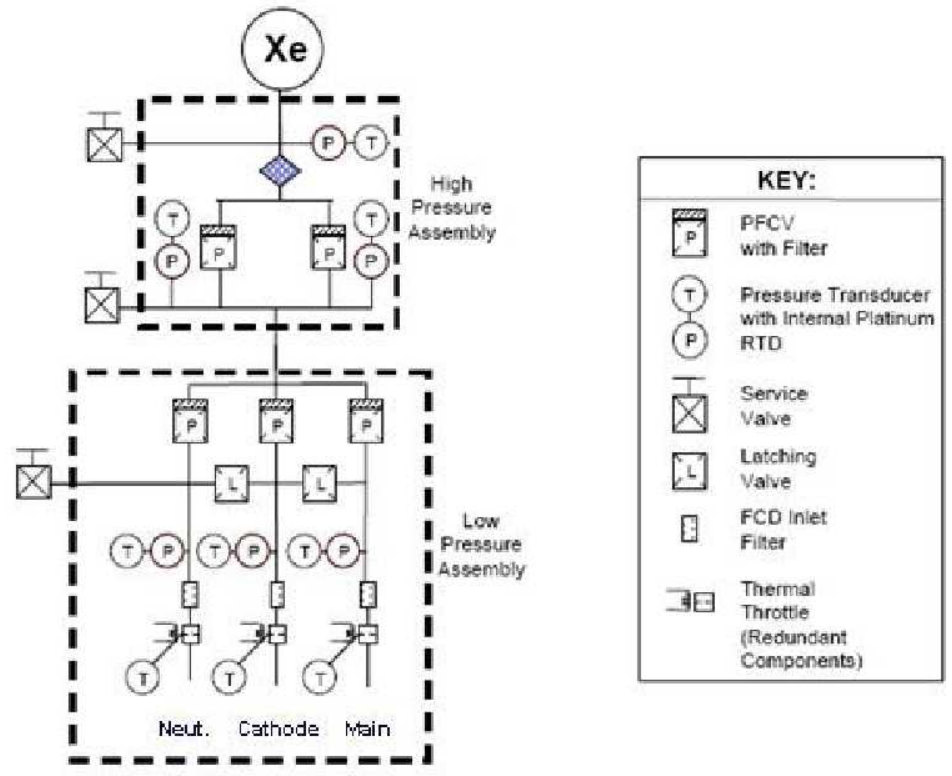

Figure 2.-Schematic of the NEXT PMS. The xenon tank is not included in the NEXT PMS development.

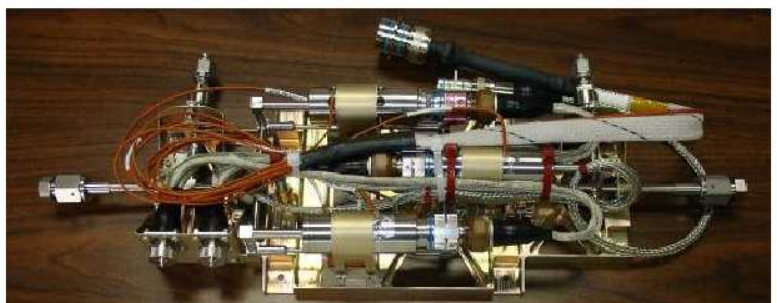

Figure 3.-Photograph of the engineering model HPA.

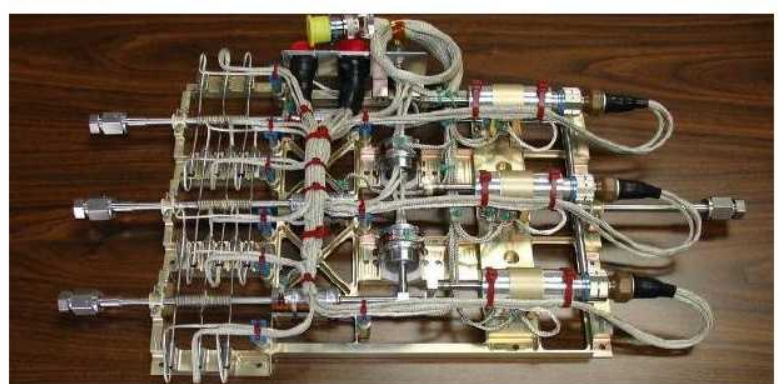

Figure 4.-Photograph of the engineering model LPA.

\section{Power Processor Unit}

The PPU used in the system integration test was an engineering model unit that was designed and built by the NEXT program's industrial partner L-3 Communications. The PPU consists of six power supplies that process power over a wide range of input voltages and output power levels, and a "slice" circuit that transmits controls, status, and telemetry through a digital interface to the DCIU.

A block diagram of the PPU and its electrical interfaces to the thruster, power buses, and DCIU are shown in Figure 5. Only the beam, accelerator, discharge, and neutralizer keeper power supplies are needed for steady state operation, while the neutralizer and discharge cathode heater supplies are used for cathode conditioning and thruster ignition. 


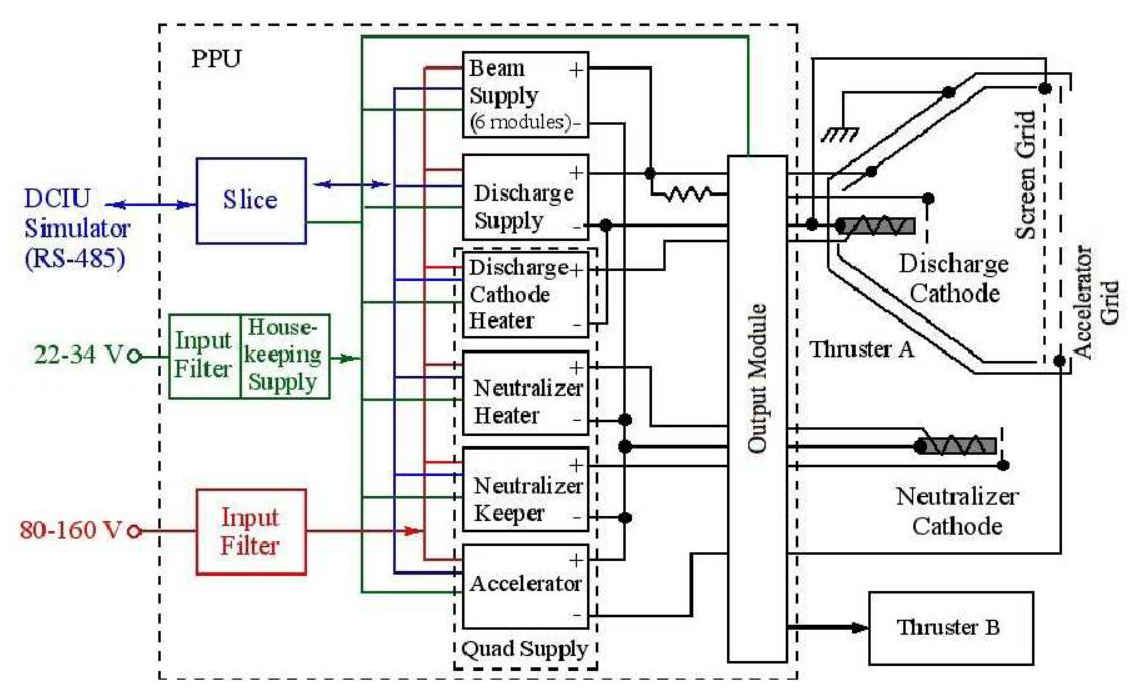

Figure 5.-Schematic of the NEXT PPU including interfaces.

The most important of these power supplies is the beam supply. It processes up to 93 percent of the thruster output power at output voltages as high as $1800 \mathrm{~V}$. The beam supply consists of six addressable power modules that operate in parallel and a master control module. The power modules use a phaseshift/pulse-width modulated dual-bridge topology (Ref. 11) that is capable of efficient operation throughout a very wide range of input and output voltages. A module addressing circuit, controlled by the DCIU, selects the number of operational beam modules. So, unused modules can be turned off to increase efficiency because housekeeping power consumption is reduced while the remaining modules are operated closer to optimum load conditions.

The discharge supply uses a hard-switched, full-bridge topology with current-mode pulse-width modulated control to regulate the output current from 4 to 24 Adc in a single module. The remaining power supplies provide very low power (accelerator and neutralizer keeper supplies) or are only used to start the thruster (neutralizer and discharge heater supplies). These power supplies were combined in one power converter, call the quad supply, based on a full-bridge topology where the top MOSFETs are shared by all the power supplies. The quad supply has heritage from the NSTAR PPU. Both the discharge and neutralizer keeper supplies include a pulsed igniter circuit for cathode ignition.

A housekeeping supply generates power for the internal control, telemetry circuits, and clock signals for control functions, and it contains square-wave oscillators for transductors used to measure several DC currents. The slice handles PPU communication with a DCIU through a RS-485 interface. It contains analog-to-digital converters for telemetry, digital-to-analog converters for control, and current sources for six thermistors located on various power supplies within the PPU. The slice also monitors a recycle fault flag from the beam supply and maintains a recycle counter. The output module contains high voltage relays that switch the PPU outputs between two thrusters and a high current relay that switches the output of the discharge supply across the thruster grids to clear shorts caused by debris.

The PPU design includes two separate power bus inputs, each with integral EMI filters. The high power bus (HPB) input provides power for all PPU power supply outputs and the PPU is capable of operating over an input voltage range of 80 to $160 \mathrm{Vdc}$. The low power bus (LPB) input is used exclusively for housekeeping power and the PPU can operate over an input voltage range of 22 to $34 \mathrm{Vdc}$. Additional information about the PPU design can be found in Reference 11.

A photograph of the NEXT engineering model PPU is shown in Figure 6 . The PPU is $51 \mathrm{~cm} \times 41 \mathrm{~cm}$ $\times 14 \mathrm{~cm}$ dimensionally and weighs $33.9 \mathrm{~kg}$. It can output up to $7.2 \mathrm{~kW}$, is conductively cooled through its baseplate, and was designed to operate over a cold plate temperature range of -20 to $65^{\circ} \mathrm{C}$. 


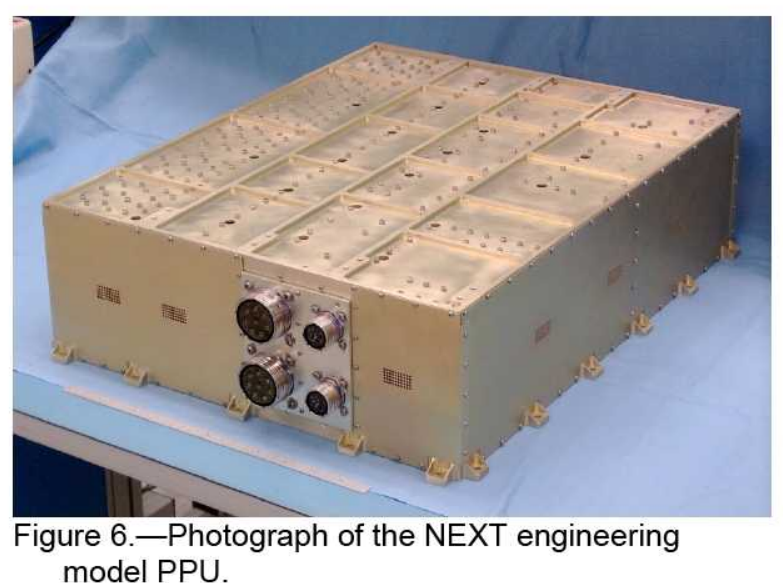

The PPU was integration tested with the PM1R thruster in June of 2006. During the test, the PPU was operated over a range of throttle points that spanned the NEXT throttle table while at atmospheric pressure. Several design issues were uncovered during the integration test, so the PPU was reworked to resolve those problems. Following bench top testing at L-3 Communications, the PPU was shipped to GRC for the system integration test. Because of the delay caused by the PPU rework, it was decided that PPU environmental testing at qualification levels would occur after the single string integration test.

\section{DCIU Simulator}

The DCIU used for the integration test was a simulator that was built by NEXT's industrial partner Aerojet. The DCIU Simulator was a data acquisition and control system used to demonstrate the performance objectives of the propulsion system elements (Ref. 10). In contrast to the other propulsion system elements, the objective of the DCIU Simulator was to act as a test console for performing groundbased testing of the propulsion system (Ref. 10). As a result, the DCIU Simulator was made of commercially available industrial control hardware. The only exception was the PFCV driver circuit which regulates pressure with a PFCV using pressure transducer for feedback. The PFCV driver circuit was designed to a brassboard level for this test, while the remainder of the DCIU Simulator was designed to a breadboard level (Refs. 4 and 6).

The DCIU Simulator controlled and read telemetry from the PMS and PPU. The DCIU Simulator also operated the Xenon Feed System Equipment (XFSE) built to support single string integration testing of the PMS (described later).

The DCIU Simulator utilized two computers to improve response times. One computer handled hardware communications and stored test data while the other computer provided a graphical user interface. Communications between the computers and the DCIU Simulator hardware were handled by an Ethernet hub. The DCIU Simulator software was written in Visual C++. The software was not written for autonomous thruster operation. So thruster functions that included cathode conditioning, ignition, throttling, beam current regulation, and shutdown had to be conducted manually by the user with the software's graphical interface.

The DCIU Simulator sent digital commands to and received digital telemetry from the PPU using an interface that converted Ethernet communications to RS-485. For the PMS interface, though, the DCIU had to power the HPA and LPA, as well as provide analog commands and digitize the incoming analog telemetry. As a result, the DCIU Simulator included separate HPA and LPA interfaces that:

- Provided an adjustable 24 to $32 \mathrm{Vdc}$ housekeeping power to operate the pressure transducers and latch valves;

- Utilized industrial hardware for digital-to-analog conversion for analog commands and analog-todigital conversion for processing analog telemetry; 
- Operated the PFCV driver circuits for pressure regulation using analog commands; and

- Operated the thermal throttles using commercial DC power supplies and software-controlled proportional-integral-derivative loops for temperature control.

The DCIU Simulator also included an XFSE interface box that:

- Operated separate pressure transducers to monitor PMS operation;

- Operated separate mass flow controllers to independently monitor PMS flow rates and to provide a separate flow path for thruster operation by actuating separate solenoid vales (described later); and

- Interfaced to a facility interlock to terminate propulsion system operation from a high facility pressure.

A brief description of the DCIU Simulator hardware can also be found in Reference 10 .

\section{Summary of Propulsion System Interfaces}

A critical part of demonstrating integrated system functionality includes verifying that interfaces between system elements are compatible. Figure 7 shows a summary of the NEXT propulsion system interfaces. Both the PPU and the DCIU receive bus power. A 22 to $34 \mathrm{Vdc}$ low power bus is used by the PPU for housekeeping functions and by the DCIU for DCIU and PMS operation. An unregulated 80 to $160 \mathrm{Vdc}$ high power bus is used by the PPU to power all PPU power supplies. The propulsion system can induce transients on the power bus as loads are changed or switched, such as that due to sudden power interruptions from thruster recycling or during thruster startup and shutdown. The PPU also has internal fault protection to shutdown from a high power bus under- or overvoltage, or from a low power bus under-voltage.

The DCIU Simulator provides power to the PMS to operate the pressure transducers, latch valves, PFCVs, and thermal throttle heaters. For flow control, the DCIU regulates LPA and HPA pressures with the PFCVs and regulates thermal throttle temperature with the throttle heaters to predefined values stored by the DCIU software. The DCIU Simulator receives analog telemetry from the PMS pressure transducers and thermal throttle temperature sensors, which are used to regulate pressures and thermal throttle temperatures. The DCIU Simulator also cycles the latch valves for fault mode operation.

The PMS delivers regulated xenon flow to the thruster through three propellant lines. The thruster and the propellant tubing can affect the xenon flow rate via backpressure (i.e., the pressure just downstream of the LPA thermal throttles). This pressure is a function of thruster inlet pressure, flow rate, and tubing dimensions.

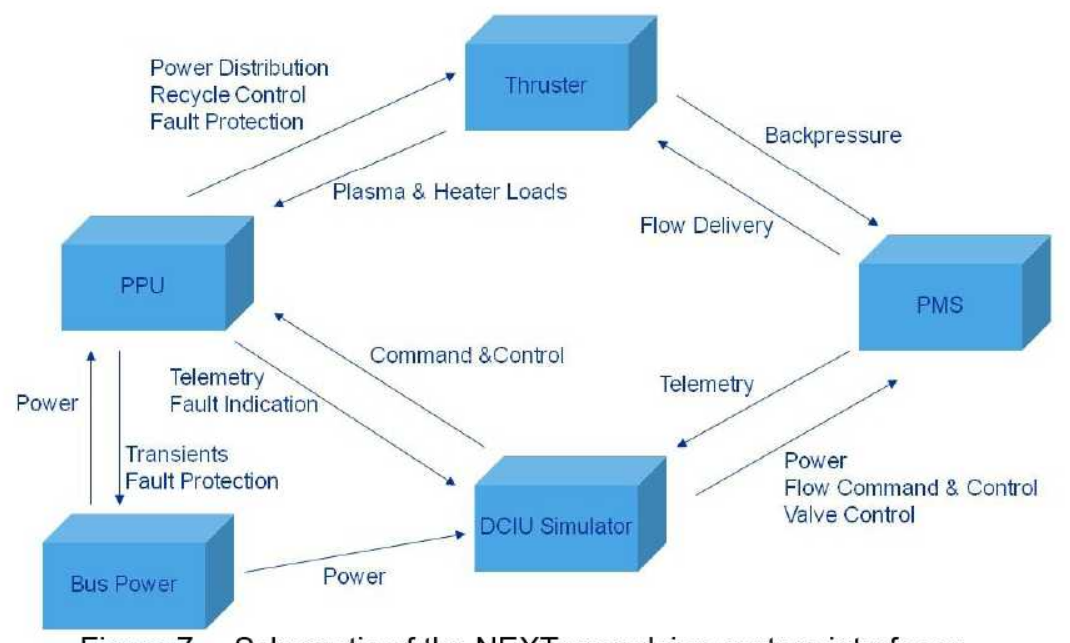

Figure 7.-Schematic of the NEXT propulsion system interfaces. 
The DCIU Simulator provides command and control of the PPU via a RS-485 digital interface to operate all PPU power supplies. The DCIU Simulator also uses this same interface to receive telemetry from the PPU that includes measured voltages, currents, recycle count, and internal PPU temperatures, and a fault indication. On a spacecraft, the sequencing of the power supplies for thruster startup and operation, including beam current regulation, would be controlled autonomously by the DCIU, but the user controlled these functions during the integration test.

The PPU distributes power to the thruster for its operation using two cable harnesses. The PPU provides regulated heater currents and ignitor voltage pulses for neutralizer and discharge cathode conditioning and ignition, and then provides regulated beam and accelerator voltages, neutralizer keeper current, and discharge current for thruster operation. The PPU also provides recycle control and fault protection from neutralizer and discharge extinctions, and for recycle rates exceeding a predefined recycle level.

\section{Integration Test Setup}

The following sections describe the test setup for the single string integration test. The overall test setup and vacuum facilities are described in the next section. This is followed by descriptions of the ion thruster and thruster plume diagnostics, the PMS and XFSE, and the PPU test setups.

\section{Overall Test Setup and Vacuum Facilities}

The integration test was conducted in two vacuum facilities. The PM1R thruster and PMS, along with part of the XFSE, were installed in the NASA GRC's Vacuum Facility 6 (VF6), shown in Figure 8. This vacuum facility has a diameter of $7.6 \mathrm{~m}$ and an overall length of $22.9 \mathrm{~m}$. It is cryogenically pumped with twelve internal cryogenic pumps for a total measured pumping speed of $290,000 \mathrm{~L} / \mathrm{s}$ with xenon and a base pressure of about $1.3 \times 10^{-5} \mathrm{~Pa}\left(1 \times 10^{-7}\right.$ torr $)$. The facility also has a turbomolecular pump for the removal of lighter gases and a residual gas analyzer for monitoring residual gas partial pressures. Background pressures during full power thruster operation were within $3.7 \times 10^{-4} \mathrm{~Pa}\left(2.8 \times 10^{-6}\right.$ torr $)$, as measured by a internal ion gage located $41 \mathrm{~cm}$ below the centerline of and $25 \mathrm{~cm}$ behind the PM1R thruster. Most of the vacuum facility's stainless steel interior surfaces were lined with a flexible carbon material to reduce the amount of back-sputtered material onto the thruster and PMS. This facility was selected because it was easily large enough to accommodate the PMS, the PM1R thruster, and associated thruster plume diagnostics. It was also the same facility used for earlier thruster performance acceptance testing.

The PPU was mounted within NASA GRC's Vacuum Facility 14 (VF14), shown in Figure 9. This portable, rectangular facility is $0.56-$ by $0.56-$ by $0.91-\mathrm{m}$ and is pumped with a turbo-molecular pump with a $1000 \mathrm{~L} / \mathrm{s}$ pumping speed. A separate, smaller vacuum facility was chosen for the PPU to better protect the PPU from back-sputtered facility material and to allow for quicker problem resolution should the PPU require atmospheric exposure for inspection or servicing. Facility pressures were typically within $2.7 \times 10^{-4} \mathrm{~Pa}\left(2 \times 10^{-6}\right.$ torr $)$ during PPU operation. Vacuum Facility 14 was co-located with VF6 during the system integration test.

Both vacuum facilities were independently controlled. However, to ensure that a sudden pressure increase in either facility did not damage the propulsion system elements, the DCIU Simulator was operated with pressure interlocks that terminated PPU output power if either facility exceeded predefined pressure limits. 


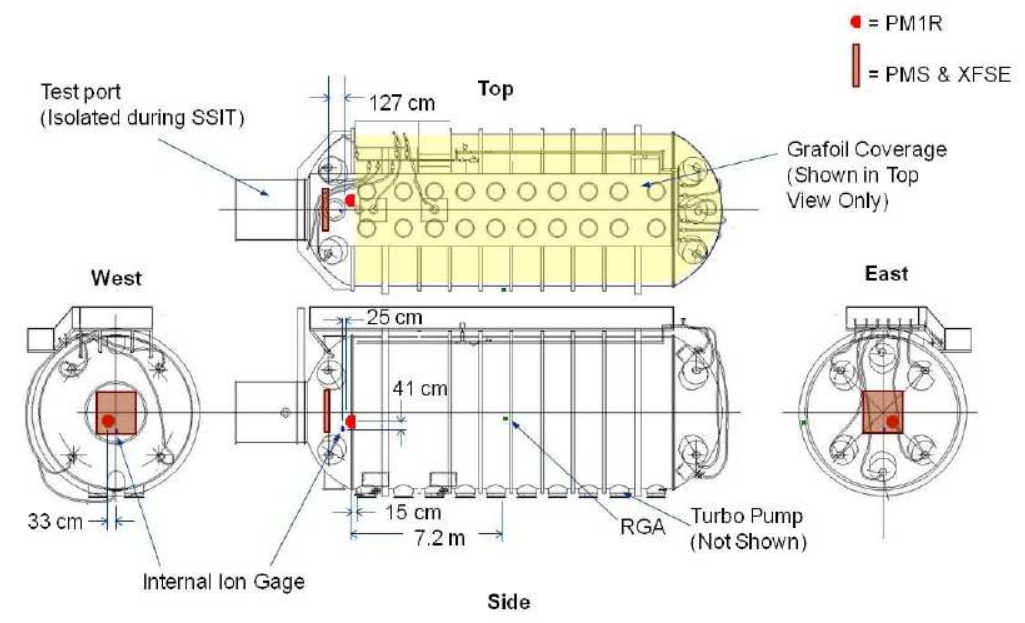

Figure 8.- Schematic of the PM1R thruster, PMS, and XFSE in GRC's VF6.

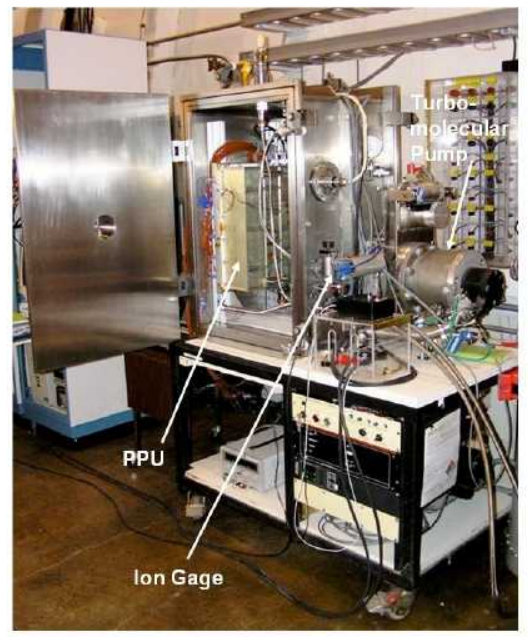

Figure 9.-Photograph of the PPU installed in GRC's VF14.

\section{Ion Thruster and Plume Diagnostics Setup}

The PM1R thruster was mounted in VF6 on the multi-thruster array test mount, as shown in Figure 10 (Ref. 18). The setup was nearly identical to that used for performance acceptance testing the thruster (Ref. 13). Taking advantage of an existing test setup was done to reduce cost and to allow for a multithruster test of the PMS. The PMS and XFSE were mounted behind the PM1R thruster, as shown in Figure 10. The NEXT GRC-built thrusters surrounding PM1R were not operated during the single string integration test reported herein.

Ion beam plume diagnostics included circular planar probes mounted onto to a two-axis probe positioning system for measuring beam current density profiles, shown in Figure 10. There were a total of six planar probes with a $1 \mathrm{~cm}^{2}$ circular current-collecting area mounted onto a probe rake, also shown in Figure 10. The positioning system, which was operated by a separate data acquisition and control system, swept the probes in the radial and axial directions downstream of the engine ion optics, with $1.5 \mathrm{~m}$ travel in each axis. To measure beam current density, the probes were biased negative with respect to beam plasma potential to repel electrons and were grounded through separate resistors that acted as shunts to measure collected currents. 


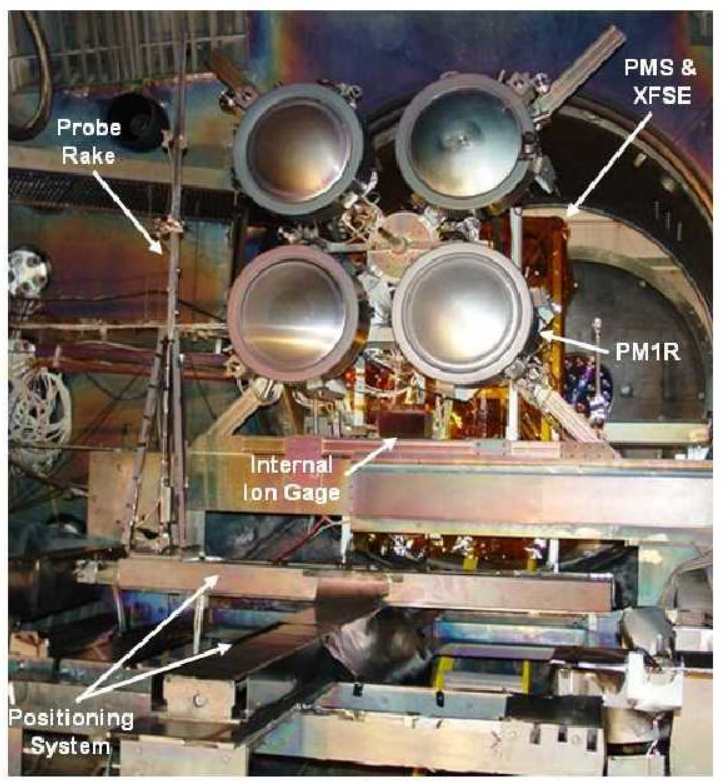

Figure 10.-Photograph of PM1R and plume diagnostics mounted in GRC's VF6.

\section{Propellant Management System and XFSE Setup}

The PMS was integrated into a XFSE assembly, as shown on the schematic in Figure 11. The XFSE is ground test-support equipment and, therefore, not a part of the flight system but was still controlled by the DCIU Simulator. The XFSE was used to monitor the operation of the PMS during the integration test and to provide a secondary thruster gas feed system. The XFSE was divided into two systems. The external XFSE was located on atmospheric side of VF6. It included mass flow controllers for checking LPA flow rate calibrations and could independently provide flow to the thruster using mass flow controllers, thus allowing for thruster operation using a standard flow regulation configuration. The internal XFSE was located within VF6. It included manual and solenoid valves that allowed for configuration changes, such as thruster operation with and without the PMS. The internal XFSE included one HPA and three LPAs for multi-thruster PMS operation. Only one LPA was operated for the results reported herein, and is indicated in Figure 11. The internal XFSE and PMS were covered with a polyimide foil for protection against back-sputtered material deposition.

Tubing and components of the PMS and XFSE were wrapped with heater tape for a bake-out to remove air and adsorbed moisture on surfaces exposed to atmosphere. About twenty thermocouples were mounted on key PMS and XFSE components and were monitored and recorded by the DCIU Simulator throughout testing. To simulate pressure drops due to viscosity, the tubing leading from the LPA outlet to the thruster inlet included $3.5 \mathrm{~m}$ of $0.32-\mathrm{cm}$ diam by $0.71-\mathrm{mm}$ wall tubing, which is similar to the longest tubing length used with the Dawn ion thruster propellant management system.

For the system integration test, the DCIU Simulator monitored and recorded all pressures, temperatures, and flows measured by the PMS and XFSE. The DCIU Simulator also monitored and recorded PMS component input currents and voltages other than those of the pressure transducers, which were manually recorded. For the PMS, the DCIU Simulator regulated HPA outlet pressure, LPA outlet flow rates, and thermal throttle temperatures, and controlled latch valve position and the selection of primary or redundant thermal throttle heaters. For the XFSE, the DCIU Simulator controlled and recorded telemetry from the mass flow controllers. 


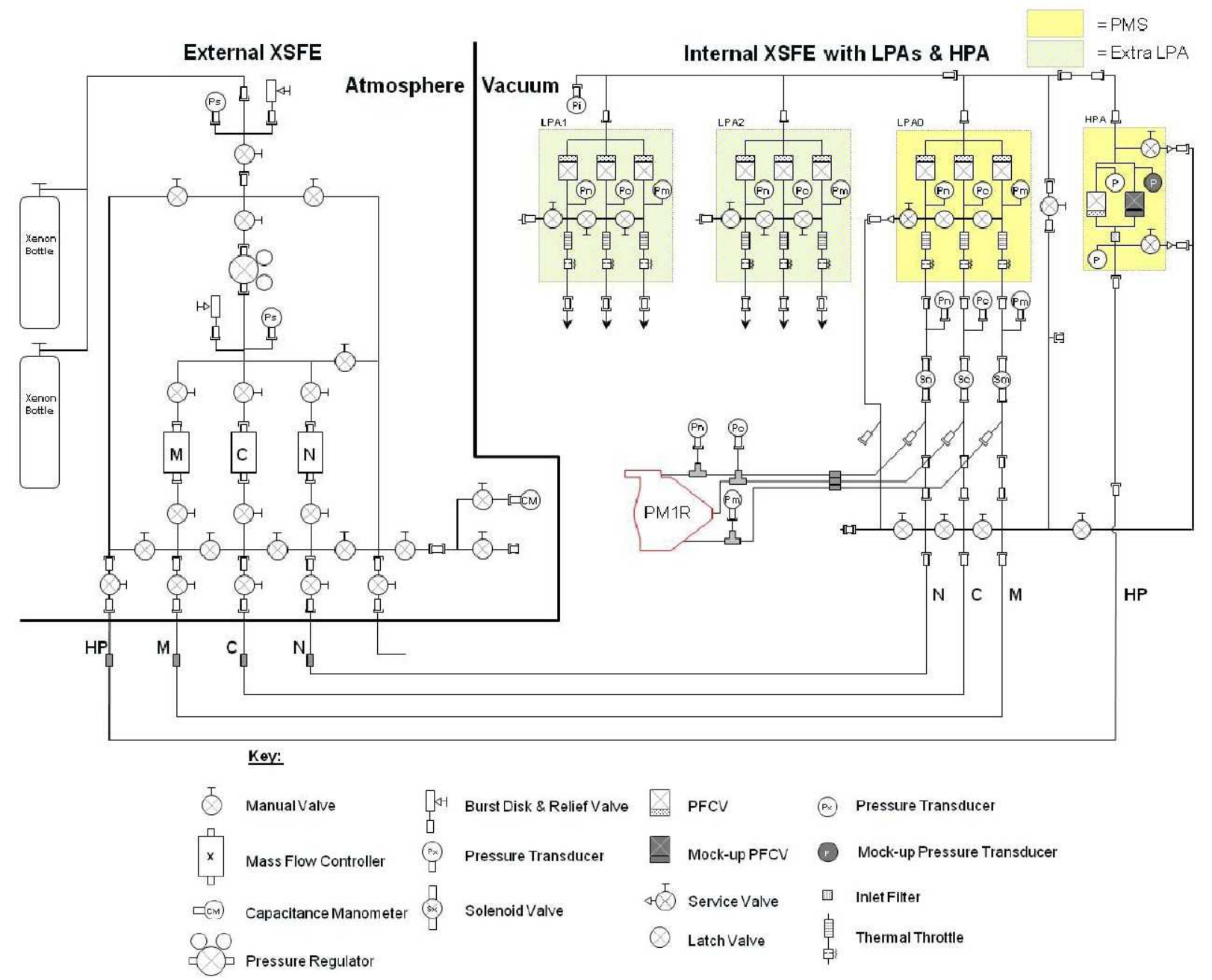

Figure 11.- Schematic of the PMS and XFSE. The HPA and LPA of the PMS used in this study are highlighted in yellow. Here, "M", " $\mathrm{C}$ ", and "N" are the main, cathode, and neutralizer flow branches, respectively, and "HP" is the high pressure outlet of the internal XFSE that leads to the HPA inlet.

\section{Power Processor Unit Setup}

For all tests reported herein, the PPU was under vacuum in VF14 and was mounted on a cold plate for removal of PPU waste heat, which was measured to be as high as $503 \mathrm{~W}$ during full power operation. The cold plate was an aluminum alloy plate with machined internal passages for the cooling fluid. A high thermal conductivity gasket was used as an interface material to ensure a good thermal contact between the PPU thermal interface and cold plate. The cold plate was connected to a heat exchanger that had a $>1000 \mathrm{~W}$ heat removal capability. A photograph of the PPU on its cold plate in VF14 is shown in Figure 12.

Cold plate and external power processor temperatures were monitored with 28 thermocouples. One thermocouple served as the reference temperature for the PPU baseplate and was located on the cold plate next to the PPU beam power supply modules as shown in Figure 12. The heat exchanger controlled the PPU reference thermocouple to a predefined value throughout all tests. All of these thermocouples were monitored by a separate data logging computer. 


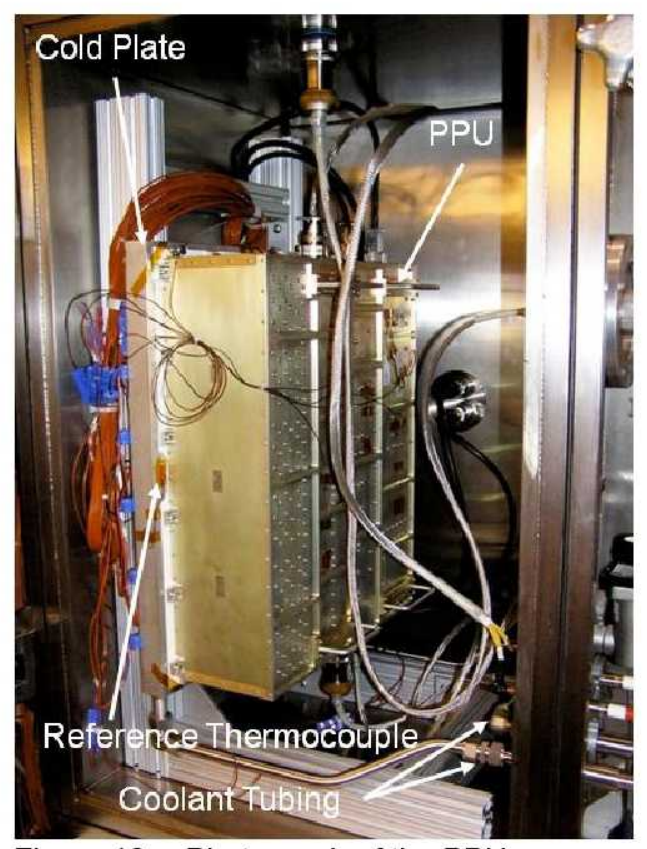

Figure 12.-Photograph of the PPU mounted on its cold plate. The reference thermocouple location is also shown.

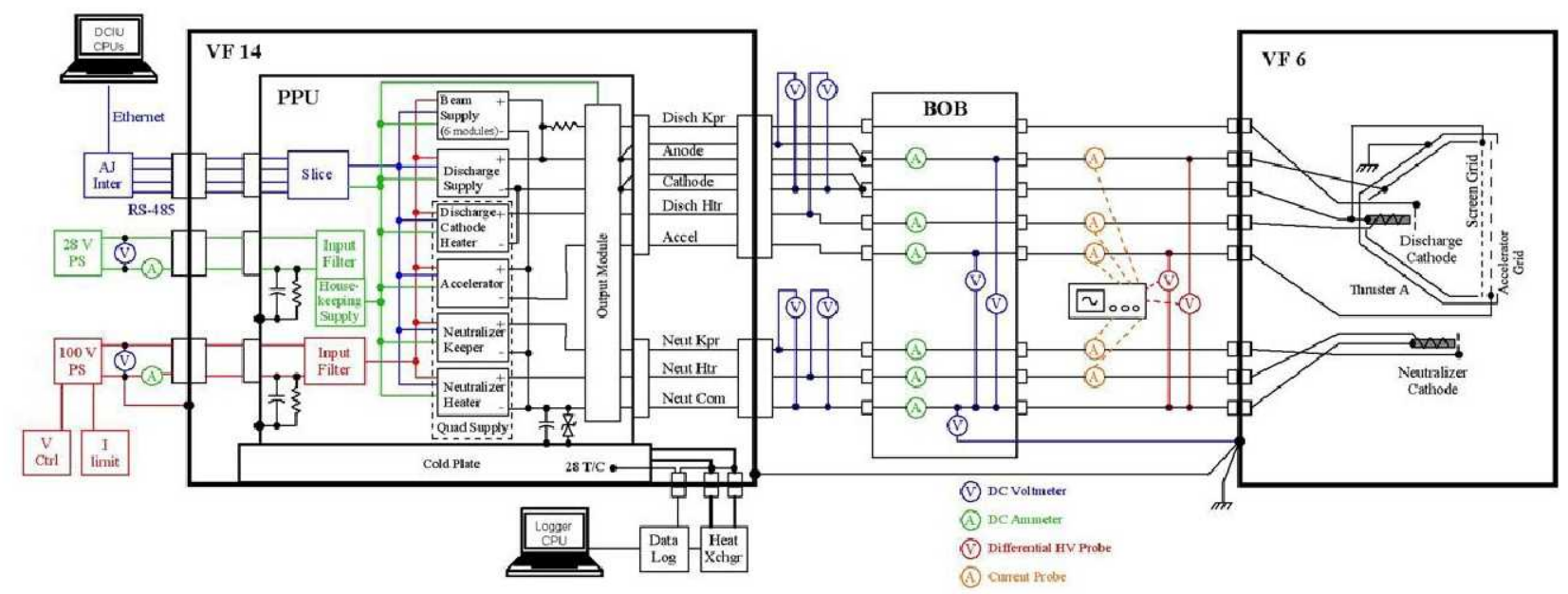

Figure 13.-Schematic of the PPU wired to the thruster during the integration test. Here, "BOB" refers to the breakout box.

The PPU was tested both with the PM1R thruster and on a resistive load for requirements verification and validation. A schematic of the PPU wired to the thruster is shown below in Figure 13. High and low power bus power to the PPU was provided by voltage regulated, commercially available power supplies. The peak input current from the high power bus was further interlocked to the high power bus output to protect the PPU from an unintended over-current. The PPU outputs were wired through a breakout box that allowed for independent measurements of PPU output currents and voltages. Oscilloscopes were used to measure current and voltage transients during recycles and cathode ignition.

The objectives of PPU tests with a resistive load included, for example, determining power supply output ranges and verifying interlock settings. The test setup was identical to that shown in Figure 13 except that the thruster in VF6 was replaced with a resistive load. 
For the integration test, the DCIU Simulator monitored and recorded all digital telemetry from the PPU. This telemetry included not only all PPU power supply output voltages and currents, but also the high power bus input voltage and current and temperatures from the six thermistors within the PPU. All PPU current and voltage telemetry was verified by independent measurements with digital multimeters and shunts, which were manually recorded. Low power bus current and voltage were also monitored with digital multimeters. All measured voltages that were used to verify and validate PPU operation were measured as close as possible to the PPU to eliminate voltage drops. Oscilloscope traces were stored electronically.

\section{Test Plan}

A detailed test plan was developed for the system integration test. The test plan was developed "bottoms up" from project requirements, but also included system-level concerns not specified in the requirements, such as PMS operation at the expected range of fluid input conditions, electrical transients produced by the propulsion system on the power bus, and PPU regulation at beam module control mode changes. The test plan also included expanded PPU integration tests since these tests had not been completed earlier.

The system integration test plan was divided into three major test types. These test types included propulsion system demonstrations of performance, functionality, and fault handling. Propulsion system demonstrations of performance included measurements of propulsion element performance at standard input conditions and over the full range of PPU and PMS input conditions. Power processor testing included operation at the maximum acceptable flight baseplate temperature of $50{ }^{\circ} \mathrm{C}$ to verify systems interfaces were still functional at this elevated temperature and because the PPU had not yet completed thermal vacuum testing. Table 1 lists the various PPU and PMS input parameters that were tested.

TABLE 1.-PPU AND PMS INPUT PARAMETER SETTINGS AS A FUNCTION OF INPUT CONDITION FOR THE SYSTEM INTEGRATION TESTS

\begin{tabular}{|c|c|c|c|c|}
\hline Input Parameter & $\begin{array}{l}\text { Standard input } \\
\text { conditions }\end{array}$ & $\begin{array}{l}\text { Full range of PPU } \\
\text { input conditions }\end{array}$ & $\begin{array}{c}\text { Elevated PPU } \\
\text { temperature input } \\
\text { conditions }\end{array}$ & $\begin{array}{l}\text { Full range of PMS input } \\
\text { conditions }\end{array}$ \\
\hline PPU LPB Voltage, V & 28 & 22,34 & 28 & 28 \\
\hline PPU HPB Voltage, $\mathrm{V}$ & 100 & $80-160$ & $80-160$ & 100 \\
\hline PPU baseplate temperature, ${ }^{\circ} \mathrm{C}$ & 25 & 25 & 50 & 25 \\
\hline PMS LPB voltage, $\mathrm{V}$ & 28 & 28 & 28 & 22,34 \\
\hline PMS HPA inlet pressure, $\mathrm{kPa}$ (psia) & $350(50)$ & $350(50)$ & $350(50)$ & $350(50), 6,200(900)^{\mathrm{a}}$ \\
\hline PMS HPA outlet pressure, $\mathrm{kPa}$ (psia) & $240(35)$ & $240(35)$ & $240(35)$ & $230(33), 260(37)$ \\
\hline LPA thermal throttle temperature, ${ }^{\circ} \mathrm{C}$ & 75 & 75 & 75 & 75 \\
\hline
\end{tabular}

${ }^{a}$ Highest xenon PMS inlet pressure available for the test.

Table 2 lists the throttle levels selected for the various tests above. Table 3 lists thruster throttling input parameters and predicted power, thrust, and specific impulse for these throttle points. A total of 16 throttle points were selected for demonstrating thruster operation at standard input conditions and the full range of PPU input conditions. These throttle points included the highest and lowest power levels, beam currents, beam voltages, accelerator voltages, and discharge power, and all sets of independent throttle table flows. Although PPU testing at elevated PPU baseplate temperatures also contained the same number of throttle points, the list was later pared down to seven throttle points to reduce testing costs, but these points still covered the full throttle range. For the full range of PMS input conditions, a total of four throttle points were selected, and these included the highest and lowest flow rate settings and two intermediate flow rate settings, as shown in Table 2. 
TABLE 2.-THROTTLE POINTS USED TO DEMONSTRATE OF SYSTEM

PERFORMANCE, FUNCTIONALITY, AND FAULT HANDLING

\begin{tabular}{|c|c|c|c|c|c|c|c|c|c|}
\hline \multicolumn{2}{|c|}{ Throttle point } & \multirow{2}{*}{$\begin{array}{l}\text { PM1R } \\
\text { RePAT }\end{array}$} & \multirow{2}{*}{$\begin{array}{l}\text { PM1R-PMS } \\
\text { integration }\end{array}$} & \multicolumn{6}{|c|}{ System integration tests } \\
\hline $\begin{array}{c}\text { Beam } \\
\text { current, } \\
\text { A }\end{array}$ & $\begin{array}{c}\text { Beam } \\
\text { supply } \\
\text { voltage, } \\
\text { V } \\
\end{array}$ & & & $\begin{array}{l}\text { Standard } \\
\text { input } \\
\text { conditions }\end{array}$ & \begin{tabular}{|c|} 
Full range of \\
PPU input \\
conditions
\end{tabular} & $\begin{array}{l}\text { Elevated } \\
\text { temperature } \\
\text { input } \\
\text { conditions }\end{array}$ & $\begin{array}{l}\text { Full range of } \\
\text { PMS } \\
\text { conditions }\end{array}$ & $\begin{array}{c}\text { PMS end-of- } \\
\text { life pressure } \\
\text { demo }\end{array}$ & $\begin{array}{l}\text { PMS fault } \\
\text { mode demo }\end{array}$ \\
\hline 3.52 & 1800 & $\checkmark$ & $\checkmark$ & $\checkmark$ & $\checkmark$ & $\checkmark$ & --- & --- & -- \\
\hline 3.52 & 1179 & $\checkmark$ & $\checkmark$ & $\checkmark$ & $\checkmark$ & $\checkmark$ & $\checkmark$ & $\checkmark$ & $\checkmark$ \\
\hline 3.10 & 1800 & --- & --- & $\checkmark$ & $\checkmark$ & --- & --- & --- & --- \\
\hline 2.70 & 1800 & $\checkmark$ & --- & $\checkmark$ & $\checkmark$ & -- & $\checkmark$ & $\checkmark$ & $\checkmark$ \\
\hline 2.70 & 1021 & $\checkmark$ & --- & $\checkmark$ & $\checkmark$ & --- & --- & --- & --- \\
\hline 2.35 & 1800 & --- & -- & $\checkmark$ & $\checkmark$ & --- & -- & -- & --- \\
\hline 2.35 & 1179 & --. & --. & $\checkmark$ & $\checkmark$ & --- & -.- & --. & --. \\
\hline 2.00 & 1800 & $\checkmark$ & $\checkmark$ & $\checkmark$ & $\checkmark$ & $\checkmark$ & $\checkmark$ & $\checkmark$ & --- \\
\hline 2.00 & 1396 & --- & --- & $\checkmark$ & $\checkmark$ & -- & -- & -- & -- \\
\hline 2.00 & 1021 & $\checkmark$ & --- & $\checkmark$ & $\checkmark$ & $\checkmark$ & --- & -- & -- \\
\hline 1.60 & 1800 & -- & --- & $\checkmark$ & $\checkmark$ & --- & -- & --- & --- \\
\hline 1.20 & 1800 & $\checkmark$ & $\checkmark$ & $\checkmark$ & $\checkmark$ & $\checkmark$ & -- & --- & -- \\
\hline 1.20 & 1179 & $\checkmark$ & -- & $\checkmark$ & $\checkmark$ & -- & -- & -- & -- \\
\hline 1.20 & 679 & $\checkmark$ & $\checkmark$ & $\checkmark$ & $\checkmark$ & $\checkmark$ & --- & --- & --- \\
\hline 1.20 & 300 & --- & --- & $\checkmark$ & $\checkmark$ & -- & -- & -- & -- \\
\hline 1.00 & 275 & $\checkmark$ & -- & $\checkmark$ & $\checkmark$ & $\checkmark$ & $\checkmark$ & $\checkmark$ & $\checkmark$ \\
\hline
\end{tabular}

TABLE 3.-THRUSTER THROTTLE TABLE WITH PREDICTED THRUST AND SPECIFIC IMPULSE

FOR RELEVANT THROTTLE POINTS (THE COMPLETE THROTTLE TABLE CONTAINS

40 THROTTLE POINTS). ALL NEUTRALIZER KEEPER CURRENTS ARE $3.0 \mathrm{~A}$.

\begin{tabular}{|c|c|c|c|c|c|c|c|c|}
\hline $\begin{array}{c}\text { Nominal } \\
\text { thruster input } \\
\text { power, } \\
\text { kW }\end{array}$ & $\begin{array}{c}\text { Beam } \\
\text { current, } \\
\text { A }\end{array}$ & $\begin{array}{c}\text { Beam supply } \\
\text { voltage, } \\
\text { V }\end{array}$ & $\begin{array}{c}\text { Accel. } \\
\text { voltage, } \\
\text { V }\end{array}$ & $\begin{array}{l}\text { Main flow } \\
\text { rate, } \\
\text { sccm }\end{array}$ & $\begin{array}{l}\text { Cat. flow } \\
\text { rate, } \\
\text { sccm }\end{array}$ & $\begin{array}{l}\text { Neut. flow } \\
\text { rate, } \\
\text { sccm }\end{array}$ & $\begin{array}{c}\text { Thrust, } \\
\mathrm{mN}\end{array}$ & $\begin{array}{c}\text { Specific } \\
\text { impulse, } \\
\text { S }\end{array}$ \\
\hline 4.68 & 3.52 & 1179 & -200 & 49.6 & 4.87 & 4.01 & 192 & 3390 \\
\hline 6.03 & 3.10 & 1800 & -210 & 43.5 & 4.54 & 4.01 & 208 & 4150 \\
\hline 5.27 & 2.70 & 1800 & -210 & 37.6 & 4.26 & 3.50 & 181 & 4150 \\
\hline 3.20 & 2.70 & 1021 & -175 & 37.6 & 4.26 & 3.50 & 137 & 3130 \\
\hline 4.60 & 2.35 & 1800 & -210 & 32.4 & 4.05 & 3.50 & 158 & 4100 \\
\hline 3.16 & 2.35 & 1179 & -200 & 32.4 & 4.05 & 3.50 & 139 & 3620 \\
\hline 4.00 & 2.00 & 1800 & -210 & 25.8 & 3.87 & 2.50 & 134 & 4310 \\
\hline 3.20 & 2.00 & 1396 & -210 & 25.8 & 3.87 & 2.50 & 118 & 3800 \\
\hline 2.46 & 2.00 & 1021 & -175 & 25.8 & 3.87 & 2.50 & 101 & 3250 \\
\hline 3.24 & 1.60 & 1800 & -210 & 20.0 & 3.70 & 2.75 & 107 & 4190 \\
\hline 2.43 & 1.20 & 1800 & -210 & 14.2 & 3.70 & 3.00 & 80.2 & 4000 \\
\hline 1.70 & 1.20 & 1179 & -200 & 14.2 & 3.70 & 3.00 & 60.4 & 3010 \\
\hline 0.66 & 1.20 & 300 & -525 & 14.2 & 3.70 & 3.00 & 31.8 & 1590 \\
\hline 0.53 & 1.00 & 275 & -500 & 12.3 & 3.52 & 3.00 & 25.5 & 1400 \\
\hline
\end{tabular}

Typical measurements made during these tests included: standard thruster currents and voltages with digital multimeters; PPU output voltages; input currents and voltages to the PPU and PMS components; all PMS analog signals; and flow line pressure downstream of PMS. During tests over the full range of PPU input conditions and at the elevated PPU baseplate temperature, additional measurements included: ripples on PPU regulated and unregulated parameters; recycle behavior and accelerator grid surge current; heater currents and voltages and ignitor waveforms during cathode ignitions; power bus transients during ignition, high voltage application, and throttling; monitoring PPU regulation and performance while the HPB was ramped between 80 and $160 \mathrm{~V}$; and determining beam module cross-over input voltage between phase-shift and pulse width modulation.

Propulsion system demonstrations of functionality were broken into four subgroups. The first subgroup was engine testing at full power for the verification of DCIU system monitoring and data collection and safe mode operation. The second was PMS-DCIU testing without engine operation for a point-of-use purity check, demonstrations of full flow rate range, flow throttling times, and latch valve actuation. The third subgroup was PPU-DCIU testing without engine operation for measuring regulation 
across full power supply ranges, testing the programmable discharge current cutback, verifying activation of thruster relays and switches, and measuring power bus transients due to PPU turn-on. The fourth subgroup was system operation at PMS end-of-life inlet pressures to demonstrate operation with a thruster at the lowest possible PMS inlet pressures. The first three subgroups were essentially acceptance testing of the PPU, PMS, and DCIU Simulator in a system configuration while the fourth was a demonstration of PMS capability.

Propulsion system demonstrations of fault handling were also broken into four subgroups. The first subgroup was PMS fault mode operation. Tests included a system demonstration with separate simulated PMS failures of a LPA PFCV failed closed, a LPA PFCV failed open, and a HPA PFCV failed open. The second was electrical fault testing, which amounted to PPU and DCIU acceptance testing on a resistive load. For this subgroup, PPU-related faults were simulated and the system response to these faults was monitored. The third subgroup was a demonstration of data and telemetry faults, which was essentially DCIU Simulator acceptance testing. The fourth subgroup was demonstrations of system safing due to a high recycle rate, a PPU high voltage interlock on discharge and neutralizer low current, a cathode heater interlock on facility pressure, and power-on reset states of the DCIU and PPU.

Table 2 also lists the throttle levels selected for the system demonstrations of PMS operation at endof-life inlet pressure and PMS fault mode operation. The flow rates included the highest and lowest settings and one or two intermediate settings. System input conditions during these tests were the standard input conditions of Table 1. Typical measurements made during all tests included: standard thruster currents and voltages with digital multimeters; input currents and voltages to the PMS components; all PMS analog signals; and flow line pressure downstream of PMS.

Prior to the conduct of the aforementioned system integration tests, three earlier tests were performed as a part of the overall test plan. The first test was a PPU test on a resistive load while under vacuum and at baseplate temperatures of 25 and $50{ }^{\circ} \mathrm{C}$. This was a risk-reduction test designed to verify that the PPU could operate under vacuum as designed and at maximum acceptable flight baseplate temperature. The second test, referred to as the PM1R reperformance acceptance test, or RePAT, was conducted prior to all integration testing. The objectives of the test were to verify that PM1R thruster performance had not changed since the initial PAT was conducted and to provide baseline thruster performance parameters for comparisons. Thruster flows were provided by the mass flow controllers of the XFSE and power was provided by a power console made of commercially-available power supplies, which is briefly described in Reference 13. The third test was a PMS-thruster integration test. This was a risk-reduction test designed to verify that the PMS could properly operate a thruster. Power to the thruster was provided by the aforementioned power console. The throttle points used for latter two tests are included in Table 2.

Prior to and following all tests involving the PMS, calibration checks were performed on each individual LPA branch to verify that PMS flow rates were still within calibration and to support future requirements verification analyses. The LPA branch flow rates were compared to independent XFSE mass flow controller measurements for these calibration checks.

\section{Test Results and Discussions}

This section will present the test results of the SSIT, which included all tests associated with propulsion system demonstration of performance and demonstrations of PMS operation at end-of-life inlet pressure and PMS fault mode operation. Some system demonstrations of PMS and PPU functionality will also be presented, as will the results of the RePAT, the PM1R-PMS integration test, and the PMS calibration checks. The remaining SSIT results will be presented later in a separate verification and validation report. 


\section{PM1R Thruster RePAT}

During the PM1R thruster RePAT, the mass flow controllers of the XFSE were used to provide flow to the thruster. The flow path and valve positions for the PMS and XFSE are shown in Figure 14. To isolate the PMS, the solenoid valves downstream of the LPA were closed, as was the manual valve leading to the HPA inlet. This allowed for thruster operation using a standard flow regulation configuration. The mass flow controllers were calibrated at an upstream pressure of $350 \mathrm{kPa}$ (50 psia). The power console used for this test was identical to the one used for the first PM1R PAT and is described in Reference 13. The throttle points used for the RePAT are shown in Table 2.

All PM1R RePAT results were compared to those of the PAT test performed in the summer of 2007. Discharge voltages and discharge losses are shown in Figure 15 and Figure 16, respectively. Discharge voltages measured during the PAT and RePAT were within $1.2 \mathrm{~V}$. Discharge losses measured during the PAT and RePAT were within $8 \mathrm{~W} / \mathrm{A}$, although dispersions at the lower beam currents were as large as $10 \mathrm{~W} / \mathrm{A}$. These large dispersions at the lower beam currents were investigated further and were found to be the result of two causes. The first cause was the sensitivity of discharge losses to discharge propellant utilization efficiency, which is shown in Figure 17 for constant discharge voltages. At the highest beam current in the figure, discharge losses exhibit a relatively small sensitivity to variations in propellant utilization efficiency. However at the lower beam currents, this sensitivity increases, especially at the nominal flow rates. For the $1.20 \mathrm{~A}$ case, discharge losses can vary as much as $20 \mathrm{~W} / \mathrm{A}$ for a 2 percent change in propellant utilization efficiency, which could be caused by mass flow controller error for example. The second cause of the discharge loss dispersions was variations in discharge voltages, which could be large at low beam currents. Discharge losses are also sensitive to changes in discharge voltages. As a result of this discharge losses dispersion investigation, discharge chamber performance was considered nominal. In addition to these data, discharge cathode ignition times during the PAT and RePAT were within 7.5 min.

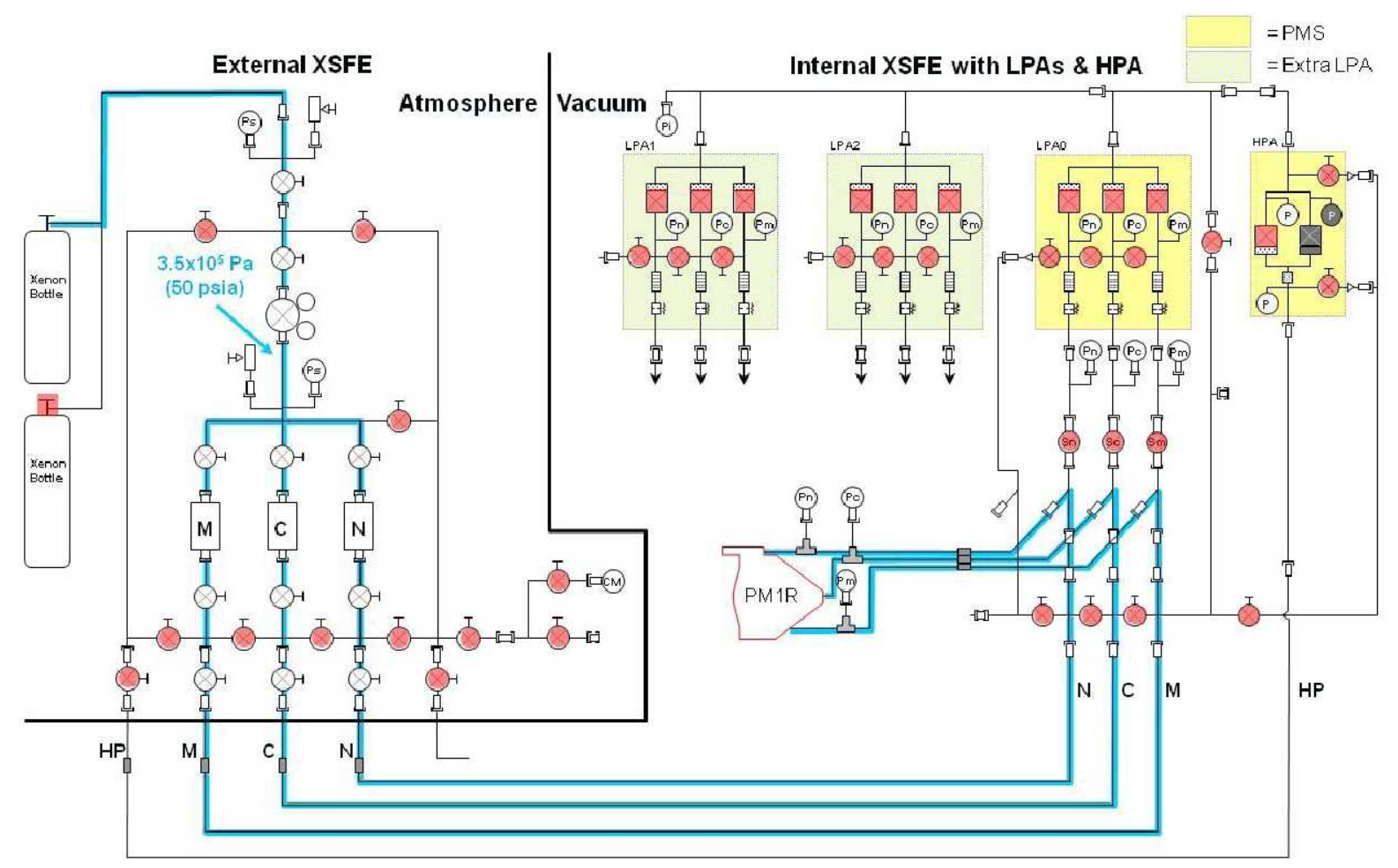

Figure 14.-Flow path through the PMS and XFSE during the PM1R RePAT. The blue lines indicate flow path, a red valve indicates that it was closed, and a white valve indicates that it was open. The key for this schematic is identical to that of Figure 11. 
The neutralizer keeper and coupling voltages are shown in Figure 18 and Figure 19, respectively. Neutralizer keeper voltages measured during PAT and RePAT were within $1 \mathrm{~V}$ and coupling voltages were within $0.5 \mathrm{~V}$, indicating little change between these tests. Neutralizer spot-plume mode transition flow rates, defined as the flow rate where the peak-to-peak neutralizer keeper voltage was $\geq 5 \mathrm{~V}$, are plotted in Figure 20. Transition flow rates for the PAT and RePAT were within $0.1 \mathrm{sccm}$, which was the uncertainty of the measurement. Neutralizer ignition times during the PAT and RePAT were all within $4.5 \mathrm{~min}$.
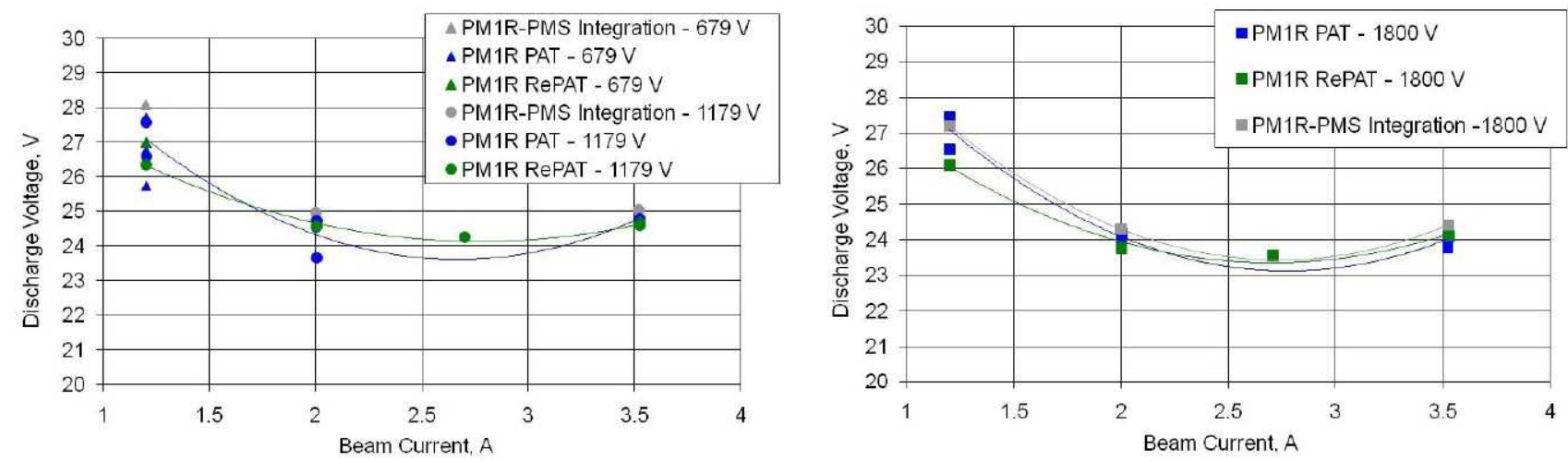

Figure 15.-Discharge voltages as a function of beam current at beam supply voltages of 679,1179 , and $1800 \mathrm{~V}$ during the PAT, RePAT, and PM1R-PMS integration test. A power console was employed.
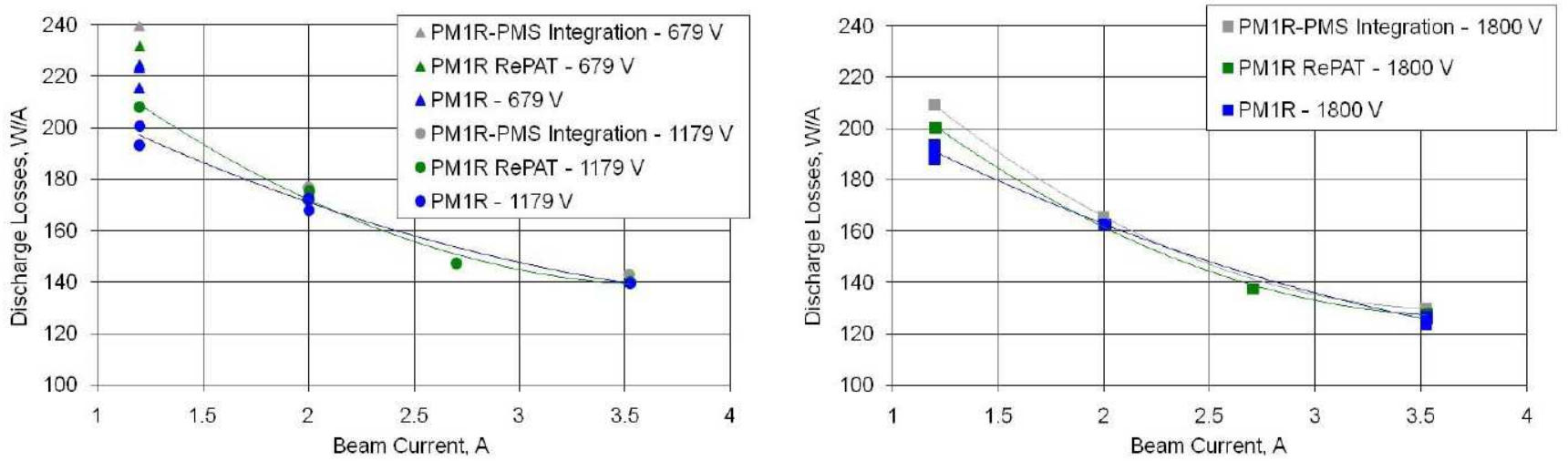

Figure 16.-Discharge losses as a function of beam current at beam supply voltages of 679,1179 , and $1800 \mathrm{~V}$ during the PAT, RePAT, and PM1R-PMS integration test. A power console was employed. 


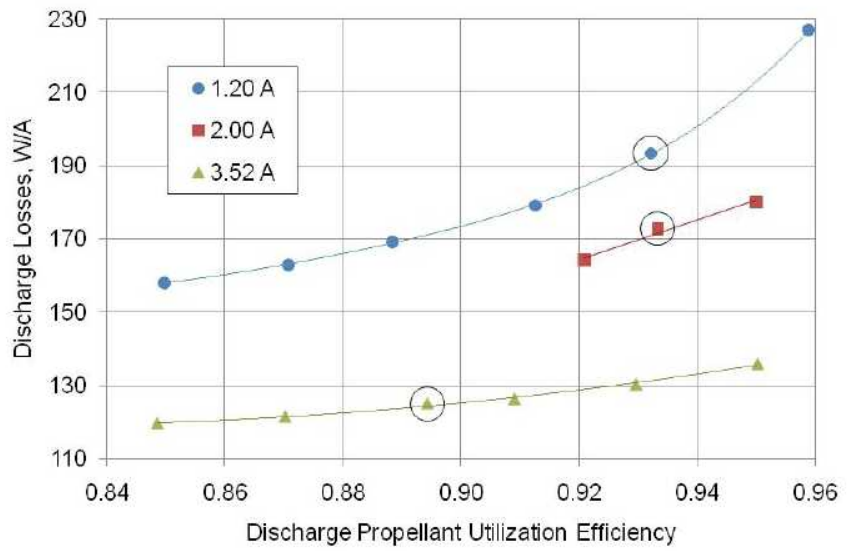

Figure 17.-Discharge losses as a function of discharge propellant utilization efficiency for constant discharge voltages at beam currents of $1.20,2.00$, and $3.52 \mathrm{~A}$. Circled symbols are the nominal operating conditions.
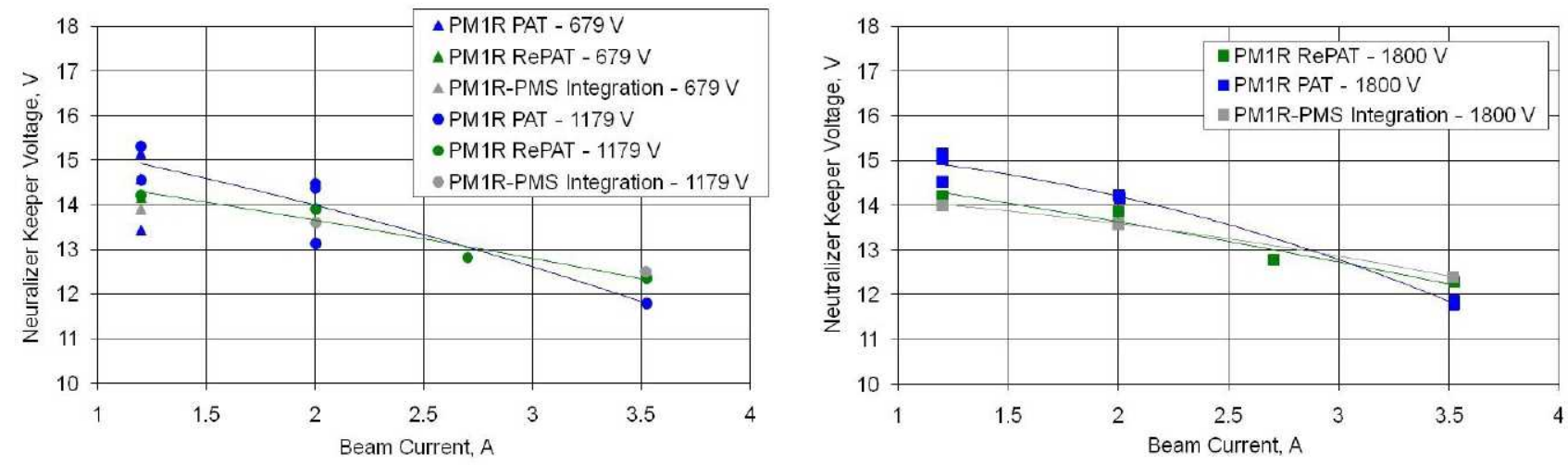

Figure 18.-Neutralizer keeper voltages as a function of beam current at beam supply voltages of 679,1179 , and $1800 \mathrm{~V}$ during the PAT, RePAT, and PM1R-PMS integration test. A power console was employed.
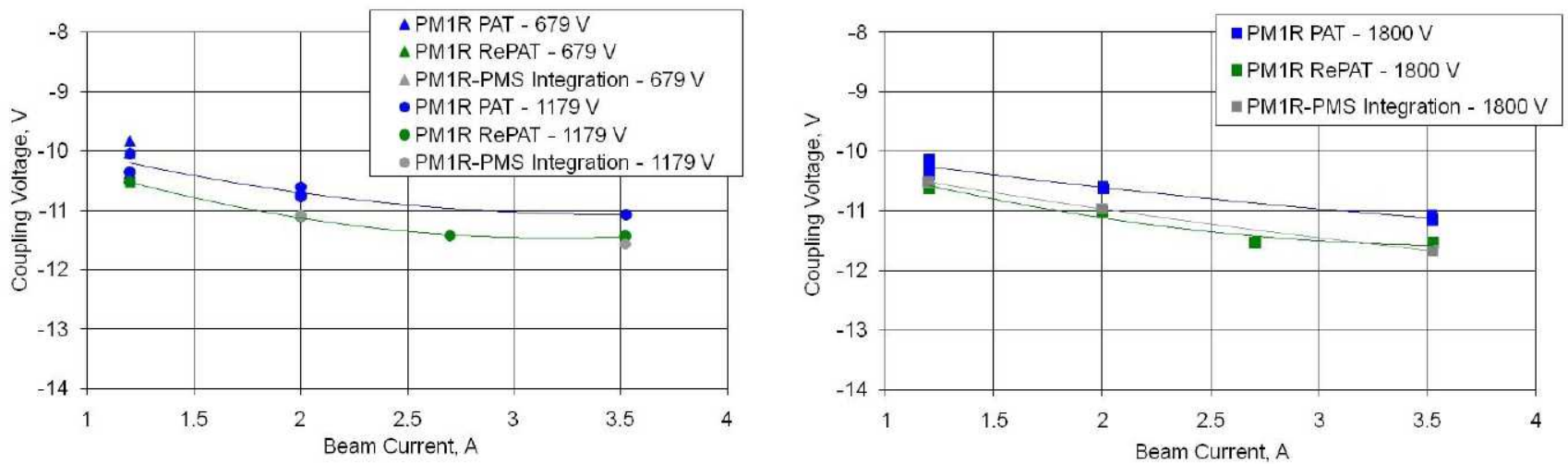

Figure 19.-Coupling voltages as a function of beam current at beam supply voltages of 679,1179 , and $1800 \mathrm{~V}$ during the PAT, RePAT, and PM1R-PMS integration test. A power console was employed. 


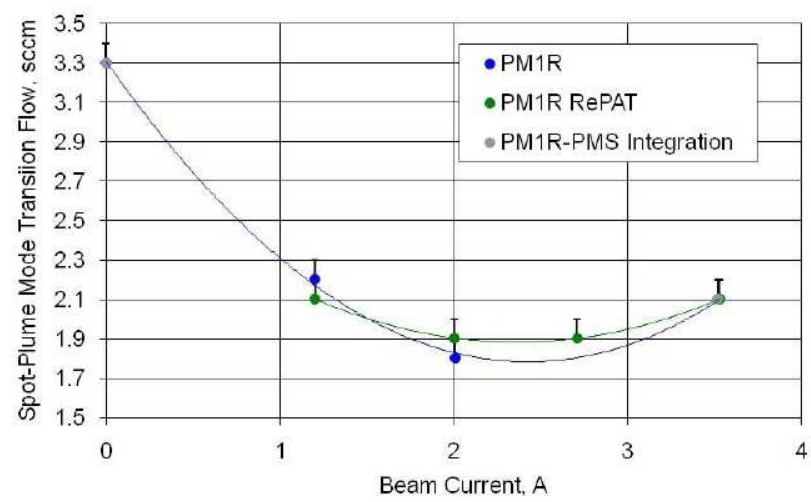

Figure 20.-Spot-plume transition flow rates as a function of beam current during the PAT, RePAT, and PM1R-PMS integration test. A power console was employed.

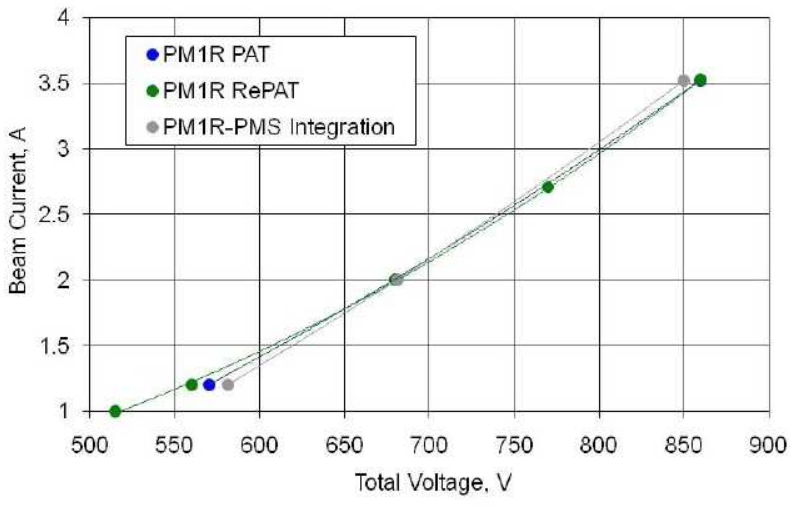

Figure 21.-Perveance limits measured during the PAT, RePAT, and PM1R-PMS integration test. A power console was employed.
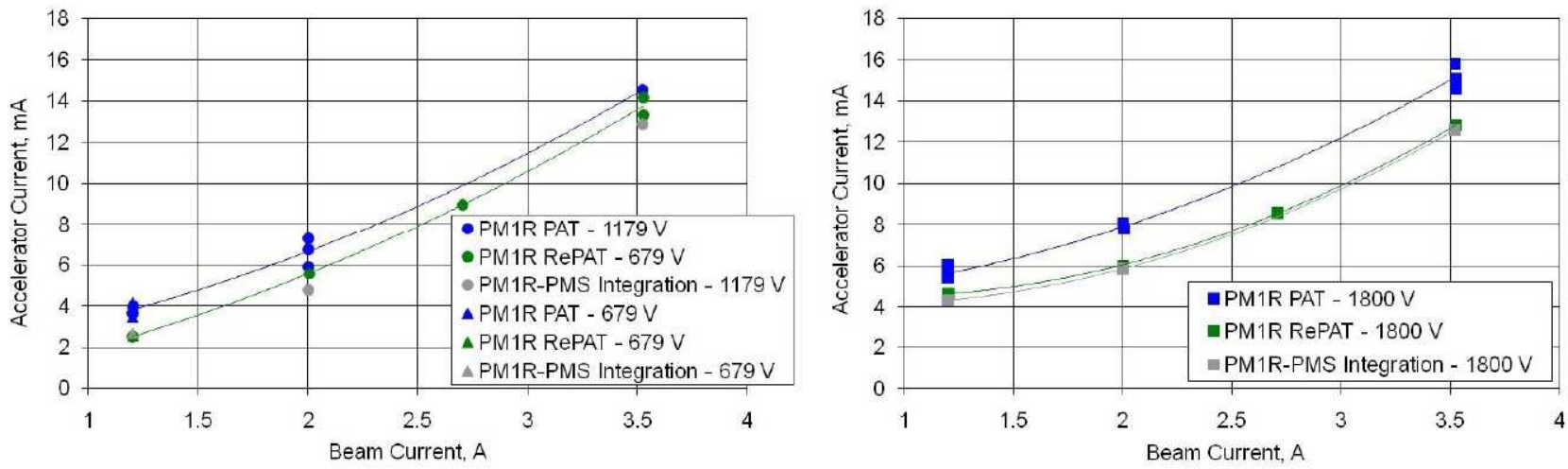

Figure 22.-Accelerator currents as a function of beam current at beam supply voltages of 679,1179 , and $1800 \mathrm{~V}$ during the PAT, RePAT, and PM1R-PMS integration test. A power console was employed. 
Perveance limits are plotted in Figure 21. Perveance limits were determined from plots of accelerator current as a function of total voltage where the slope was $0.02 \mathrm{~mA} / \mathrm{V}$. Perveance limits measured during PAT and RePAT were within $10 \mathrm{~V}$, which is within the estimated measurement uncertainty of $\pm 15 \mathrm{~V}$ (Ref. 19). Accelerator currents shown in Figure 22 were within $2 \mathrm{~mA}$ between the two tests, but accelerator currents were typically lower for the RePAT. The cause for the reduced accelerator currents of the RePAT is not presently understood, though it posed no issues for continued testing. Electron backstreaming limits are tabulated in Table 4. Electron backstreaming limits were determined by lowering the magnitude of the accelerator voltage until the beam power supply current increased by $1 \mathrm{~mA}$ due to backstreaming electrons. All electron backstreaming limits measured during PAT and RePAT were within $2 \mathrm{~V}$, which is within the estimated measurement uncertainty of $\pm 2.5 \mathrm{~V}$ (Ref. 19).

TABLE 4.-ELECTRON BACKSTREAMING LIMITS MEASURED DURING THE PMIR PAT, RePAT AND THE PMIR-PMS INTEGRATION TEST. A POWER CONSOLE WAS EMPLOYED

\begin{tabular}{|c|c|c|c|c|}
\hline \multicolumn{3}{|c|}{ Throttle point } & \multicolumn{3}{c|}{ Electron backstreaming limits, } \\
\hline $\begin{array}{c}\text { Beam current, } \\
\text { A }\end{array}$ & Beam supply voltage, & PM1R PAT & PM1R & PM1R-PMS \\
V & RePAT & integration test \\
\hline 3.52 & 1800 & -167 & -167 & -167 \\
3.52 & 1179 & -121 & -122 & -123 \\
2.70 & 1800 & - & -149 & - \\
2.70 & 1179 & - & -110 & - \\
2.70 & 1021 & - & -95 & - \\
2.00 & 1800 & -127 & -126 & -127 \\
2.00 & 1179 & -101 & - & -101 \\
2.00 & 1021 & -87 & -88 & - \\
1.20 & 1800 & -80 & -86 & -86 \\
1.20 & 1179 & -80 & - \\
1.20 & 679 & & -49 & -49 \\
\hline
\end{tabular}

Other than the overall decrease in accelerator current, the RePAT demonstrated that PM1R thruster operation and subassembly performance had not changed significantly since the PAT test. The RePAT also established a baseline set of data for comparisons with the remaining tests reported herein.

Because the thermal throttle flow rate can be sensitive to downstream pressure, knowledge of PM thruster inlet pressures are necessary for accurately estimating these pressures as a function of PMS design. Therefore, the tubing leading to the thruster was outfitted with pressure transducers at the three thruster inlets to measure thruster inlet pressures throughout the throttling range. The results are presented in Figure 23. Thruster inlet pressures were a strong function of beam current and not beam voltage because the beam current controls all flow rates and the discharge and neutralizer currents, which in turn control cathode internal pressures. In addition, the beam current controls thruster temperatures because of discharge losses which in turn control line pressures from xenon viscosity's dependence on temperature. As shown in the figure, the main inlet typically had the highest pressures, ranging from $4.2 \mathrm{kPa}$ (32 torr) at low power to $10.7 \mathrm{kPa}$ (80 torr) at full power. The lowest inlet pressures were measured at the cathode inlet, which ranged from $2.0 \mathrm{kPa}$ (15 torr) at low power to $3.0 \mathrm{kPa}$ (22 torr) at full power. The neutralizer inlet pressure decreased from the lowest beam current to the $2.0 \mathrm{~A}$ case because the neutralizer flow rate decreased (see Table 3). The peak neutralizer inlet pressure was $8.8 \mathrm{kPa}$ (66 torr). 


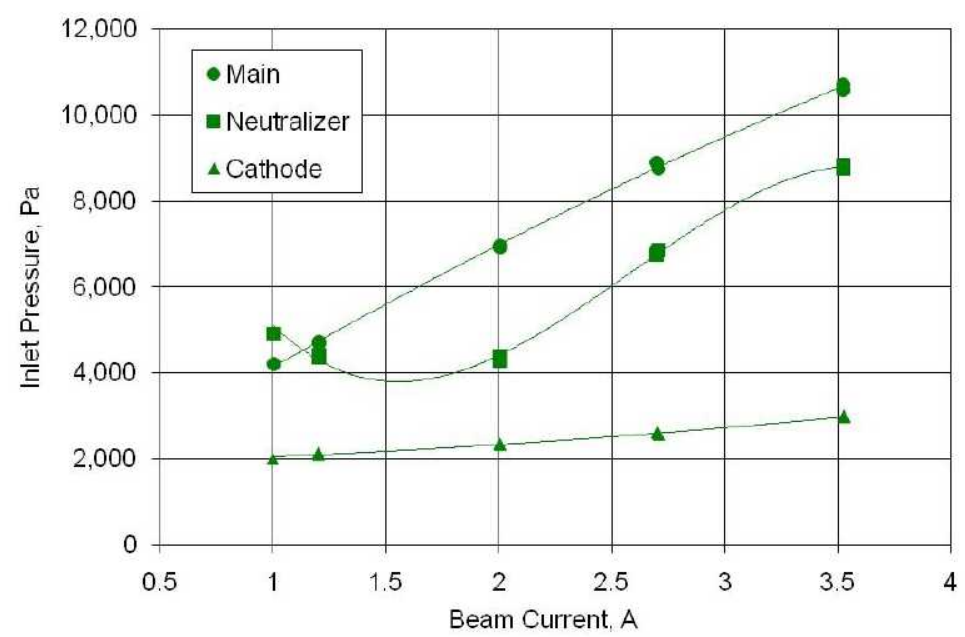

Figure 23.-Thruster inlet pressure as a function of beam current for the main, cathode, and neutralizer inlets.

\section{PMS Calibration Check}

Propellant management system calibrations were checked before and after all tests involving the PMS. Calibration checks were conducted with the PMS under vacuum and while connected to the PM1R thruster, which was not operational. Calibration checks were conducted over the full flow rate range during both normal and fault mode PMS operation. Figure 24 shows the flow path and valve positions for main LPA branch calibration checks while Figure 25 shows the flow path and valve positions for cathode and neutralizer LPA branch calibration checks. Calibration checks were performed on individual LPA branches by comparing them to XFSE mass flow controller indicated flow rates. During these calibration checks, mass flow controller internal valves were fully opened so that the flow controller would only measure, and not regulate, flow rate. To reduce mass flow controller measurement error, calibration measurements were made in $5 \mathrm{~s}$ intervals for $5 \mathrm{~min}$ and averaged to determine the actual flow rate.

Initial calibration checks revealed that the test setup introduced two significant error sources in the mass flow controller measurements that had to be resolved early in the calibration process. The large volume downstream of the mass flow controllers and upstream of the HPA made the mass flow controller readings susceptible to error from any changes in temperature or pressure as a function of time. Pressure or temperature changes as a function of time within this volume are measured by the mass flow controller as a change in flow rate as the xenon within this volume fills or drains to change its pressure. Pressure changes with time occurred because the XFSE pressure regulator outlet pressure changed slightly as a function of flow rate. Rapid temperature changes with time occurred during any active heating of the PMS with external heater tapes. To eliminate these error sources, sufficient time was allowed between mass flow rate changes for the pressure to reach equilibrium and the PMS was not actively heated with heater tapes during these tests. Future tests utilizing this setup should minimize this volume and utilize a $\mathrm{XFSE}$ pressure regulator with better regulation as a function of flow rate. 


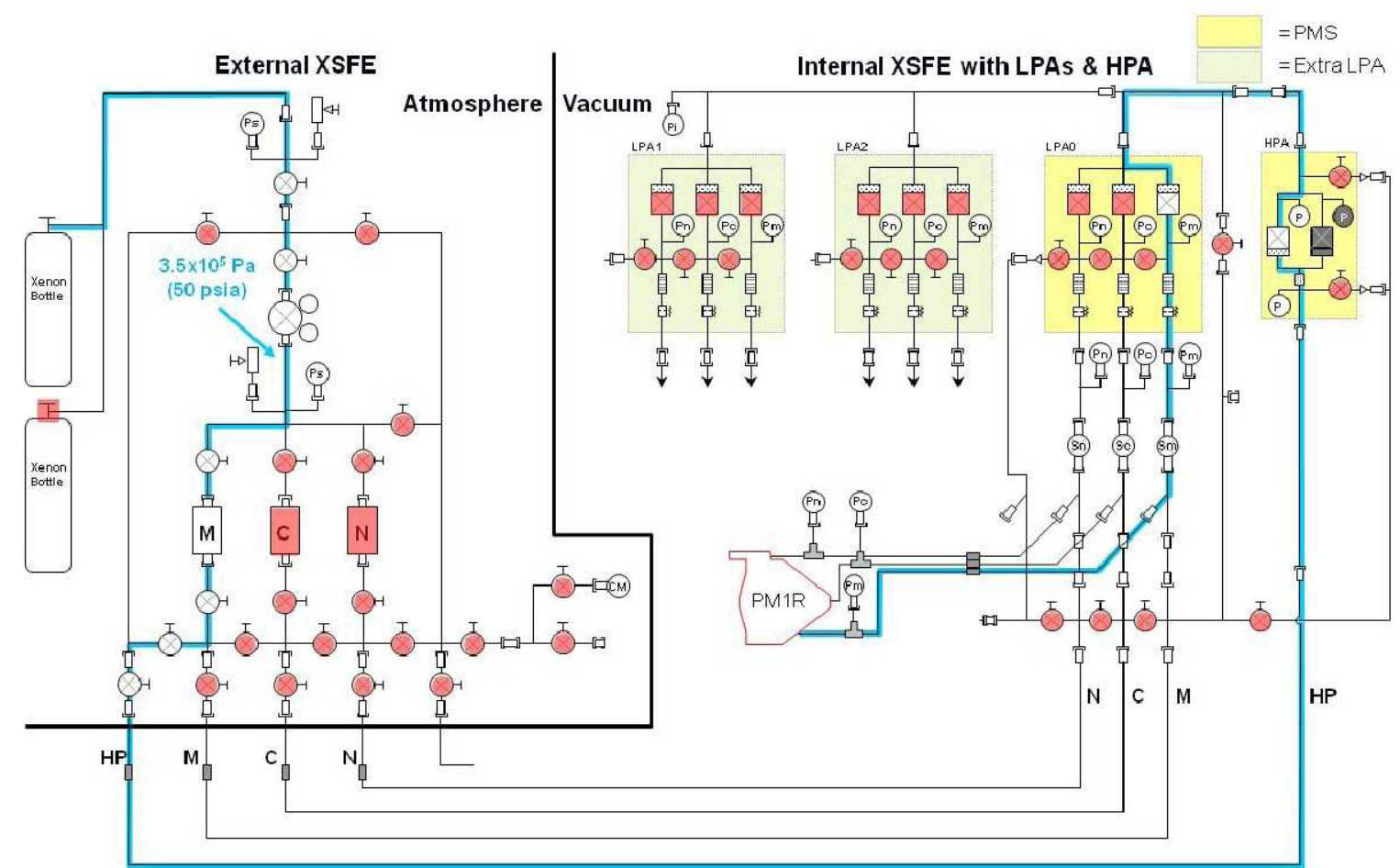

Figure 24.-Flow path through the PMS and XFSE during main LPA branch calibration. The blue lines indicate flow path, a red valve indicates that it was closed, and a white valve indicates that it was open. The key for this schematic is identical to that of Figure 11.

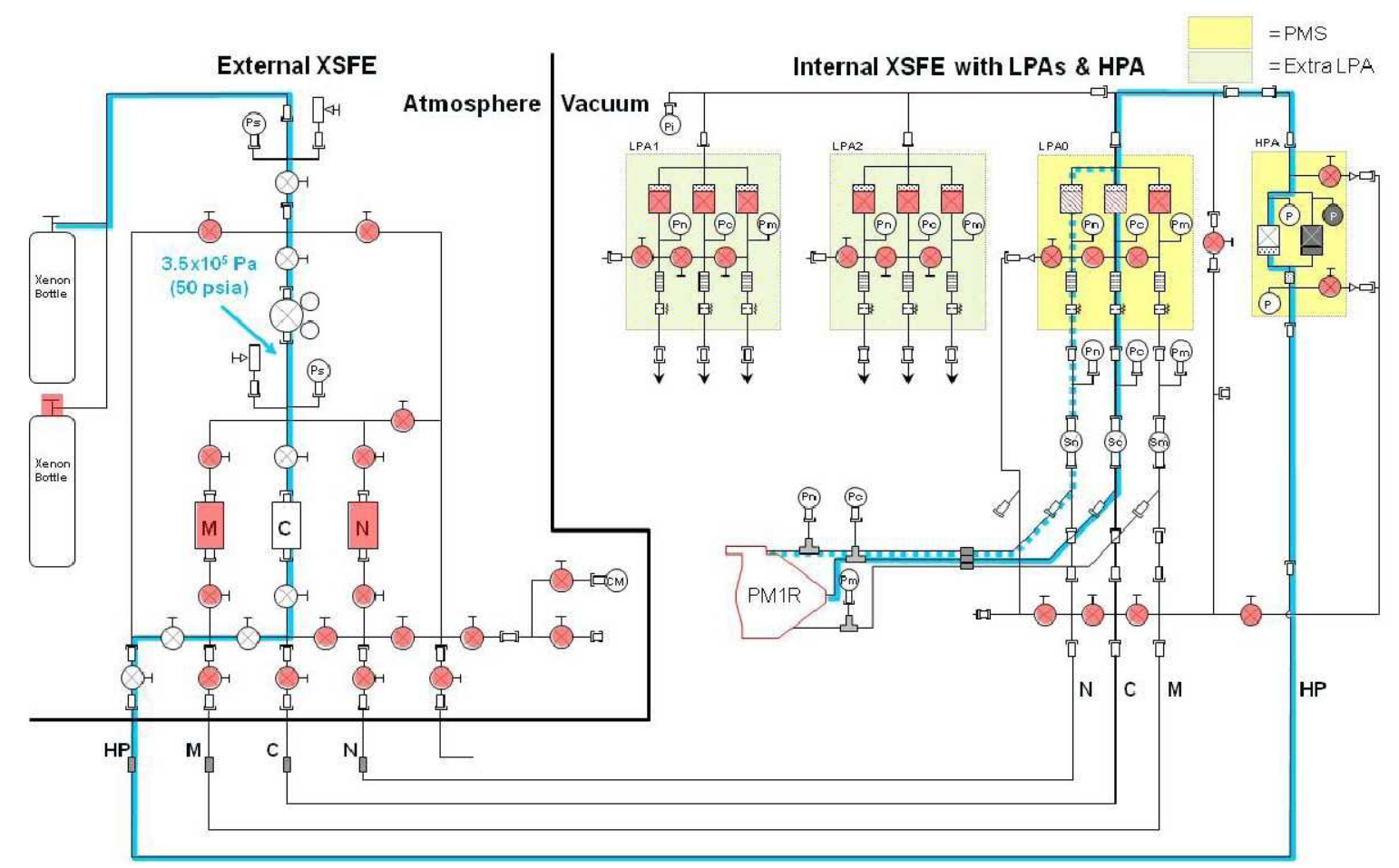

Figure 25.-Flow path through the PMS and XFSE during cathode and neutralizer LPA branch calibrations. The blue lines indicate flow path, a red valve indicates that it was closed, and a white valve indicates that it was open. The key for this schematic is identical to that of Figure 11. 
Two PMS shortcomings were uncovered during initial calibration checks. The first involved the PFCV driver circuit. While this driver circuit properly commanded flow rates to the desired levels when a single LPA branch was operating, the true flow rates decreased by 2.4 to 5.1 percent of the commanded flow rates when more than one LPA branch was flowing xenon. This created an issue because the flow rates were required to be within \pm 3 percent of the commanded flows. The cause of this effect was likely common-mode noise between the separate branches of the PFCV driver circuit caused by the electricallyisolated pressure transducer analog signals. Unfortunately, the circuit could not be repaired for this test. Regardless, the LPA indicated flow rates were still properly read back by the DCIU Simulator. It was decided to continue testing while relying on the LPA indicated flow rates to determine the proper flow set point.

The second PMS issue was related to prior LPA flow rate calibrations. While the PMS was fully capable of operating over the full range of throttle table flow rates during LPA fault mode operation, an insufficient amount of calibration data was obtained prior to the integration test to fully demonstrate this capability. As a result, fault mode operation at beam currents $\leq 1.60 \mathrm{~A}$, and at $3.52 \mathrm{~A}$ in one case, could not be demonstrated during these fault mode tests. In addition, there was insufficient calibration data collected at a thermal throttle temperature of $25{ }^{\circ} \mathrm{C}$ to validate the PMS's full ability to operate at the lowest possible inlet pressures. As a result, this testing was done at a $75^{\circ} \mathrm{C}$ thermal throttle temperature.

Mass flow controller accuracy had to be considered when assessing LPA flow rate error. Mass flow controller accuracy as a function of the percentage of full flow controller flow rate is plotted in Figure 26. The main mass flow controller full flow rate was $75 \mathrm{sccm}$ while the cathode and neutralizer flow controllers' full flow rate was $10 \mathrm{sccm}$ each. So, mass flow controller accuracies were \pm 1 percent for flow rates $\geq 26.3 \mathrm{sccm}$ for the main flow controller and $\geq 3.5 \mathrm{sccm}$ for the cathode flow controller. At lower flow rates, inaccuracies increased as shown in the figure.

The results of the calibration checks are tabulated in Table 5. Two main LPA branch flow rate errors were found to be large in comparison to the others during pre- and post-test calibration checks. The anomalously large main LPA branch flow rate errors were both at the lowest LPA flow rate during normal operation. A post-test investigation revealed that these errors were caused by the calibration equation used for this branch. The equation was determined by curve-fitting to data over an inappropriate flow rate range. The resulting calibration equation produced a high error at this lowest flow rate. Throughout the remainder of Table 5, however, the LPA indicated flow rate calibrations were low and almost always $<3$ percent.

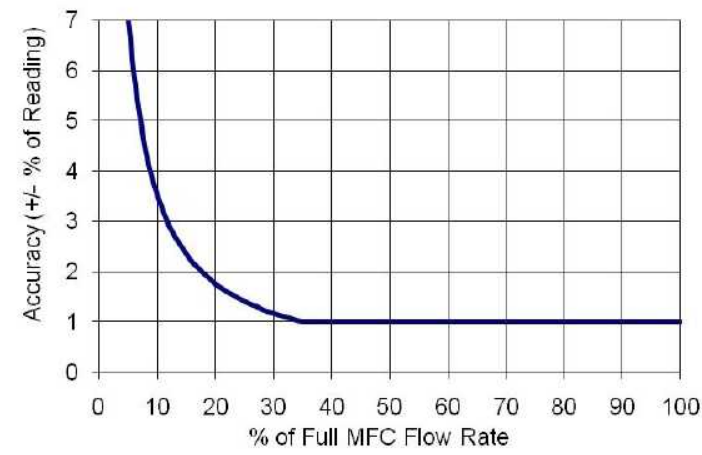

Figure 26.-Mass flow controller accuracy as a function of percentage of full flow controller flow rate range. 
TABLE 5.-PRE- AND POST-TEST PMS CALIBRATION CHECKS RESULTS

[Gray boxes indicate that LPA branch flow rates were relatively large]

\begin{tabular}{|c|c|c|c|c|c|c|c|c|c|c|c|c|}
\hline \multirow[b]{2}{*}{$\begin{array}{l}\text { LPA } \\
\text { branch and } \\
\text { mode of } \\
\text { operation }\end{array}$} & \multicolumn{6}{|c|}{ Pretest } & \multicolumn{6}{|c|}{ Post-Test } \\
\hline & $\begin{array}{c}\text { Thermal } \\
\text { throttle } \\
\text { temperature, } \\
{ }^{\circ} \mathrm{C}\end{array}$ & \begin{tabular}{|c|} 
Branch \\
pressure, \\
$\mathrm{Pa}$
\end{tabular} & \begin{tabular}{|c|} 
LPA \\
indicated \\
flow rate, \\
sccm \\
\end{tabular} & $\begin{array}{c}\text { MFC } \\
\text { flow rate, } \\
\text { sccm }\end{array}$ & \begin{tabular}{|c|} 
LPA \\
indicated \\
error, \\
$\%$ \\
\end{tabular} & \begin{tabular}{|c|} 
MFC \\
accuracy, \\
$\pm \%$ \\
reading \\
\end{tabular} & $\begin{array}{c}\text { Thermal } \\
\text { throttle } \\
\text { temperature, } \\
{ }^{\circ} \mathrm{C} \\
\end{array}$ & \begin{tabular}{|c|} 
Branch \\
pressure, \\
$\mathrm{Pa}$
\end{tabular} & \begin{tabular}{|c|} 
LPA \\
indicated \\
flow rate, \\
sccm \\
\end{tabular} & \begin{tabular}{|c|} 
MFC \\
flow rate, \\
sccm
\end{tabular} & \begin{tabular}{|c|} 
LPA \\
indicated \\
error, \\
$\%$ \\
\end{tabular} & \begin{tabular}{|c|} 
MFC \\
accuracy, \\
$\pm \%$ \\
reading \\
\end{tabular} \\
\hline \multirow{4}{*}{$\begin{array}{l}\text { Neutralizer } \\
\text { normal } \\
\text { mode }\end{array}$} & 75.0 & $1.89 \mathrm{E}+05$ & 6.02 & 5.95 & 1.26 & 1.00 & 75.0 & $1.89 \mathrm{E}+05$ & 6.02 & 5.99 & 0.63 & 1.00 \\
\hline & 75.0 & $1.53 \mathrm{E}+05$ & 4.04 & 3.99 & 1.26 & 1.00 & 75.0 & $1.53 \mathrm{E}+05$ & 4.04 & 4.03 & 0.25 & 1.00 \\
\hline & 75.0 & $1.32 \mathrm{E}+05$ & 3.03 & 3.00 & 0.78 & 1.17 & 75.0 & $1.32 \mathrm{E}+05$ & 3.03 & 3.05 & -0.75 & 1.16 \\
\hline & 75.0 & $1.20 \mathrm{E}+05$ & 2.52 & 2.54 & -0.75 & 1.38 & 75.0 & $1.20 \mathrm{E}+05$ & 2.53 & 2.56 & -1.39 & 1.39 \\
\hline \multirow{9}{*}{$\begin{array}{l}\text { Neutralizer } \\
\text { fault mode }\end{array}$} & - & - & - & - & - & - & 44.2 & $1.74 \mathrm{E}+05$ & 6.00 & 6.00 & -0.01 & 1.00 \\
\hline & 87.7 & $1.73 \mathrm{E}+05$ & 4.83 & 4.70 & 2.75 & 1.00 & - & - & - & - & - & - \\
\hline & 57.1 & $1.38 \mathrm{E}+05$ & 3.68 & 3.62 & 1.54 & 1.00 & - & - & - & - & - & - \\
\hline & 64.4 & $1.38 \mathrm{E}+05$ & 3.55 & 3.50 & 1.42 & 1.00 & - & - & - & - & - & - \\
\hline & - & - & - & - & - & - & - & - & - & - & - & - \\
\hline & - & - & - & - & - & - & 99.7 & $1.39 \mathrm{E}+05$ & 3.00 & 3.00 & -0.14 & 1.17 \\
\hline & - & - & - & - & - & - & 119.2 & $1.39 \mathrm{E}+05$ & 2.75 & 2.78 & -1.19 & 1.26 \\
\hline & - & - & - & - & - & - & 127.7 & $1.74 \mathrm{E}+05$ & 4.01 & 4.04 & -0.84 & 1.00 \\
\hline & - & - & - & - & - & - & 303.0 & $1.74 \mathrm{E}+05$ & 2.50 & 2.55 & -2.01 & 1.37 \\
\hline \multirow{5}{*}{$\begin{array}{l}\text { Cathode } \\
\text { normal } \\
\text { mode }\end{array}$} & 75.0 & $1.88 \mathrm{E}+05$ & 6.03 & 5.88 & 2.53 & 1.00 & 75.0 & $1.88 \mathrm{E}+05$ & 6.03 & 5.90 & 2.30 & 1.00 \\
\hline & 75.0 & $1.68 \mathrm{E}+05$ & 4.90 & 4.84 & 1.26 & 1.00 & 75.0 & $1.68 \mathrm{E}+05$ & 4.90 & 4.78 & 2.52 & 1.00 \\
\hline & 75.0 & $1.57 \mathrm{E}+05$ & 4.28 & 4.24 & 0.87 & 1.00 & - & - & - & - & - & - \\
\hline & 75.0 & $1.41 \mathrm{E}+05$ & 3.53 & 3.49 & 1.26 & 1.00 & 75.0 & $1.41 \mathrm{E}+05$ & 3.54 & 3.47 & 1.88 & 1.00 \\
\hline & 75.0 & $1.04 \mathrm{E}+05$ & 1.99 & 1.97 & 1.00 & 1.77 & 75.0 & $1.04 \mathrm{E}+05$ & 2.00 & 1.97 & 1.16 & 1.75 \\
\hline \multirow{6}{*}{$\begin{array}{l}\text { Cathode } \\
\text { fault mode }\end{array}$} & 87.8 & $1.72 \mathrm{E}+05$ & 4.87 & 4.71 & 3.42 & 1.00 & 87.7 & $1.74 \mathrm{E}+05$ & 4.87 & 4.77 & 2.20 & 1.00 \\
\hline & - & - & - & - & - & - & 117.4 & $1.74 \mathrm{E}+05$ & 4.26 & 4.19 & 1.60 & 1.00 \\
\hline & - & - & - & - & - & - & 47.9 & $1.39 \mathrm{E}+05$ & 3.87 & 3.89 & -0.58 & 1.00 \\
\hline & 140.1 & $1.72 \mathrm{E}+05$ & 3.87 & 3.76 & 2.90 & 1.00 & 140.0 & $1.74 \mathrm{E}+05$ & 3.87 & 3.82 & 1.28 & 1.00 \\
\hline & 64.4 & $1.38 \mathrm{E}+05$ & 3.57 & 3.52 & 1.47 & 1.00 & - & - & - & - & - & - \\
\hline & - & - & - & - & - & - & 67.3 & $1.39 \mathrm{E}+05$ & 3.52 & 3.53 & -0.33 & 1.00 \\
\hline \multirow{4}{*}{$\begin{array}{l}\text { Main } \\
\text { normal } \\
\text { mode }\end{array}$} & 75.0 & $1.75 \mathrm{E}+05$ & 50.0 & 49.3 & 1.43 & 1.00 & 75.0 & $1.75 \mathrm{E}+05$ & 50.0 & 49.6 & 0.63 & 1.00 \\
\hline & 75.0 & $1.49 \mathrm{E}+05$ & 37.6 & 37.0 & 1.62 & 1.00 & 75.0 & $1.49 \mathrm{E}+05$ & 37.6 & 37.2 & 0.98 & 1.00 \\
\hline & 75.0 & $1.20 \mathrm{E}+05$ & 26.0 & 25.3 & 2.69 & 1.04 & 75.0 & $1.20 \mathrm{E}+05$ & 25.9 & 25.4 & 2.12 & 1.01 \\
\hline & 75.0 & $7.80 \mathrm{E}+04$ & 12.2 & 11.6 & 5.98 & 2.27 & 75.0 & $7.80 \mathrm{E}+04$ & 12.2 & 11.5 & 6.03 & 2.15 \\
\hline \multirow{3}{*}{$\begin{array}{l}\text { Main fault } \\
\text { mode }\end{array}$} & 82.4 & $1.73 \mathrm{E}+05$ & 49.6 & 47.1 & $5.37^{\mathrm{a}}$ & 1.00 & 82.4 & $1.74 \mathrm{E}+05$ & 49.6 & 48.1 & 3.17 & 1.00 \\
\hline & 234.7 & $1.73 E+05$ & 37.6 & 36.6 & 2.64 & 1.00 & 234.7 & $1.74 \mathrm{E}+05$ & 37.6 & 37.3 & 0.73 & 1.00 \\
\hline & 198.7 & $1.38 \mathrm{E}+05$ & 25.8 & 25.2 & 2.24 & 1.04 & 198.7 & $1.39 \mathrm{E}+05$ & 25.8 & 25.7 & 0.48 & 1.02 \\
\hline
\end{tabular}

${ }^{2} \mathrm{LPA}$ indicated flow rate error was largely due to an improper pressure setting.

\section{PM1R-PMS Integration Test}

During the PM1R-PMS integration test, the thruster was operated with the PMS and a power console. The power console used for this test was identical to the one used for the first PM1R PAT and RePAT. The DCIU Simulator controlled the PMS, as well as the XFSE. The flow path and valve positions for the PMS and XFSE are shown in Figure 27. The main mass flow controller monitored the total flow rate to the PMS. The inlet pressure to the HPA was $350 \mathrm{kPa}(50 \mathrm{psia})$, which was the calibration pressure for the mass flow controller. The setup was similar to that of the main flow branch calibration check except that the main mass flow controller was used to monitor total PMS flow rate. This configuration was also the same as that used during the first NEXT system integration test with lower fidelity hardware (Refs. 5 and 16). As with the calibration checks, measurements were made in $5 \mathrm{~s}$ intervals for 5 min and averaged to reduce mass flow controller measurement error. The throttle points used for this test are shown in Table 2 .

Results from the PMS calibration checks will be analyzed with the results from these total flow rate measurements later. For this study, only the total PMS flow rates will be discussed. 


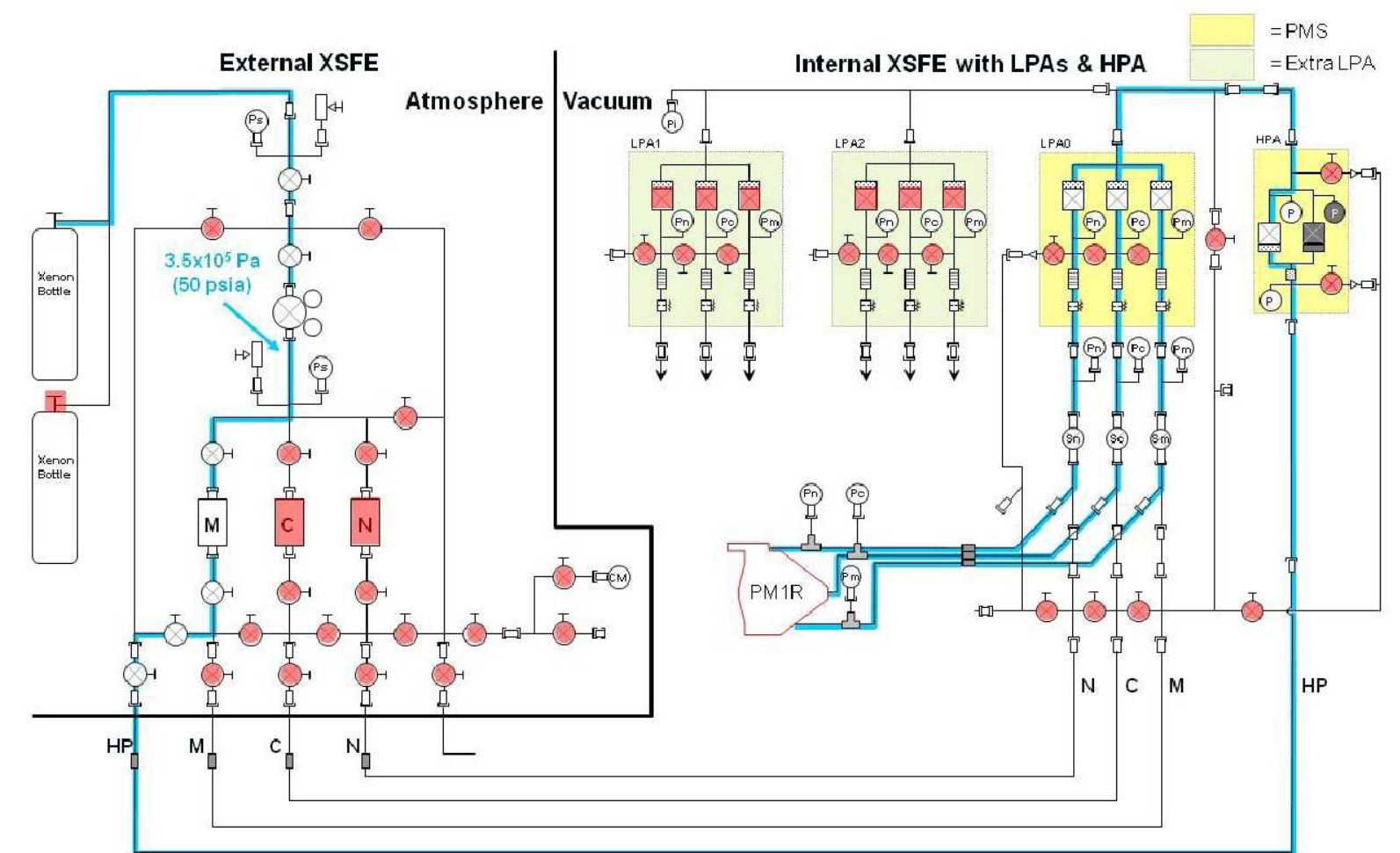

Figure 27.-Flow path through the PMS and XFSE during all integration tests other than PMS operation at high inlet pressures. The blue lines indicate flow path, a red valve indicates that it was closed, and a white valve indicates that it was open. The key for this schematic is identical to that of Figure 11.

The sum of the indicated LPA flow rates measured during the PM1R-PMS integration test are compared to the mass flow controller flow rates in Table 6. Total LPA flow rates were found to be within 3 percent of the mass flow controller flow rates. The LPA total flow rate error increased with decreasing flow rate. This was largely due the main LPA branch flow rate calibration, which tended to yield higher flow rate errors at lower flow rates as shown in Table 5.

TABLE 6.-LPA INDICATED AND MASS FLOW CONTROLLER FLOW RATES MEASURED DURING THE PMIR-PMS INTEGRATION TEST

\begin{tabular}{|c|c|c|c|c|c|c|c|}
\hline \multicolumn{2}{|c|}{ Throttle point } & \multicolumn{4}{|c|}{$\begin{array}{l}\text { LPA indicated flow rates, } \\
\text { sccm }\end{array}$} & \multirow[t]{2}{*}{$\begin{array}{l}\text { MFC flow rate, } \\
\text { sccm }\end{array}$} & \multirow{2}{*}{$\begin{array}{l}\text { LPA total flow } \\
\text { rate error, } \\
\%\end{array}$} \\
\hline $\begin{array}{c}\text { Beam current, } \\
\text { A }\end{array}$ & $\begin{array}{c}\text { Beam supply voltage, } \\
\text { V }\end{array}$ & Main & Cat. & Neut. & Total & & \\
\hline 3.52 & 1800 & 48.5 & 4.90 & 4.01 & 58.5 & 57.7 & 1.34 \\
\hline 3.52 & 1179 & --- & ---- & ---- & ---- & ---- & ---- \\
\hline 2.00 & 1800 & 25.9 & 3.89 & 2.50 & 32.3 & 31.8 & 1.61 \\
\hline 2.00 & 1179 & 25.9 & 3.89 & 2.50 & 32.3 & 31.8 & 1.66 \\
\hline 1.20 & 1800 & 14.4 & 3.58 & 3.00 & 21.0 & 20.4 & 2.93 \\
\hline 1.20 & 679 & 14.4 & 3.58 & 3.01 & 21.0 & 20.4 & 3.00 \\
\hline
\end{tabular}

All thruster performance results obtained during the PM1R-PMS integration were compared to those of the RePAT. Discharge voltages and discharge losses are shown in Figure 15 and Figure 16, respectively. Discharge voltages measured during the PM1R-PMS integration test and RePAT were within 1.1 V. Discharge losses were within $9 \mathrm{~W} / \mathrm{A}$. Discharge chamber performance was therefore considered nominal. In addition to these data, discharge cathode ignition times during both tests were within $7.5 \mathrm{~min}$. 
The neutralizer keeper and coupling voltages are shown in Figure 18 and Figure 19, respectively. Neutralizer keeper voltages were within $0.3 \mathrm{~V}$ and coupling voltages were within $0.2 \mathrm{~V}$, indicating little change between these tests. Neutralizer spot-plume mode transition flow rates are plotted in Figure 20. Transition flow rates between the two tests were within $0.1 \mathrm{sccm}$, which was the uncertainty of the measurement. Neutralizer ignition times during both tests were all within 4.5 min.

Perveance limits, plotted in Figure 21, measured during both tests were within $21 \mathrm{~V}$, which is within the estimated measurement uncertainty. Accelerator currents shown in Figure 22 were within $0.9 \mathrm{~mA}$ between the two tests. Electron backstreaming limits between the two tests, tabulated in Table 4, were within $1 \mathrm{~V}$, which is within the estimated measurement uncertainty.

The PMS-PM1R integration test ultimately demonstrated that PMS could successfully interface with and operate a NEXT ion thruster with no anomalous thruster or PMS behavior.

\section{Propulsion System Performance of the PM1R Thruster, the PMS, and the PPU}

Propulsion system demonstrations of performance were divided into three separate tests. The first test was conducted at a PPU baseplate temperature of $25^{\circ} \mathrm{C}$ and a PMS inlet pressure of $350 \mathrm{kPa}(50 \mathrm{psia})$. It included measurements of system performance at standard input conditions, over the full range of PPU inputs conditions, and over the full range of PMS input conditions other than the $6,200 \mathrm{kPa}(900 \mathrm{psia})$ PMS inlet pressure, as listed in Table 1. The second test was conducted at a PPU baseplate temperature of $50{ }^{\circ} \mathrm{C}$, and included measurements of system performance at elevated PPU temperature input conditions, as listed in Table 1. The third test was conducted at a PMS inlet pressure of $6,200 \mathrm{kPa}$ (900 psia). It included measurements of system performance over the full range of PMS input conditions other than the $340 \mathrm{kPa}(50 \mathrm{psia}) \mathrm{PMS}$ inlet pressure. The results of the first two tests will be described in this section. The results of the third test will be described in the next section.

During the system performance tests described in this section, the PM1R thruster was operated with the PMS and the PPU. The DCIU Simulator controlled both the PMS and PPU, as well as the XFSE. The flow path and valve positions for the PMS and XFSE are identical to that used in the PM1R-PMS integration test, as shown in Figure 27. As with prior tests, mass flow controller measurements were made in $5 \mathrm{~s}$ intervals for $5 \mathrm{~min}$ and averaged to reduce mass flow controller measurement error. The PPU was configured as shown in Figure 13. The throttle points used for these tests are listed in Table 2.

The following sections will separately discuss the results of thruster, PMS, and PPU operation and performance. The thruster section will focus on the operational behavior of the thruster while integrated with the PMS and PPU to ensure there were no interface issues. The PMS section will present mass flow rate and PMS input power test results. Finally, the PPU section will present efficiency and recycle operation.

\section{Thruster Operation}

All thruster performance results obtained during the two propulsion system performance tests were compared to those of the RePAT. The thruster voltages and currents below were independently measured with multimeters and current shunts. Discharge voltages and discharge losses are shown in Figure 28 and Figure 29, respectively. Discharge voltages measured during the two system performance tests and RePAT were within $0.5 \mathrm{~V}$ at full power, but this bandwidth increased to $1.5 \mathrm{~V}$ at low power. Similarly, discharge losses were within $3 \mathrm{~W} / \mathrm{A}$ at full power, but this bandwidth increased to about $20 \mathrm{~W} / \mathrm{A}$ at low power. These larger dispersions at low power were due to the sensitivity of the discharge losses to propellant utilization efficiency at the lower beam currents and variations in discharge voltage, which is a characteristic of the PM1R thruster. Discharge chamber performance was therefore considered nominal. In addition to these data, discharge cathode ignition times during both system performance tests were within $6.0 \mathrm{~min}$.

The neutralizer keeper and coupling voltages are shown in Figure 30 and Figure 31, respectively. Neutralizer keeper and coupling voltages were both within $0.8 \mathrm{~V}$ of the RePAT results, indicating little 
change between these tests. Neutralizer ignition times during both system performance tests were all within $4.0 \mathrm{~min}$.

Perveance and electron backstreaming limit measurements were only made during PPU operation at a $25^{\circ} \mathrm{C}$ baseplate temperature. Perveance limits, plotted in Figure 32 were within $10 \mathrm{~V}$ of the RePAT results using the power console. These results are within the estimated measurement uncertainty. Electron backstreaming limits between the two tests, tabulated in Table 7, were within $2 \mathrm{~V}$, which is within the estimated measurement uncertainty. Accelerator currents, shown in Figure 33, were within $0.7 \mathrm{~mA}$ of the RePAT results.

The results of the two propulsion system performance tests ultimately demonstrated that PPU and PMS could successfully interface with and operate a NEXT ion thruster with no anomalous thruster behavior for the operating conditions presented.
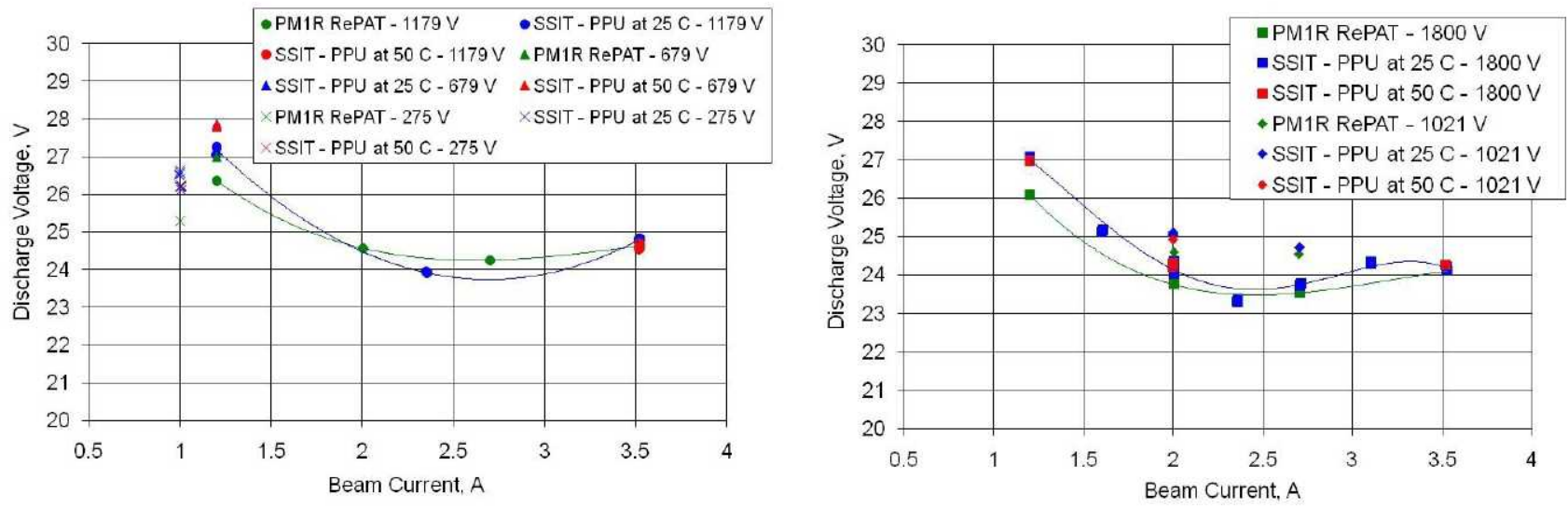

Figure 28.-Discharge voltages as a function of beam current at beam supply voltages of $275,679,1021,1179$, and $1800 \mathrm{~V}$ during the RePAT and propulsion system performance tests at PPU baseplate temperatures of 25 and $50^{\circ} \mathrm{C}$.
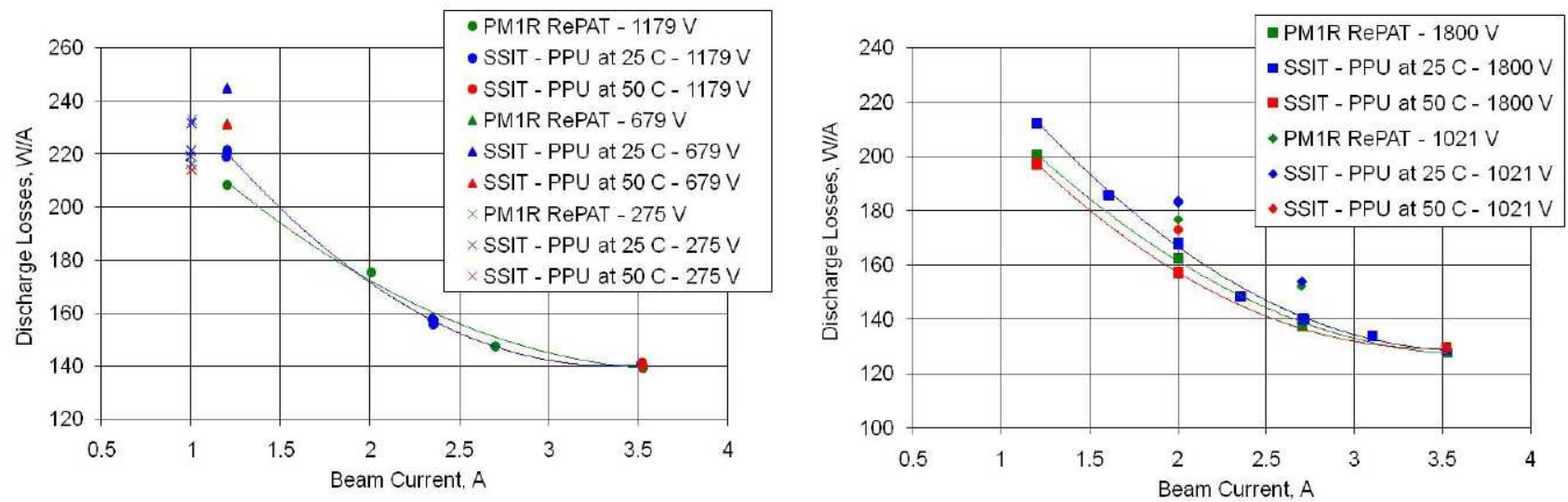

Figure 29.-Discharge losses as a function of beam current at beam supply voltages of $275,679,1021,1179$, and $1800 \mathrm{~V}$ during the RePAT and propulsion system performance tests at PPU baseplate temperatures of 25 and $50{ }^{\circ} \mathrm{C}$. 

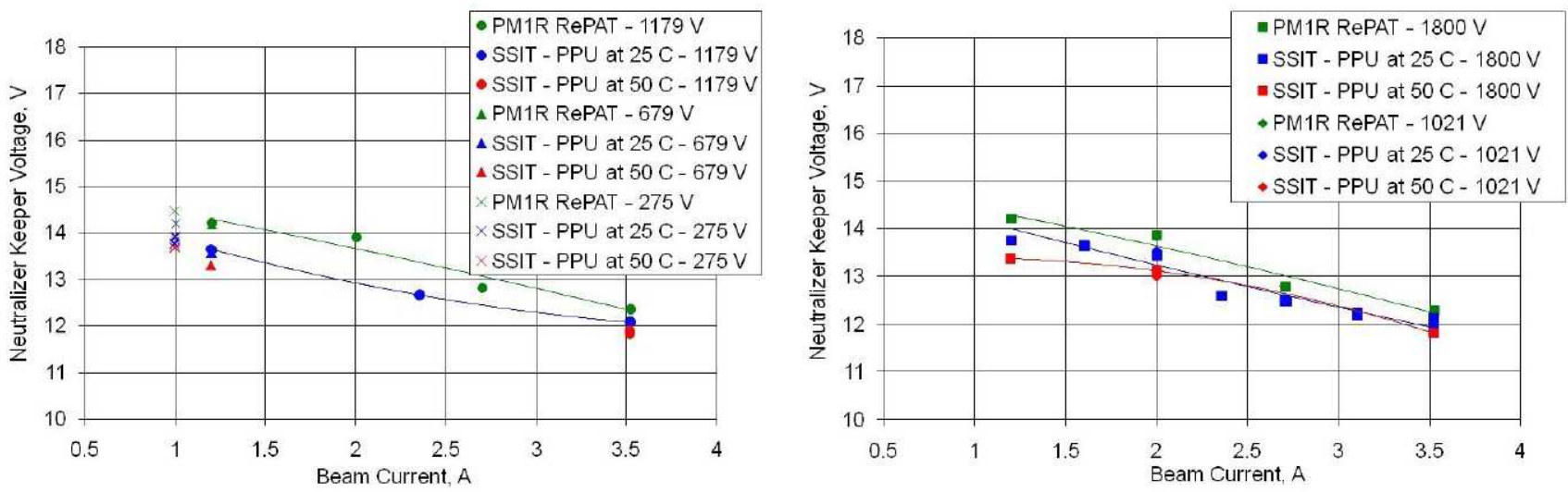

Figure 30.-Neutralizer keeper voltages as a function of beam current at beam supply voltages of $275,679,1021,1179$, and $1800 \mathrm{~V}$ during the RePAT and propulsion system performance tests at PPU baseplate temperatures of 25 and $50^{\circ} \mathrm{C}$.
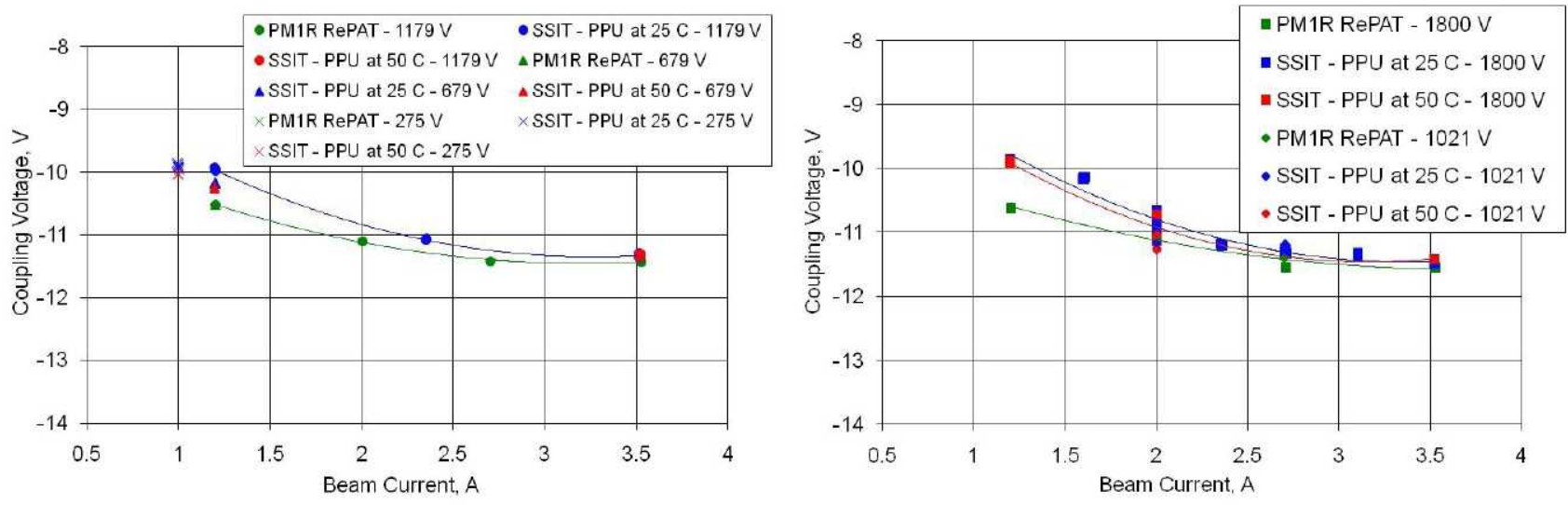

Figure 31.-Coupling voltages as a function of beam current at beam supply voltages of $275,679,1021,1179$, and $1800 \mathrm{~V}$ during the RePAT and propulsion system performance tests at PPU baseplate temperatures of 25 and $50^{\circ} \mathrm{C}$.

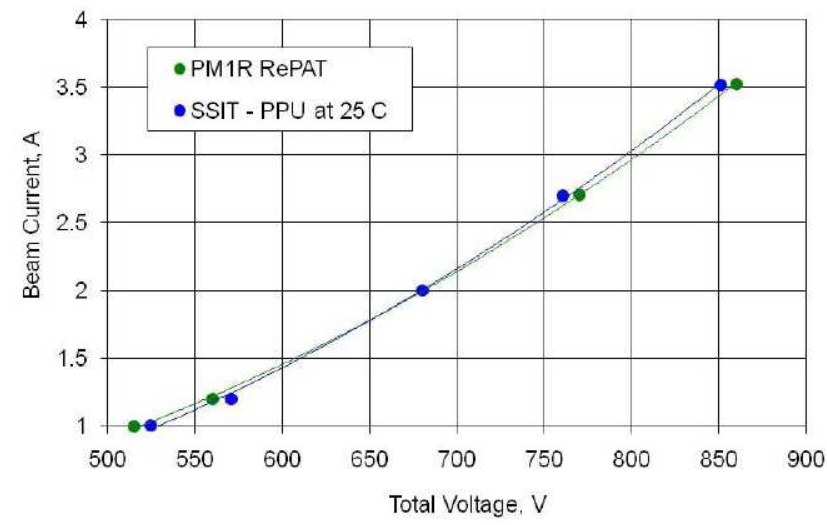

Figure 32.-Perveance limits measured during the RePAT and the propulsion system performance test at a PPU baseplate temperatures of $25^{\circ} \mathrm{C}$. 

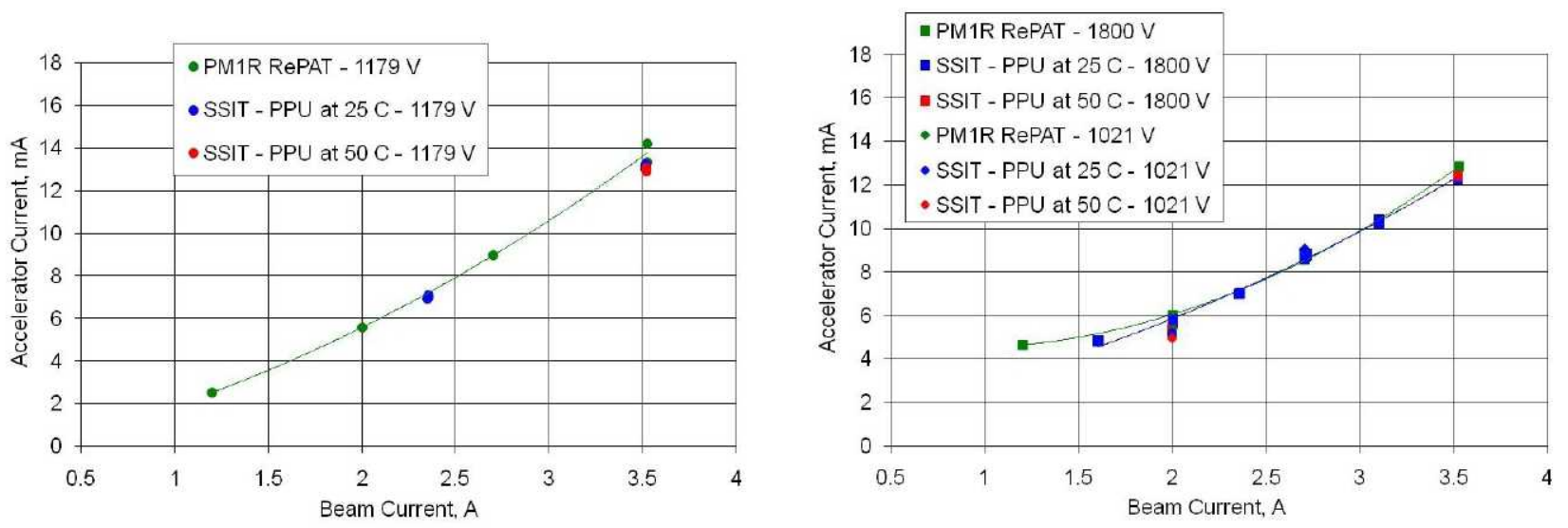

Figure 33.-Accelerator currents as a function of beam current at beam supply voltages of 1021,1179 , and $1800 \mathrm{~V}$ during the RePAT and propulsion system performance tests at PPU baseplate temperatures of 25 and $50{ }^{\circ} \mathrm{C}$.

TABLE 7.-ELECTRON BACKSTREAMING LIMITS MEASURED DURING THE PM1R RePAT AND THE SINGLE STRING PROPULSION SYSTEM PERFORMANCE TEST

\begin{tabular}{|c|c|c|c|}
\hline \multicolumn{2}{|c|}{ Throttle Point } & \multicolumn{2}{c|}{ Electron backstreaming limits, } \\
\hline $\begin{array}{c}\text { Beam Current, } \\
\text { A }\end{array}$ & Beam supply voltage, & $\begin{array}{c}\text { PM1R } \\
\text { RePAT }\end{array}$ & $\begin{array}{c}\text { Test with 25 }{ }^{\circ} \mathrm{C} \text { PPU } \\
\text { baseplate }\end{array}$ \\
\hline 3.52 & 1800 & -167 & -168 \\
3.52 & 1179 & -122 & -123 \\
3.10 & 1800 & ---- & -159 \\
2.70 & 1800 & -149 & -150 \\
2.70 & 1179 & -110 & --- \\
2.70 & 1021 & -95 & -95 \\
2.36 & 1800 & ---- & -139 \\
2.00 & 1800 & -126 & -113 \\
2.00 & 1396 & ----- & - \\
2.00 & 1179 & --8 & -88 \\
2.00 & 1021 & -88 & -106 \\
1.60 & 1800 & ---- & -84 \\
1.20 & 1800 & -86 & -79 \\
1.20 & 1179 & -80 & -48 \\
1.20 & 679 & -49 & \\
\hline
\end{tabular}

\section{PMS Performance}

The total LPA indicated flow rate (i.e., the sum of the indicated LPA branch flow rates) error measured during the two propulsion system performance tests is plotted in Figure 34. Also included in the plot is the maximum commanded LPA branch flow rate error requirement for reference. Total LPA flow rates were found to be within 3.25 percent of the mass flow controller flow rate. The LPA total flow rate error was also found to increase with decreasing flow rate. This was largely due the main LPA branch flow calibration, which dominated the total flow rate and tended to yield higher flow rate errors at lower flow rates, as shown in Table 5. Mass flow controller error is shown as green error bars in the figure. Mass flow controller error was \pm 1.0 percent of reading for all flow rates except the two lowest, which reached \pm 1.4 percent.

Low pressure assembly outlet pressures were also measured by pressure transducers on the XFSE and recorded by the DCIU Simulator. These pressures were compared to those of the PM1R-PMS integration test. The results are shown in Figure 35. As the figure shows, LPA outlet pressures measured during the propulsion system performance tests were nearly identical to those of the PM1R-PMS integration test, which indicates that the flow rates were likely similar. The highest measured pressure was at the outlet of 
the main LPA branch at full power, which was $13 \mathrm{kPa}$ (100 torr). These data will be used in a later analysis, along with the PMS calibration check data, to assess that individual LPA branch flow rate error.

Propellant management system power consumption is tabulated in Table 8 . These powers were determined from currents and voltages that were measured by the DCIU Simulator for the thermal throttles and PFCVs, and by multimeters for the pressure transducers. Average PMS power consumption at a $28 \mathrm{~V}$ low power bus voltage was $9.52 \mathrm{~W}$, with the LPA consuming $7.90 \mathrm{~W}$. The thermal throttle heaters consumed up to 49 percent of the total PMS power. At low power bus voltages of 22 and $34 \mathrm{~V}$, average PMS power consumptions were 8.97 and $9.97 \mathrm{~W}$, respectively. Not surprisingly, the changes were due to changes in pressure transducer power consumption. The pressure transducers were the only PMS components directly powered by the low power bus. All other PMS components are powered by low power bus power that is processed by the DCIU. Regardless, the PMS demonstrated successful operation over the full input power bus voltage range of 24 to $32 \mathrm{~V}$.

The PMS also met its power requirements for normal mode operation during steady state operation. The maximum measured LPA power consumption during normal mode operation was $8.35 \mathrm{~W}$, which was less than the $15 \mathrm{~W}$ maximum requirement. The maximum measured HPA power consumption during normal mode operation was $1.83 \mathrm{~W}$, which was also less than the $5 \mathrm{~W}$ maximum requirement. Note, however, that the redundant HPA outlet pressure transducer was a mock-up. If this redundant pressure transducer power is included, the maximum HPA power consumption would have been $2.41 \mathrm{~W}$, which is still less than the $5 \mathrm{~W}$ maximum.

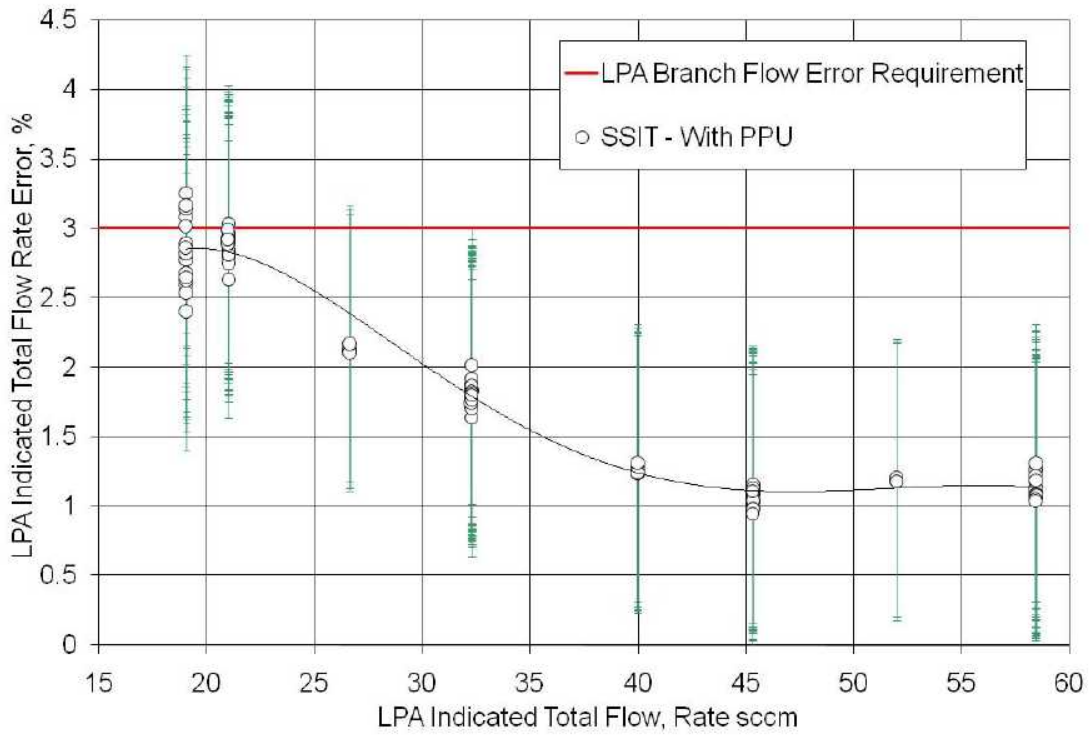

Figure 34.-LPA indicated total flow rate error as a function of LPA total flow rate. Error bars denote mass flow controller error. 


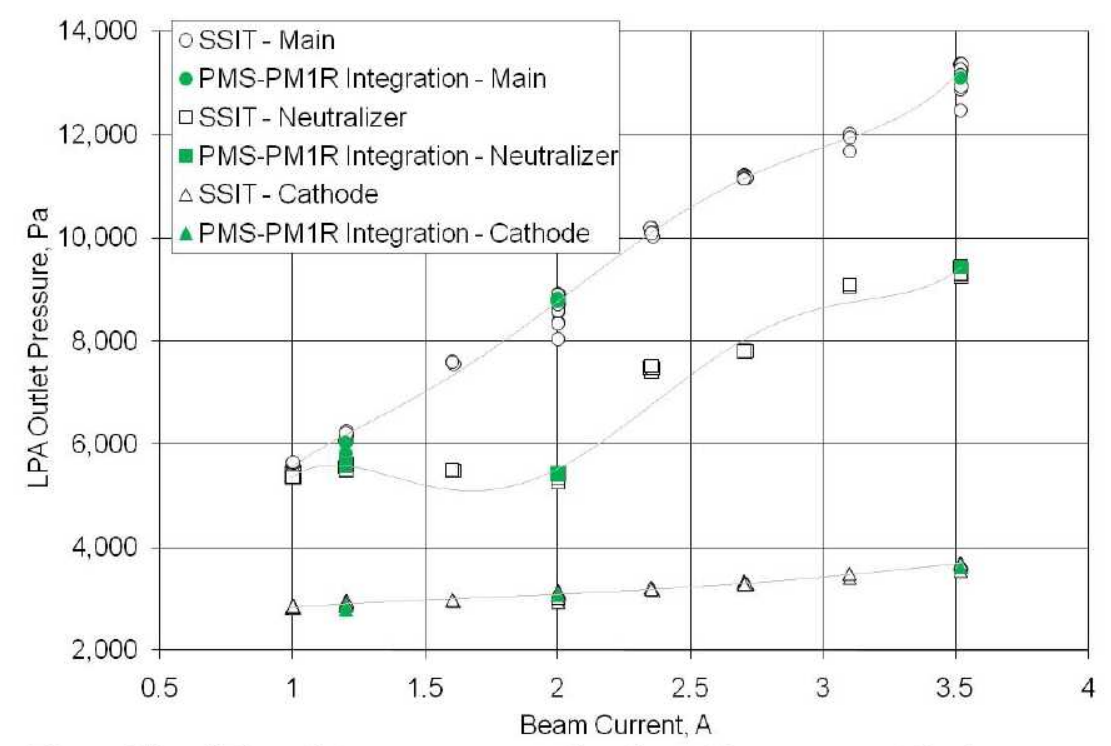

Figure 35.-LPA outlet pressures as a function of beam current for the propulsion system performance and PM1R-PMS integration tests.

TABLE 8.-PMS POWER CONSUMPTION AVERAGES, MAXIMA, AND MINIMA AS A FUNCTION OF LOW POWER BUS VOLTAGE DURING PROPULSION SYSTEM PERFORMANCE TESTS

\begin{tabular}{|c|c|c|c|c|c|c|c|c|c|}
\hline \multirow[t]{2}{*}{$\begin{array}{l}\text { PMS LPB } \\
\text { voltage, V }\end{array}$} & & \multicolumn{3}{|c|}{$\begin{array}{c}\text { HPA power, } \\
\text { W }\end{array}$} & \multicolumn{4}{|c|}{$\begin{array}{c}\text { LPA power, } \\
\text { W }\end{array}$} & \multirow[t]{2}{*}{$\begin{array}{l}\text { Total PMS } \\
\text { power, W }\end{array}$} \\
\hline & & $\begin{array}{c}\text { Pressure } \\
\text { transducers }\end{array}$ & PFCV & Total & $\begin{array}{c}\text { Pressure } \\
\text { transducers }\end{array}$ & PFCV & $\begin{array}{l}\text { Thermal } \\
\text { throttle }\end{array}$ & Total & \\
\hline 22 & Average & 0.75 & 0.66 & 1.41 & 1.11 & 1.87 & 4.58 & 7.55 & 8.97 \\
\hline 22 & Maximum & 0.76 & 0.67 & 1.42 & 1.11 & 1.90 & 4.82 & 7.76 & 9.16 \\
\hline 22 & Minimum & 0.75 & 0.64 & 1.40 & 1.10 & 1.84 & 4.44 & 7.42 & 8.84 \\
\hline 28 & Average & 0.96 & 0.66 & 1.61 & 1.40 & 1.86 & 4.64 & 7.90 & 9.52 \\
\hline 28 & Maximum & 0.96 & 0.67 & 1.63 & 1.41 & 1.90 & 4.91 & 8.15 & 9.75 \\
\hline 28 & Minimum & 0.95 & 0.64 & 1.60 & 1.40 & 1.83 & 4.43 & 7.71 & 9.34 \\
\hline 34 & Average & 1.16 & 0.66 & 1.82 & 1.70 & 1.87 & 4.58 & 8.15 & 9.97 \\
\hline 34 & Maximum & 1.16 & 0.67 & 1.83 & 1.70 & 1.90 & 4.81 & 8.35 & 10.16 \\
\hline 34 & Minimum & 1.16 & 0.64 & 1.81 & 1.70 & 1.84 & 4.43 & 8.01 & 9.84 \\
\hline
\end{tabular}

\section{PPU Performance}

Power processor efficiency as a function of throttle level, and high and low power bus input voltages during testing at a $25^{\circ} \mathrm{C}$ PPU baseplate temperature are tabulated in Table 9. Here, total efficiency is the output power divided by the sum of the high and low power bus input powers, while power efficiency excludes the low power bus input power. The currents and voltages used for these calculations were independently measured with multimeters and current shunts at the PPU vacuum facility feed-throughs and were further corrected to exclude any line losses. The peak PPU power efficiency was 0.954 and occurred at the highest beam supply voltage. The table also includes PPU power efficiency requirements. As the table shows, the PPU successfully satisfied all power efficiency requirements against which it was tested. 
TABLE 9.-POWER PROCESSOR EFFICIENCY AS A FUNCTION OF THROTTLE LEVEL, AND LPB AND HPB INPUTS DURING PROPULSION SYSTEM DEMONSTRATIONS

OF PERFORMANCE AT A $25^{\circ} \mathrm{C}$ PPU BASEPLATE TEMPERATURE

\begin{tabular}{|c|c|c|c|c|c|c|c|c|c|c|}
\hline $\begin{array}{c}\text { Beam } \\
\text { supply } \\
\text { voltage, } \\
\text { V }\end{array}$ & $\begin{array}{c}\text { Beam } \\
\text { supply } \\
\text { current, } \\
\text { A }\end{array}$ & $\begin{array}{c}\text { HPB } \\
\text { voltage, } \\
\mathrm{V}\end{array}$ & $\begin{array}{c}\text { HPB } \\
\text { current, } \\
\text { A }\end{array}$ & $\begin{array}{c}\text { LPB } \\
\text { voltage, } \\
\text { V }\end{array}$ & $\begin{array}{c}\text { LPB } \\
\text { current, } \\
\text { A }\end{array}$ & $\begin{array}{l}\text { No. beam } \\
\text { modules }\end{array}$ & $\begin{array}{c}\text { Total } \\
\text { efficiency }\end{array}$ & $\begin{array}{c}\text { Power } \\
\text { efficiency }\end{array}$ & $\begin{array}{c}\text { Min. } \\
\text { required } \\
\text { power } \\
\text { efficiency }\end{array}$ & $\begin{array}{l}\text { Req. } \\
\text { met? }\end{array}$ \\
\hline 277 & 1.01 & 100 & 6.41 & 28.0 & 0.576 & 1 & 0.847 & 0.869 & - & - \\
\hline 276 & 1.00 & 80.3 & 7.90 & 22.1 & 0.644 & 1 & 0.859 & 0.878 & - & - \\
\hline 277 & 1.00 & 160 & 4.24 & 22.1 & 0.638 & 1 & 0.802 & 0.819 & - & - \\
\hline 276 & 1.00 & 80.3 & 7.94 & 34.0 & 0.478 & 1 & 0.858 & 0.880 & - & - \\
\hline 277 & 1.00 & 160 & 4.26 & 34.0 & 0.473 & 1 & 0.803 & 0.822 & - & - \\
\hline 277 & 1.01 & 100 & 6.61 & 28.1 & 0.576 & 1 & 0.851 & 0.871 & - & - \\
\hline 303 & 1.20 & 100 & 8.33 & 28.0 & 0.578 & 1 & 0.855 & 0.872 & - & - \\
\hline 303 & 1.20 & 80.2 & 10.3 & 28.0 & 0.580 & 1 & 0.866 & 0.883 & - & - \\
\hline 303 & 1.20 & 160 & 5.44 & 28.0 & 0.573 & 1 & 0.818 & 0.833 & - & - \\
\hline 681 & 1.20 & 100 & 12.8 & 28.0 & 0.651 & 2 & 0.909 & 0.922 & - & - \\
\hline 681 & 1.20 & 80.2 & 15.9 & 28.0 & 0.653 & 2 & 0.917 & 0.930 & - & - \\
\hline 682 & 1.20 & 160 & 8.24 & 28.0 & 0.649 & 2 & 0.883 & 0.895 & - & - \\
\hline 1181 & 1.20 & 100 & 18.6 & 28.0 & 0.659 & 2 & 0.936 & 0.945 & - & - \\
\hline 1181 & 1.20 & 80.0 & 23.2 & 22.1 & 0.719 & 2 & 0.934 & 0.942 & - & - \\
\hline 1181 & 1.20 & 160 & 11.8 & 22.1 & 0.724 & 2 & 0.917 & 0.924 & - & - \\
\hline 1181 & 1.20 & 80.0 & 23.3 & 34.0 & 0.537 & 2 & 0.934 & 0.943 & - & - \\
\hline 1182 & 1.21 & 160 & 11.9 & 34.0 & 0.541 & 2 & 0.917 & 0.926 & - & - \\
\hline 1802 & 1.20 & 99.9 & 26.3 & 28.0 & 0.652 & 2 & 0.943 & 0.950 & 0.938 & Yes \\
\hline 1802 & 1.20 & 79.8 & 33.0 & 28.0 & 0.655 & 2 & 0.942 & 0.948 & - & - \\
\hline 1803 & 1.21 & 160 & 16.5 & 28.0 & 0.661 & 2 & 0.937 & 0.944 & - & - \\
\hline 1803 & 1.61 & 99.8 & 34.5 & 28.0 & 0.807 & 4 & 0.946 & 0.952 & - & - \\
\hline 1803 & 1.61 & 79.6 & 43.3 & 28.0 & 0.811 & 4 & 0.948 & 0.954 & - & - \\
\hline 1803 & 1.61 & 160 & 21.7 & 28.0 & 0.827 & 4 & 0.936 & 0.942 & - & - \\
\hline 1024 & 2.01 & 99.9 & 26.9 & 28.0 & 0.823 & 4 & 0.930 & 0.938 & - & - \\
\hline 1024 & 2.01 & 79.5 & 33.6 & 22.1 & 0.892 & 4 & 0.938 & 0.945 & - & - \\
\hline 1024 & 2.00 & 160 & 17.2 & 22.1 & 0.885 & 4 & 0.908 & 0.914 & - & - \\
\hline 1024 & 2.01 & 79.8 & 33.5 & 34.0 & 0.680 & 4 & 0.935 & 0.943 & - & - \\
\hline 1024 & 2.01 & 160 & 17.1 & 34.0 & 0.671 & 4 & 0.909 & 0.917 & - & - \\
\hline 1399 & 2.01 & 99.8 & 34.5 & 28.0 & 0.806 & 4 & 0.940 & 0.946 & - & - \\
\hline 1399 & 2.01 & 79.5 & 43.3 & 28.0 & 0.811 & 4 & 0.942 & 0.948 & - & - \\
\hline 1399 & 2.00 & 160 & 21.7 & 28.0 & 0.821 & 4 & 0.927 & 0.933 & - & - \\
\hline 1803 & 2.00 & 99.6 & 42.8 & 28.0 & 0.816 & 4 & 0.946 & 0.951 & 0.936 & Yes \\
\hline 1803 & 2.01 & 79.3 & 53.9 & 28.0 & 0.814 & 4 & 0.946 & 0.951 & - & - \\
\hline 1803 & 2.00 & 160 & 26.8 & 28.0 & 0.835 & 4 & 0.933 & 0.938 & - & - \\
\hline 1183 & 2.36 & 100 & 34.7 & 28.0 & 0.827 & 4 & 0.935 & 0.941 & - & - \\
\hline 1182 & 2.36 & 80.2 & 43.3 & 28.0 & 0.811 & 4 & 0.934 & 0.941 & - & - \\
\hline 1183 & 2.36 & 160 & 22.1 & 28.0 & 0.819 & 4 & 0.919 & 0.925 & - & - \\
\hline 1803 & 2.36 & 100 & 49.8 & 28.0 & 0.810 & 4 & 0.945 & 0.949 & 0.932 & Yes \\
\hline 1803 & 2.37 & 80.0 & 62.6 & 28.0 & 0.817 & 4 & 0.945 & 0.949 & - & - \\
\hline 1803 & 2.36 & 160 & 31.2 & 28.0 & 0.827 & 4 & 0.939 & 0.943 & - & - \\
\hline 1025 & 2.71 & 100 & 35.3 & 28.0 & 0.993 & 6 & 0.931 & 0.938 & - & - \\
\hline 1024 & 2.72 & 79.9 & 44.0 & 28.0 & 1.003 & 6 & 0.936 & 0.944 & - & - \\
\hline 1025 & 2.71 & 160.2 & 22.5 & 28.0 & 0.983 & 6 & 0.911 & 0.918 & - & - \\
\hline 1804 & 2.71 & 100 & 56.7 & 28.0 & 0.970 & 6 & 0.947 & 0.952 & 0.930 & Yes \\
\hline 1805 & 2.72 & 80.1 & 71.0 & 28.0 & 0.975 & 6 & 0.948 & 0.952 & - & - \\
\hline 1803 & 2.71 & 160 & 35.6 & 28.0 & 0.998 & 6 & 0.939 & 0.943 & - & - \\
\hline 1804 & 3.11 & 100 & 64.8 & 28.0 & 0.973 & 6 & 0.946 & 0.950 & 0.933 & Yes \\
\hline 1803 & 3.11 & 80.4 & 81.0 & 28.0 & 0.977 & 6 & 0.945 & 0.949 & - & - \\
\hline 1803 & 3.11 & 160 & 40.7 & 28.0 & 0.998 & 6 & 0.938 & 0.942 & - & - \\
\hline 1182 & 3.53 & 80.3 & 64.1 & 28.0 & 0.975 & 6 & 0.934 & 0.939 & - & - \\
\hline 1183 & 3.53 & 160 & 32.5 & 28.0 & 0.989 & 6 & 0.919 & 0.924 & - & - \\
\hline 1183 & 3.54 & 100 & 51.2 & 28.0 & 1.004 & 6 & 0.936 & 0.941 & - & - \\
\hline 1804 & 3.54 & 100 & 73.7 & 28.0 & 0.975 & 6 & 0.945 & 0.949 & 0.932 & Yes \\
\hline 1803 & 3.53 & 87.1 & 85.1 & 22.0 & 1.047 & 6 & 0.941 & 0.944 & - & - \\
\hline 1804 & 3.53 & 160 & 46.1 & 22.0 & 1.067 & 6 & 0.937 & 0.940 & - & - \\
\hline 1804 & 3.53 & 80.5 & 92.2 & 34.0 & 0.803 & 6 & 0.941 & 0.945 & - & - \\
\hline 1804 & 3.53 & 159 & 46.5 & 34.0 & 0.819 & 6 & 0.939 & 0.942 & - & - \\
\hline
\end{tabular}

Power processor efficiencies as a function of throttle level and high power bus input voltages during testing at a $50{ }^{\circ} \mathrm{C}$ PPU baseplate temperature are tabulated in Table 10. There were no efficiency requirements levied on the PPU while operating at elevated temperatures. A comparison of total 
efficiency at the two PPU baseplate temperatures tested is given in Figure 36. As the figure shows, total efficiencies were almost always lower at a $50{ }^{\circ} \mathrm{C}$ baseplate temperature due to increased resistive losses, but they were still typically within 0.01 of the $25{ }^{\circ} \mathrm{C}$ baseplate temperature efficiencies. The figure also demonstrates several important characteristics about the PPU. Power processor efficiency is a strong function of beam power supply voltage. This is because beam power dominates PPU output power and beam module efficiency is sensitive to beam voltage. Regarding the latter, higher beam voltages improve efficiency because they result in higher duty cycles and because the beam modules transition from pulsewidth modulation to phase-shift mode, which is more efficient. In addition, the figure shows that the PPU is generally more efficient at lower power bus voltages.

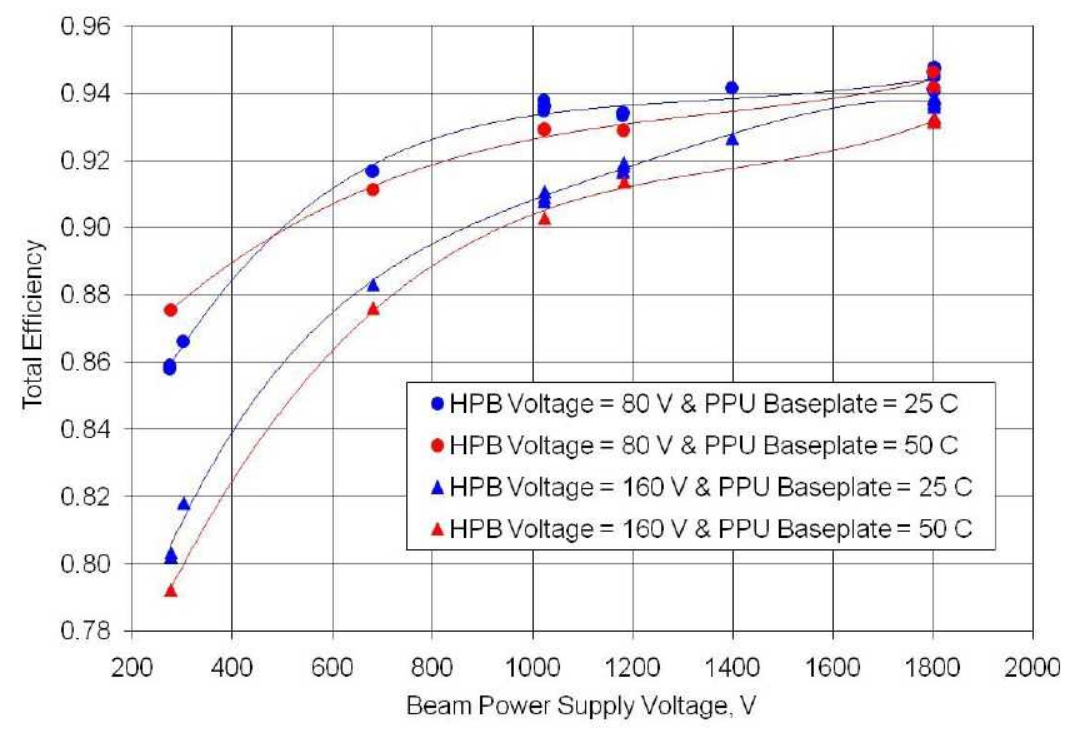

Figure 36.-Power processor total efficiency as a function of beam power supply voltage during propulsion system demonstrations of performance at 25 and $50{ }^{\circ} \mathrm{C}$ PPU baseplate temperature, and at HPB voltages of 80 and $160 \mathrm{~V}$.

TABLE 10.-PPU EFFICIENCY AS A FUNCTION OF THROTTLE LEVEL, AND LPB AND HPB INPUTS DURING PROPULSION SYSTEM DEMONSTRATIONS OF PERFORMANCE

\begin{tabular}{|c|c|c|c|c|c|c|c|c|}
\hline \multicolumn{10}{c|}{ AT A $50{ }^{\circ}$ C PPU BASEPLATE TEMPERATURE } \\
$\begin{array}{c}\text { Beam } \\
\text { voltage, }\end{array}$ & $\begin{array}{c}\text { Beam } \\
\text { supply } \\
\text { current, }\end{array}$ & $\begin{array}{c}\text { HPB } \\
\text { voltage, } \\
\text { V }\end{array}$ & $\begin{array}{c}\text { HPB } \\
\text { current, } \\
\text { A }\end{array}$ & $\begin{array}{c}\text { LPB } \\
\text { voltage, } \\
\text { V }\end{array}$ & $\begin{array}{c}\text { LPB } \\
\text { current, } \\
\text { A }\end{array}$ & $\begin{array}{c}\text { Modules } \\
\text { efficiency } \\
\text { efficiency }\end{array}$ & \\
\hline 277 & 1.02 & 80.3 & 7.90 & 28.1 & 0.575 & 1 & 0.875 \\
277 & 1.00 & 160 & 4.24 & 28.1 & 0.569 & 0.898 & 0.792 \\
\hline 681 & 1.20 & 80.2 & 15.7 & 28.1 & 0.649 & 2 & 0.911 & 0.925 \\
681 & 1.20 & 160 & 8.16 & 28.1 & 0.645 & 2 & 0.876 \\
1802 & 1.20 & 79.9 & 32.5 & 28.0 & 0.802 & 4 & 0.946 & 0.955 \\
1802 & 1.20 & 160 & 16.4 & 28.0 & 0.649 & 2 & 0.932 \\
\hline 1024 & 2.00 & 80.4 & 33.0 & 28.0 & 0.831 & 4 & 0.929 & 0.938 \\
1024 & 2.01 & 161 & 17.0 & 28.0 & 0.820 & 4 & 0.903 \\
1803 & 2.01 & 80.1 & 53.1 & 28.0 & 0.818 & 4 & 0.911 \\
1803 & 2.00 & 160 & 26.7 & 28.0 & 0.830 & 4 & 0.942 \\
\hline 1183 & 3.53 & 80.2 & 64.5 & 28.0 & 0.984 & 6 & 0.947 \\
1183 & 3.53 & 160 & 32.7 & 28.0 & 0.998 & 6 & 0.932 \\
1804 & 3.53 & 160 & 46.4 & 28.0 & 0.990 & 6 & 0.937 \\
\hline
\end{tabular}

Power processor housekeeping power (from the low power bus) as a function of the number of operational beam modules is plotted in Figure 37 at various input voltages for a $25{ }^{\circ} \mathrm{C}$ PPU baseplate temperature. As the figure shows, the PPU housekeeping power is a strong function of the number of 
operational beam modules because the PPU module addressing circuit turns off unused beam modules. The figure also shows that while housekeeping power is nearly unchanged at low power bus voltages of 28 and $34 \mathrm{~V}$, it decreases by 2 to $4 \mathrm{~W}$ at $22 \mathrm{~V}$. Housekeeping input powers at the $50^{\circ} \mathrm{C}$ PPU baseplate temperature were nearly identical to those of the baseplate at $25^{\circ} \mathrm{C}$. The maximum PPU housekeeping power was $28.1 \mathrm{~W}$, which satisfied the $\leq 30 \mathrm{~W}$ requirement.

Power processor recycles were measured throughout these integration tests. Typical recycle traces are shown in Figure 38. To initiate a recycle, the PPU senses an over-current at the input of each beam module. As the figure shows, the beam and accelerator power supply outputs are immediately terminated and the discharge current is ramped down to its cutback level at the start of a recycle. After about $480 \mathrm{~ms}$, the accelerator voltage is re-applied. The beam supply is ramped back up $140 \mathrm{~ms}$ later, and followed by the discharge current. The figure also shows accelerator voltage overshoots, and all recycles exhibited these overshoots. A later analysis revealed that these overshoots were caused by a delay in the power supply's voltage-control feedback loop during load current changes. A minor modification of the feedback circuit could have corrected this, but testing was allowed to proceed since these overshoots created no issues. While the PPU typically recycled the thruster successfully, continuous recycling caused by the PPU was found to occur during operation at elevated PPU internal temperatures and when the beam modules were operated at high output powers. A later investigation revealed that this continuous recycling was due to two separate root causes. The first root cause was that the recycle trigger current threshold was set too low, and this was later repaired. The second root cause was suspected to be related to the lack of temperature compensation on the control-mode-changing circuit of the beam modules, but was still under investigation at the time of this writing.

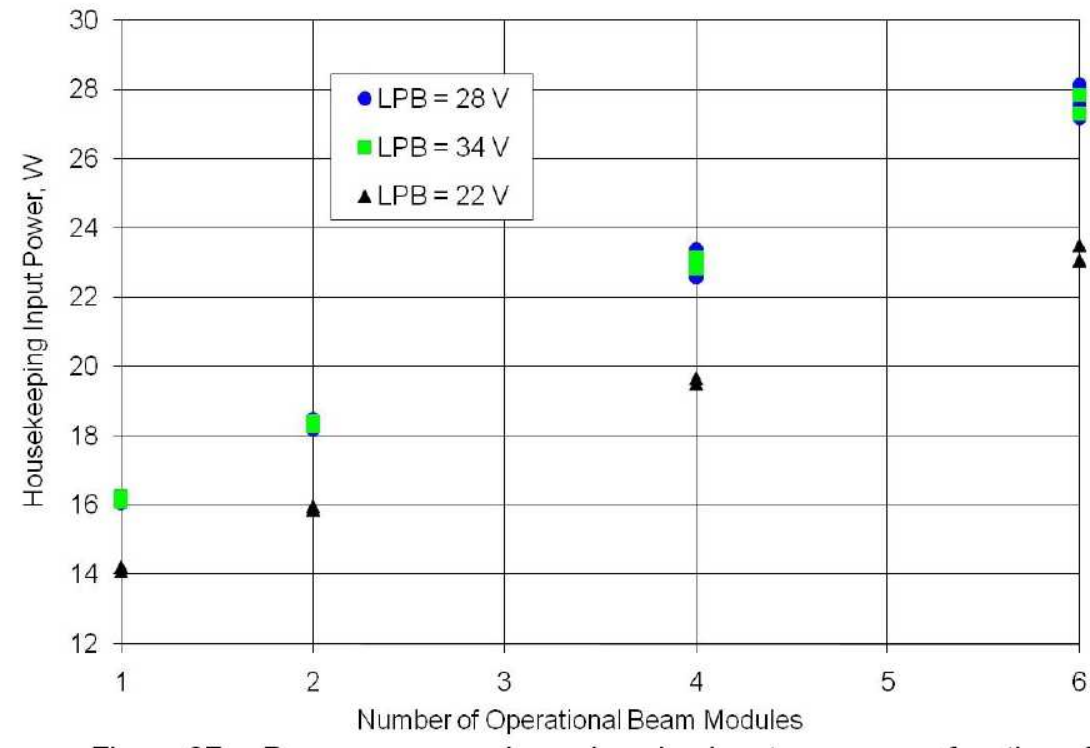

Figure 37.-Power processor housekeeping input power as a function of the number of operational beam modules during propulsion system demonstrations of performance at $25^{\circ} \mathrm{C}$ and at LPB voltages of 22 to $34 \mathrm{~V}$. 


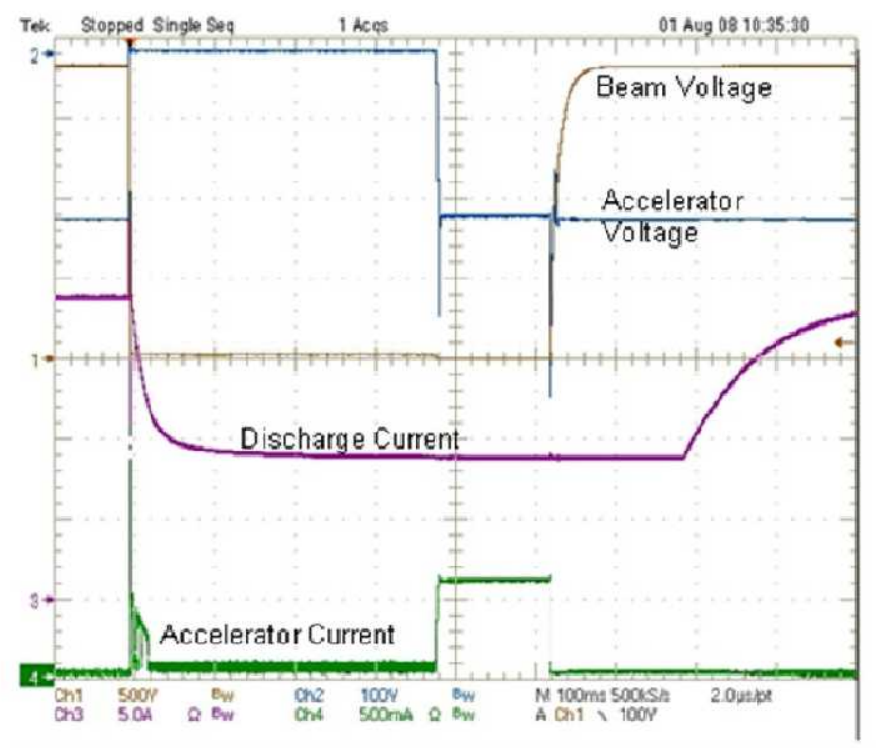

Figure 38.-Oscilloscope traces of a recycle during high power operation. Beam voltage is $500 \mathrm{~V} /$ division, accelerator voltage is $100 \mathrm{~V} /$ division, discharge current is $5 \mathrm{~A} /$ division, and accelerator current is $500 \mathrm{~mA} /$ division. The time base is $100 \mathrm{~ms} /$ division.

Power processor current and voltage telemetry and set point accuracies were also checked against the independent multimeter measurements. Four telemetry channels exhibited telemetry errors that exceeded the \pm 2 percent of full scale requirement. These channels included beam current, discharge current, discharge voltage, and coupling voltage. The latter three exhibited out-of specification values only during operation at the highest power. The beam current telemetry was not functional during testing because of a known design issue. Power processor set point accuracies were all $\leq 2.5$ percent of full scale, which met the requirement.

The PPU completed almost all of the planned propulsion system performance tests. Unfortunately, some PPU components failed during full power thruster operation at a baseplate temperature of $50{ }^{\circ} \mathrm{C}$ causing a beam module to overheat. A later inspection of the module revealed that three diodes on the overheating module output rectifier stage had failed. A failure review board determined the root cause to be the diodes themselves. The failed beam module utilized diodes from a different manufacturer than the remaining PPU diodes. These failed diodes had a longer reverse recovery time that ultimately led to diode overheating and component failure. The beam module diodes were all replaced and the PPU retested. During the retest, though, a stacked ceramic capacitor on the input filter of a beam module failed. This was the second occurrence of such a failure, so the failure review board was reconvened. Root cause determination was still in progress at the time of this writing.

Because the PPU was not available for further testing, the remaining PMS-related integration tests were conducted using a power console. This could be done because the PPU is not necessary for PMS integration tests. As shown in Figure 7, there is no direct interface between the PMS and PPU.

\section{PMS at Various Inlet Pressures and Fault Handling}

The remaining PMS integration tests were divided into three separate tests. The first test was conducted at a PMS inlet pressure of $6,200 \mathrm{kPa}(900 \mathrm{psia})$ and was a part of the test plan's demonstration of propulsion system performance. It included measurements of thruster and PMS performance over the full range of PMS input conditions other than the $350 \mathrm{kPa}$ (50 psia) PMS inlet pressure, as listed in Table 1. The second test was a demonstration of PMS fault handling that included separate simulated PMS failures of LPA PFCVs failed closed and failed open. The third test was PMS operation at end-of- 
life inlet pressures to demonstrate operation at the lowest possible PMS inlet pressures and was a part of the test plan's demonstration of propulsion system functionality.

During all of the remaining PMS tests described in this section, the PM1R thruster was operated with a power console and the PMS. The power console used for this test was identical to the one used for the RePAT and the PM1R-PMS integration test. The DCIU Simulator controlled the PMS, as well as the XFSE. For high HPA inlet pressure testing, the flow path and valve positions for the PMS and XFSE are shown in Figure 39. Total LPA flow rate could not be monitored by the mass flow controller for this test because the high pressure exceeded the controller's maximum pressure rating. For the remaining PMS tests, the flow path and valve positions for the PMS and XFSE were identical to that used in the propulsion system performance tests and the PM1R-PMS integration test, as shown in Figure 27. As with prior tests that independently measured total LPA flow rate, measurements were made in $5 \mathrm{~s}$ intervals for $5 \mathrm{~min}$ and averaged to reduce mass flow controller measurement error.

Table 2 also lists the throttle points used for PMS fault handling, however, fault mode operation could not be conducted at every point because of insufficient calibration data, and this is shown in Table 11. For fault mode operation, all possible LPA PFCV failure modes were simulated, and this is also shown in Table 11. During an LPA PFCV failed closed fault, the failed LPA branch's latch valve was opened to an adjacent branch and the adjacent branch's PFCV was used to regulate pressure to both branches while thermal throttle temperature was varied to control the flow rate. As shown in Figure 2, the cathode LPA branch is the one branch that is common to the other two branches, and so all LPA PFCV failed closed fault modes included the cathode branch, also shown in Table 11. For a LPA PFCV failed open, the HPA PFCV is used to regulate branch pressure. However, to maximize the PMS's capability to achieve the full range of flow rates, the failed branch's latch valve must be opened to the adjacent branch, and both branches must use thermal throttle temperature to control the flow rate. For either failed case, the remaining branch is operated normally.

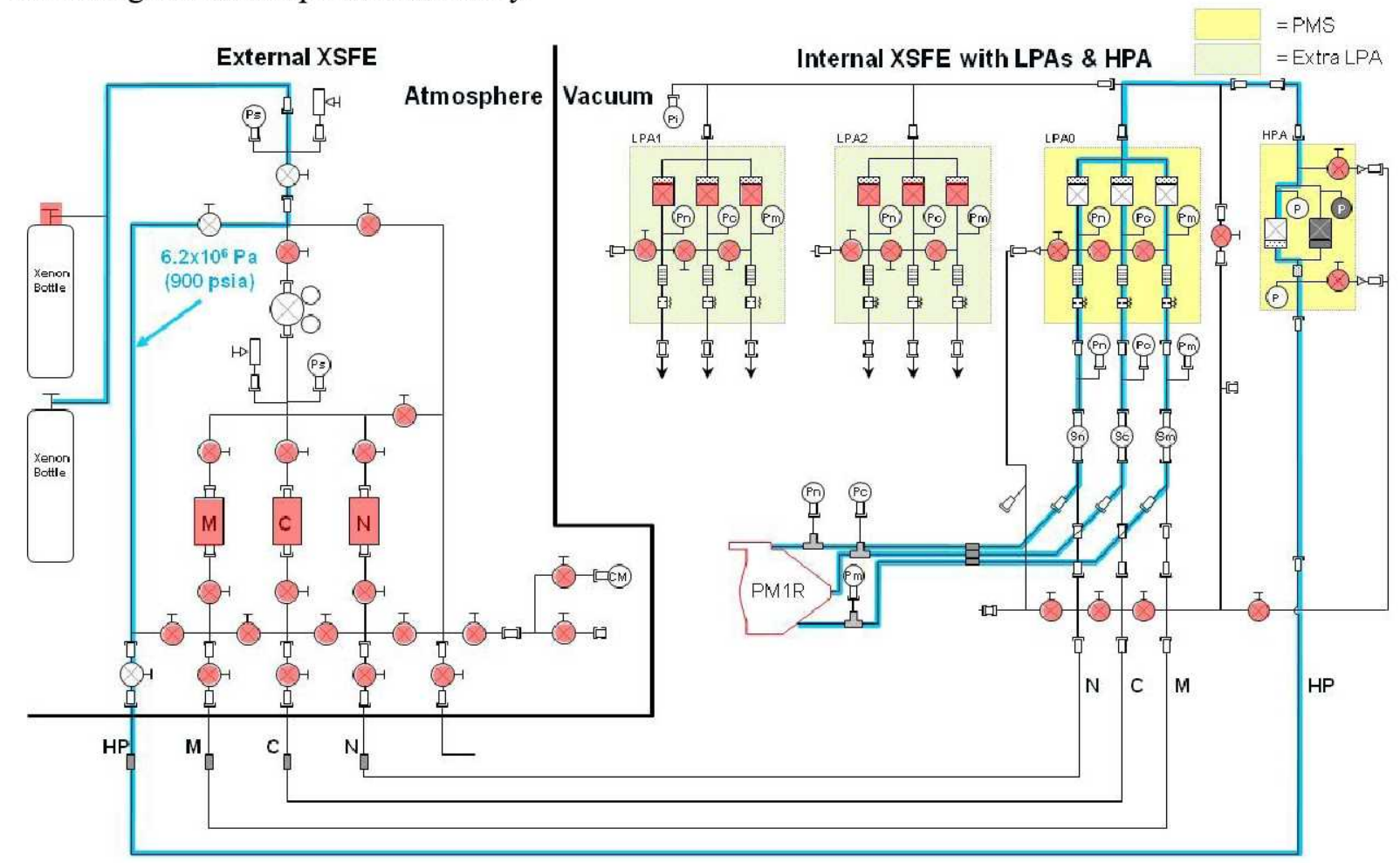

Figure 39.-Flow path through the PMS and XFSE during PMS operation at high inlet pressures. The blue lines indicate flow path, a red valve indicates that it was closed, and a white valve indicates that it was open. The key for this schematic is identical to that of Figure 11. 
There was no testing of a simulated HPA PFCV failure. A HPA PFCV failed closed test was unnecessary because the HPA design is parallel redundant. And a HPA PFCV failed open test was not conducted for reasons discussed at the end of this section.

The following sections will separately discuss the results of thruster and PMS operation and performance. The thruster section will focus on the operational behavior of the thruster while integrated with the PMS to ensure there were no interface issues. The PMS section will present mass flow rate and PMS input power test results.

TABLE 11.-LPA FAULT MODE DEMONSTRATIONS AS A FUNCTION OF THROTTLE POINT [Note that " $\times$ " signifies a throttle point that could not be demonstrated because of an incomplete PMS calibration]

\begin{tabular}{|c|c|c|c|c|c|c|}
\hline \multicolumn{2}{|c|}{ Throttle Point } & \multicolumn{2}{|c|}{ LPA PFCV failed closed } & \multicolumn{3}{|c|}{ LPA PFCV failed open } \\
\hline $\begin{array}{c}\text { Beam current, } \\
\text { A }\end{array}$ & $\begin{array}{c}\text { Beam supply voltage, } \\
\text { V }\end{array}$ & $\begin{array}{l}\text { Main or } \\
\text { cathode }\end{array}$ & $\begin{array}{l}\text { Neutralizer } \\
\text { or cathode }\end{array}$ & Main & Cathode & Neutralizer \\
\hline 3.52 & 1800 & -- & -- & -- & -- & -- \\
\hline 3.52 & 1179 & $\checkmark$ & $\checkmark$ & $\checkmark$ & $\checkmark$ & $\checkmark$ \\
\hline 3.10 & 1800 & -- & -- & -- & -- & -- \\
\hline 2.70 & 1800 & $\checkmark$ & $\checkmark$ & $\checkmark$ & $\checkmark$ & $\checkmark$ \\
\hline 2.70 & 1021 & -- & -- & -- & -- & -- \\
\hline 2.35 & 1800 & -- & -- & -- & -- & -- \\
\hline 2.35 & 1179 & -- & -- & -- & -- & -- \\
\hline 2.00 & 1800 & $\checkmark$ & $\checkmark$ & $\checkmark$ & $\checkmark$ & $\checkmark$ \\
\hline 2.00 & 1396 & -- & -- & -- & -- & -- \\
\hline 2.00 & 1021 & -- & -- & -- & -- & -- \\
\hline 1.60 & 1800 & -- & -- & -- & -- & -- \\
\hline 1.20 & 1800 & -- & -- & -- & -- & -- \\
\hline 1.20 & 1179 & -- & -- & -- & -- & -- \\
\hline 1.20 & 679 & -- & -- & -- & -- & -- \\
\hline 1.20 & 300 & -- & -- & -- & -- & -- \\
\hline 1.00 & 275 & $x$ & $x$ & $x$ & $x$ & $x$ \\
\hline
\end{tabular}

\section{Thruster Operation}

All thruster performance results obtained during the remaining three PMS integration tests were compared to those of the RePAT. The thruster voltages and currents below were independently measured with multimeters and current shunts. Discharge voltages and discharge losses are shown in Figure 40 and Figure 41, respectively. Discharge voltages measured during the three PMS integration tests and RePAT were within $0.5 \mathrm{~V}$ at full power, but this bandwidth increased to $1.5 \mathrm{~V}$ at lower powers. Similarly, discharge losses were within $5 \mathrm{~W} / \mathrm{A}$ at full power, but this bandwidth increased to about $13 \mathrm{~W} / \mathrm{A}$ at low power. These larger dispersions at low power were due to the sensitivity of the discharge losses to propellant utilization efficiency at the lower beam currents and variations in discharge voltage, which is a characteristic of the PM1R thruster. Discharge chamber performance was therefore considered nominal. In addition to these data, discharge cathode ignition times during both system performance tests were within $6.0 \mathrm{~min}$.

The neutralizer keeper and coupling voltages are shown in Figure 42 and Figure 43, respectively. Neutralizer keeper and coupling voltages were within 1.0 and $0.5 \mathrm{~V}$ of the RePAT results, respectively, indicating little change between these tests. Neutralizer ignition times during both system performance tests were all within $4.0 \mathrm{~min}$.

Perveance limits for the three PMS integration tests, plotted in Figure 44, were within $20 \mathrm{~V}$ of the RePAT results, which is within the estimated measurement uncertainty. Electron backstreaming limits between the PMS integration tests and the RePAT, tabulated Table 12, were typically within $2 \mathrm{~V}$, and at one throttle level it was as high as $4 \mathrm{~V}$, which is still considered small. Accelerator currents, shown in Figure 45 , were within $2.1 \mathrm{~mA}$ of the RePAT results.

The results of the three PMS integration tests ultimately demonstrated that for the range of PMS operating modes tested, PMS could successfully interface with and operate a NEXT ion thruster with no anomalous thruster or PMS behavior. 

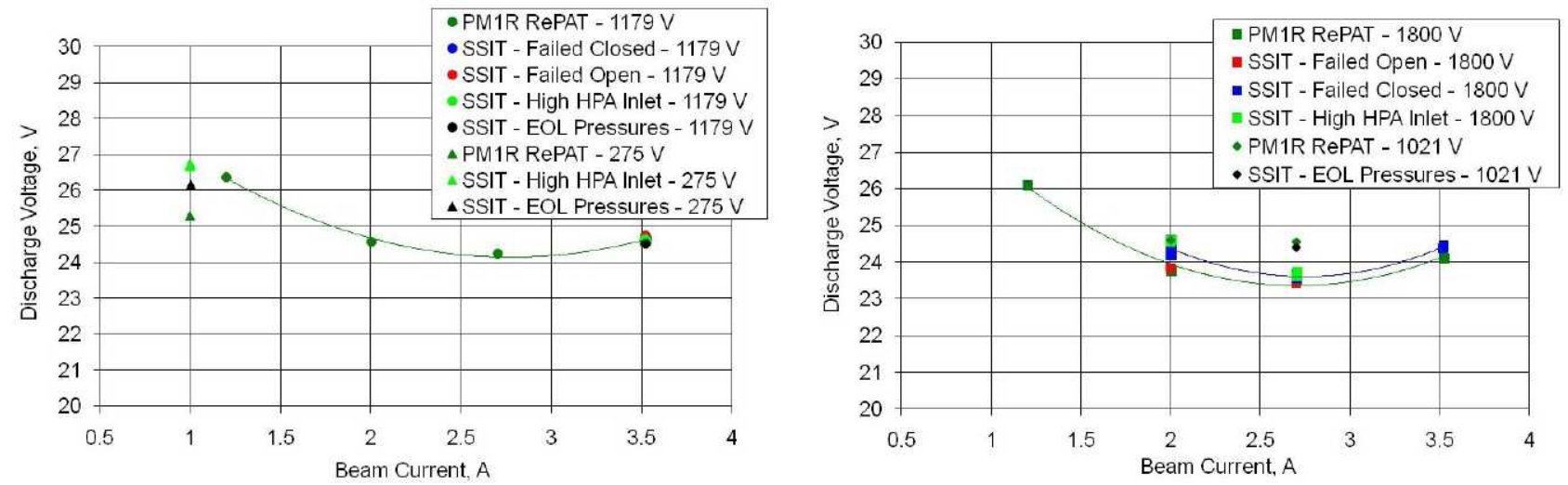

Figure 40.-Discharge voltages as a function of beam current at beam supply voltages of $275,1021,1179$, and $1800 \mathrm{~V}$ during the RePAT and various PMS tests. A power console was employed.
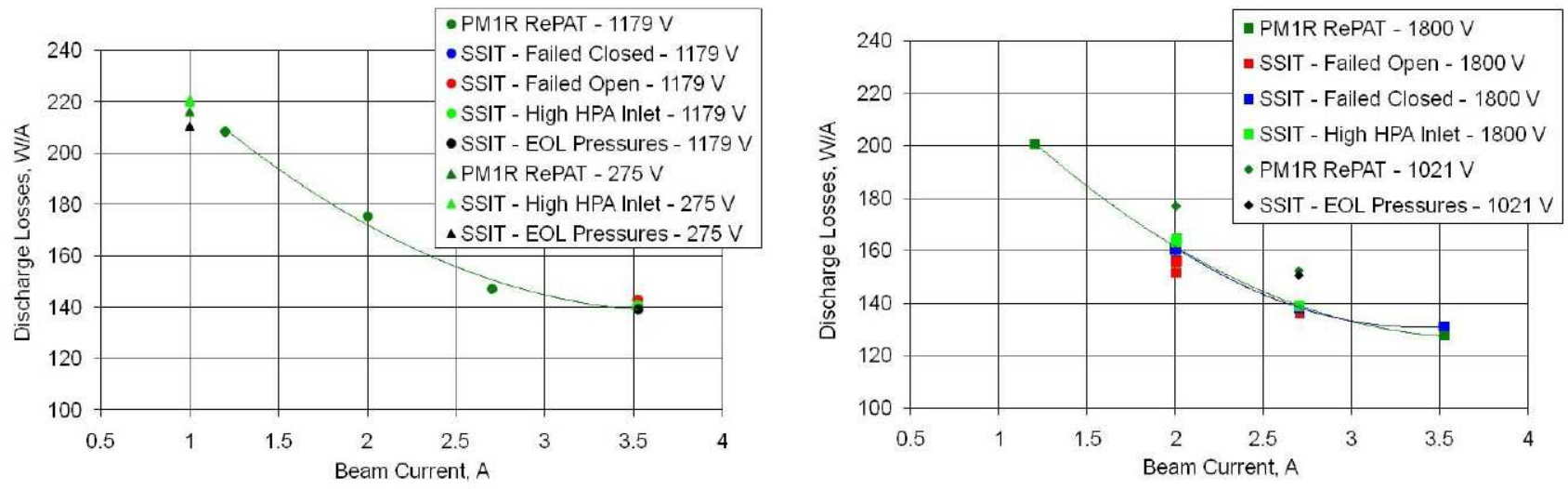

Figure 41.-Discharge losses as a function of beam current at beam supply voltages of $275,1021,1179$, and $1800 \mathrm{~V}$ during the RePAT and various PMS tests. A power console was employed.
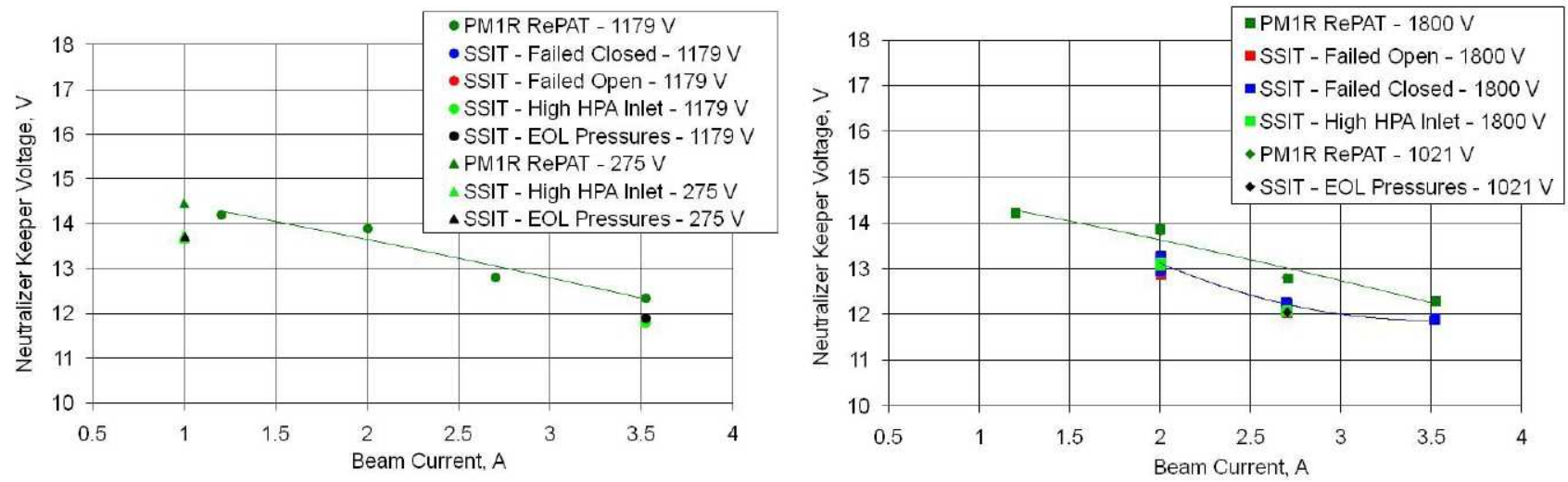

Figure 42.-Neutralizer keeper voltages as a function of beam current at beam supply voltages of $275,1021,1179$, and $1800 \mathrm{~V}$ during the RePAT and various PMS tests. A power console was employed. 

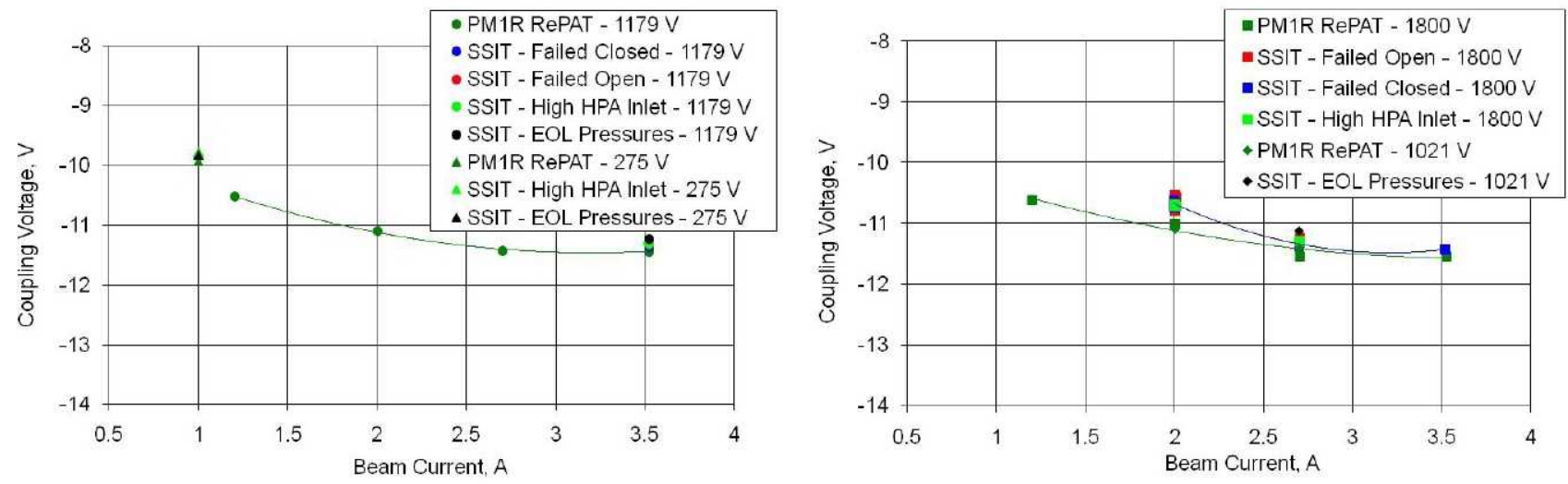

Figure 43.-Coupling voltages as a function of beam current at beam supply voltages of $275,1021,1179$, and $1800 \mathrm{~V}$ during the RePAT and various PMS tests. A power console was employed.

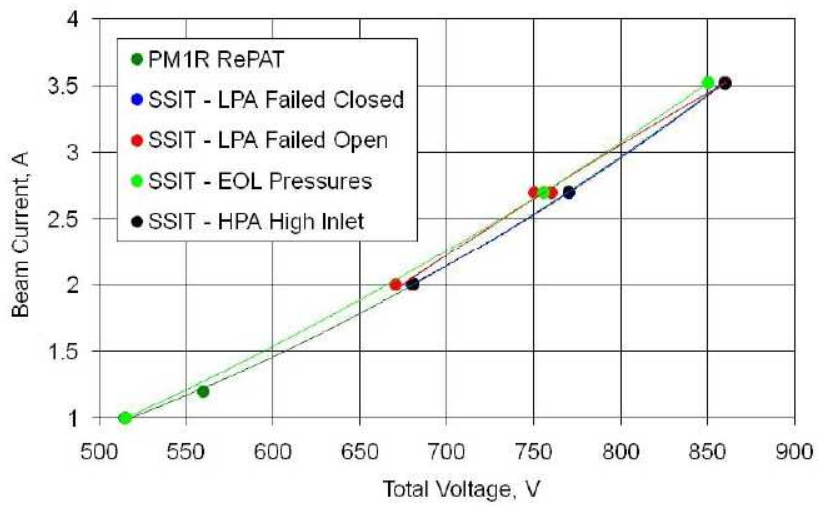

Figure 44.-Perveance limits measured during the RePAT and various PMS tests. A power console was employed.
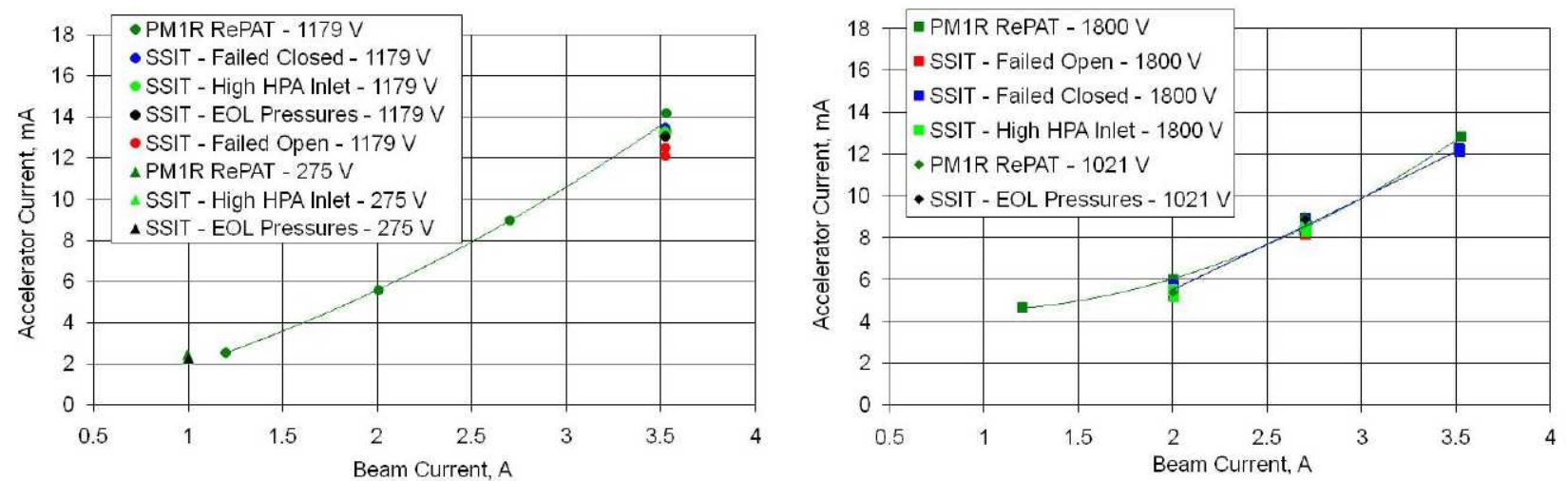

Figure 45.-Accelerator currents as a function of beam current at beam supply voltages of $275,1021,1179$, and $1800 \mathrm{~V}$ during the RePAT and various PMS tests. A power console was employed. 
TABLE 12.-ELECTRON BACKSTREAMING LIMITS MEASURED DURING THE

PMIR REPAT AND VARIOUS PMS TESTS WITH A POWER CONSOLE

\begin{tabular}{|c|c|c|c|c|c|c|}
\hline \multicolumn{2}{|c|}{ Throttle point } & \multicolumn{5}{|c|}{$\begin{array}{c}\text { Electron backstreaming limits, } \\
\text { V }\end{array}$} \\
\hline \multirow{2}{*}{$\begin{array}{l}\text { Beam current, } \\
\text { A }\end{array}$} & \multirow{2}{*}{$\begin{array}{l}\text { Beam supply voltage, } \\
\text { V }\end{array}$} & \multirow{2}{*}{$\begin{array}{l}\text { PM1R } \\
\text { RePAT }\end{array}$} & \multicolumn{2}{|c|}{ PMS fault mode } & \multirow{2}{*}{$\begin{array}{l}\text { PMS at high } \\
\text { inlet pressure }\end{array}$} & \multirow{2}{*}{$\begin{array}{l}\text { PMS at EOL } \\
\text { pressures }\end{array}$} \\
\hline & & & Failed closed & Failed open & & \\
\hline 3.52 & 1800 & -167 & -168 & ----- & ---- & ---- \\
\hline 3.52 & 1179 & -122 & -124 & $-126,-125$ & -125 & -125 \\
\hline 3.10 & 1800 & ---- & ---- & ---- & ---- & ---- \\
\hline 2.70 & 1800 & -149 & $-149,-149$ & $-149,-150$ & -151 & ---- \\
\hline 2.70 & 1179 & -110 & ---- & ---- & ---- & ---- \\
\hline 2.70 & 1021 & -95 & ---- & ---- & ---- & -98 \\
\hline 2.36 & 1800 & - & ---- & ---- & ---- & ---- \\
\hline 2.00 & 1800 & -126 & $-127,-127$ & $-126,-128$ & -127 & ----- \\
\hline 2.00 & 1396 & ---- & ---- & ---- & ---- & ---- \\
\hline 2.00 & 1179 & ---- & --- & ---- & ---- & ---- \\
\hline 2.00 & 1021 & -88 & ---- & ---- & ---- & ---- \\
\hline 1.60 & 1800 & ---- & ---- & ---- & ---- & ---- \\
\hline 1.20 & 1800 & -86 & ---- & ---- & $\cdots$ & ---- \\
\hline 1.20 & 1179 & -80 & ---- & $-\cdots$ & ---- & ---- \\
\hline 1.20 & 679 & -49 & ---- & ---- & ---- & $-\cdots$ \\
\hline
\end{tabular}

\section{PMS Performance}

The total LPA indicated flow rate error measured during LPA fault mode operation and operation at end-of-life inlet pressures are plotted in Figure 46 (total LPA flow rates during the high pressure inlet test could not be independently measured). Also included in the plot is the maximum commanded LPA branch flow rate error requirement for reference. Total LPA flow rates were found to be within 2.9 percent of the mass flow controller flow rates. The variation in flow rate error was largely due the main LPA branch flow calibration, which dominated the total. Mass flow controller error was \pm 1.0 percent of reading for all flow rates except the lowest flow rate, which was \pm 1.4 percent.

Low pressure assembly branch outlet pressures were also measured with pressure transducers on the XFSE and recorded by the DCIU Simulator during these PMS tests. These pressures were compared to those of the propulsion system performance tests. The results are shown in Figure 47. As the figure shows, LPA outlet pressures measured during the PMS integration tests of this section were nearly identical to those of the system performance test, which indicates that the flow rates were likely similar. As before, the highest measured pressure was at the outlet of the main LPA branch at full power, which was $13 \mathrm{kPa}$ (100 torr). These data will be used in a later analysis, along with the PMS calibration check data, to assess that individual LPA branch flow rate error.

To drain the propellant tank to low pressures during a mission, the NEXT PMS would operate with the HPA PFCV fully opened and the LPA inlet pressures would be allowed to be as low as that indicated in Table 13 based on the desired throttle point. The selection of these low pressures was based on the largest of the three LPA branch pressures at a particular throttling point plus the anticipated pressure drop across the HPA PFCV and margin. To simulate this mode of operation, HPA inlet pressures were still maintained at $350 \mathrm{kPa}$ (50 psia), however, the HPA outlet pressure was set to the pressures indicated in the table. Also calculated in the table below is the resulting residual propellant, assuming a $10,300 \mathrm{kPa}$ (1500 psia) tank pressure at $25^{\circ} \mathrm{C}$ and accounting for the anticipated pressure drop across a fully open HPA PFVC. As shown in the table, the highest and lowest beam current cases would yield residual propellant masses of 0.55 and 0.45 percent, respectively, of the initial propellant load. Indeed, even the normal mode of operation (i.e., at a $240 \mathrm{kPa}$ or 35 psia HPA outlet pressure) would yield a residual propellant mass of 0.72 percent of the initial propellant load. All of the aforementioned results meet the $\leq 1$ percent propellant residual requirement. 


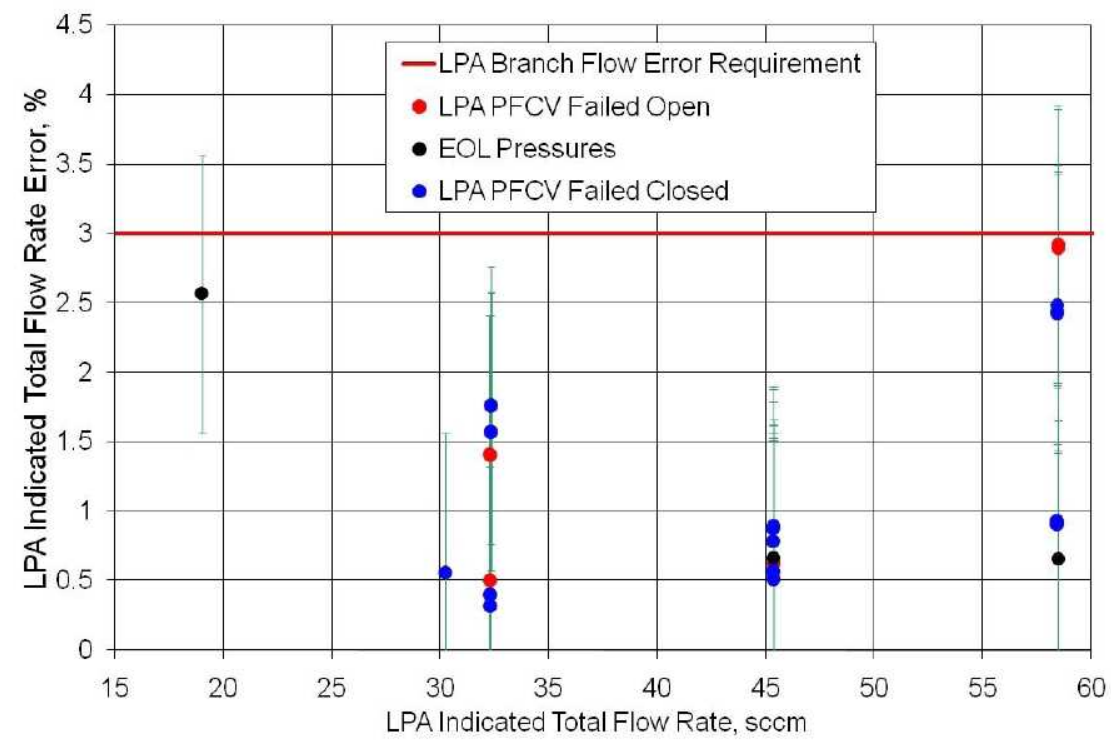

Figure 46._LPA indicated total flow rate error as a function of LPA total flow arte. Error bars denote mass flow controller error.

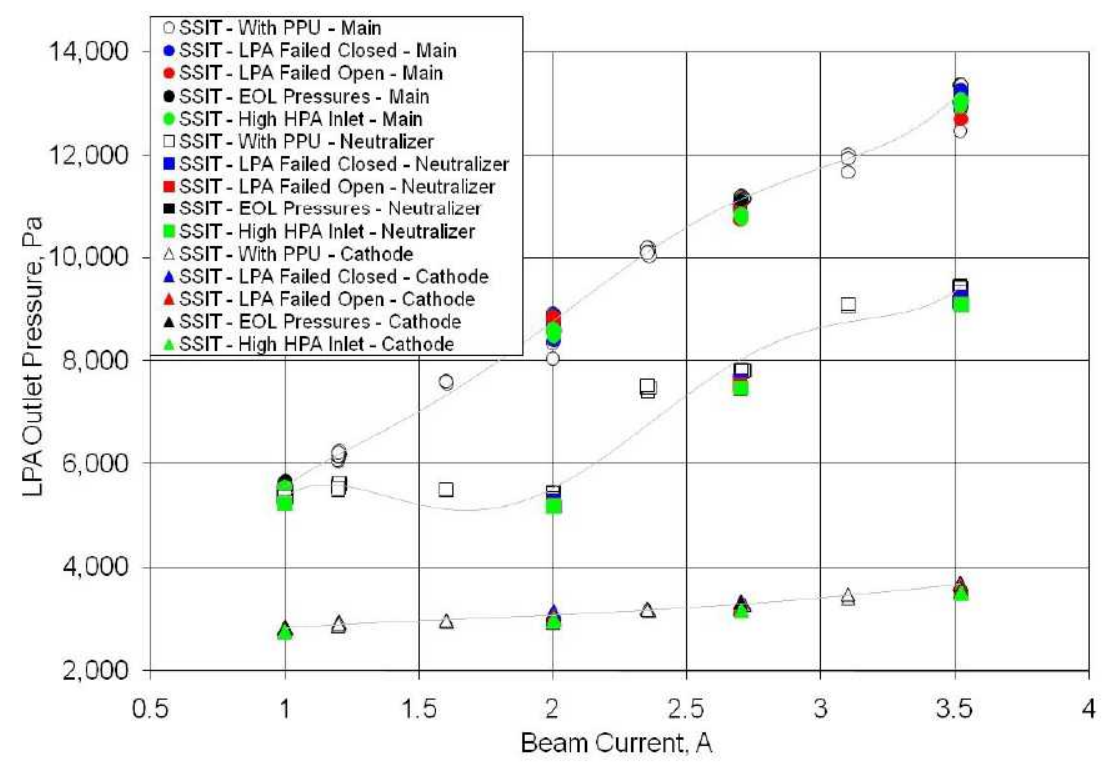

Figure 47.-LPA outlet pressures as a function of beam current for the PMS integration tests and the propulsion system performance tests.

TABLE 13.-RESIDUAL PROPELLANT AS A FUNCTION OF LPA INLET PRESSURE. THIS ASSUMES A 10,300 KPA (1500 PSIA) TANK PRESSURE AT $25^{\circ} \mathrm{C}$ AND ACCOUNTS FOR THE ANTICIPATED PRESSURE DROP ACROSS THE HPA PFVC

\begin{tabular}{|c|c|l|}
\hline $\begin{array}{c}\text { LPA inlet/HPA outlet pressure, } \\
\mathrm{kPa}(\mathrm{psia})\end{array}$ & $\begin{array}{c}\text { Residual propellant mass, percent of initial } \\
\text { propellant load }\end{array}$ & \multicolumn{1}{c|}{ Comments } \\
\hline $182(26.4)$ & 0.55 & Lowest pressure for 3.52 A \\
$165(23.9)$ & 0.49 & Lowest pressure for 2.00 A \\
$150(21.7)$ & 0.45 & Lowest pressure for 1.00 A \\
$240(35)$ & 0.72 & Normal operating mode \\
\hline
\end{tabular}


Propellant management system power consumption is tabulated in Table 14 for PMS operation at high inlet pressures and Table 15 for all other PMS integration tests. These powers were determined from currents and voltages that were measured by the DCIU Simulator for the thermal throttles and PFCVs, and by multimeters for the pressure transducers. Average PMS power consumption at a $28 \mathrm{~V}$ low power bus voltage for the high inlet pressure and end-of-life pressure tests were 9.81 and $9.83 \mathrm{~W}$, which are within 3 percent of that measured during propulsion system performance tests. As before, the thermal throttle heaters consumed up to 50 percent of the total PMS power. At the low power bus voltages of 22 and $34 \mathrm{~V}$ of Table 14, average PMS power consumptions were 9.30 and $10.30 \mathrm{~W}$, respectively, which were within 4 percent of those measured during system performance tests. As before, changes in power consumption between the low power bus voltages were only due to changes in pressure transducer power consumption because the pressure transducers were the only PMS components directly powered by the low power bus. Regardless, the PMS demonstrated successful operation over the full input power bus voltage range of 24 to $32 \mathrm{~V}$.

For PMS fault mode operation, PMS power consumption was measured to be as high as $22.39 \mathrm{~W}$ and the difference between maximum and minimum input powers ranged over a $13 \mathrm{~W}$ bandwidth, as shown in Table 15. The increased power consumption was almost entirely due to the thermal throttle heaters, which had to heat the thermal throttles to temperatures as high as $235^{\circ} \mathrm{C}$ for these tests. The large bandwidth of input powers were due to the various thermal throttle temperatures during fault mode operation.

The PMS met its power requirements for normal and fault mode operation during steady state operation. The maximum measured LPA power consumption during normal mode operation was $8.51 \mathrm{~W}$, which was less than the $15 \mathrm{~W}$ maximum requirement. The maximum measured HPA power consumption during normal mode operation was 1.92 or $2.50 \mathrm{~W}$ when the mock-up pressure transducer power is included. Both results are less than the $5 \mathrm{~W}$ maximum HPA requirement. For fault mode operation, the maximum measured LPA power consumption was $21.53 \mathrm{~W}$, which was less than the $25 \mathrm{~W}$ maximum requirement. The maximum measured HPA power consumption during fault mode operation was 1.63 or $2.11 \mathrm{~W}$ when the mock-up pressure transducer power is included. Both results are less than the $5 \mathrm{~W}$ maximum HPA requirement.

TABLE 14.-PMS POWER CONSUMPTION AVERAGES, MAXIMA, AND MINIMA AS A FUNCTION OF LOW POWER BUS VOLTAGE DURING PMS OPERATION AT HIGH INLET PRESSURE

\begin{tabular}{|c|c|c|c|c|c|c|c|c|c|}
\hline \multirow{2}{*}{$\begin{array}{c}\text { PMS LPB } \\
\text { voltage, } \\
\text { V }\end{array}$} & & \multicolumn{3}{|c|}{$\begin{array}{c}\text { HPA power, } \\
\text { W }\end{array}$} & \multicolumn{4}{|c|}{$\begin{array}{l}\text { LPA power, } \\
\text { W }\end{array}$} & \multirow{2}{*}{$\begin{array}{c}\text { Total PMS } \\
\text { power, } \\
\text { W }\end{array}$} \\
\hline & & $\begin{array}{c}\text { Pressure } \\
\text { transducers }\end{array}$ & PFCV & Total & $\begin{array}{c}\text { Pressure } \\
\text { transducers }\end{array}$ & PFCV & $\begin{array}{l}\text { Thermal } \\
\text { throttle }\end{array}$ & Total & \\
\hline 22 & Average & 0.75 & 0.75 & 1.50 & 1.11 & 1.84 & 4.86 & 7.80 & 9.30 \\
\hline 22 & Maximum & 0.75 & 0.76 & 1.51 & 1.11 & 1.87 & 4.98 & 7.92 & 9.41 \\
\hline 22 & Minimum & 0.75 & 0.72 & 1.47 & 1.11 & 1.82 & 4.73 & 7.69 & 9.20 \\
\hline 28 & Average & 0.95 & 0.75 & 1.70 & 1.41 & 1.83 & 4.87 & 8.11 & 9.81 \\
\hline 28 & Maximum & 0.96 & 0.76 & 1.71 & 1.41 & 1.87 & 5.05 & 8.27 & 9.97 \\
\hline 28 & Minimum & 0.95 & 0.72 & 1.67 & 1.40 & 1.81 & 4.72 & 7.99 & 9.70 \\
\hline 34 & Average & 1.16 & 0.75 & 1.90 & 1.71 & 1.83 & 4.86 & 8.40 & 10.30 \\
\hline 34 & Maximum & 1.16 & 0.76 & 1.92 & 1.71 & 1.87 & 4.98 & 8.51 & 10.41 \\
\hline 34 & Minimum & 1.16 & 0.72 & 1.88 & 1.70 & 1.82 & 4.73 & 8.29 & 10.21 \\
\hline
\end{tabular}

TABLE 15.-PMS POWER CONSUMPTION AVERAGES, MAXIMA, AND MINIMA AS A FUNCTION OF PMS OPERATING MODE

\begin{tabular}{|c|c|c|c|c|c|c|c|c|c|}
\hline \multirow{2}{*}{$\begin{array}{c}\text { PMS } \\
\text { operating } \\
\text { mode }\end{array}$} & & \multicolumn{3}{|c|}{$\begin{array}{c}\text { HPA power, } \\
\text { W }\end{array}$} & \multicolumn{4}{|c|}{$\begin{array}{c}\text { LPA power, } \\
\text { W }\end{array}$} & \multirow{2}{*}{$\begin{array}{c}\text { Total PMS } \\
\text { power, } \\
\text { W }\end{array}$} \\
\hline & & $\begin{array}{c}\text { Pressure } \\
\text { transducers }\end{array}$ & PFCV & Total & $\begin{array}{c}\text { Pressure } \\
\text { transducers }\end{array}$ & PFCV & $\begin{array}{l}\text { Thermal } \\
\text { throttle }\end{array}$ & Total & \\
\hline \multirow{3}{*}{$\begin{array}{l}\text { Fault mode } \\
\text { PFCV closed }\end{array}$} & Average & 0.96 & 0.65 & 1.61 & 1.41 & 1.21 & 10.23 & 12.85 & 14.46 \\
\hline & Maximum & 0.96 & 0.67 & 1.63 & 1.41 & 1.27 & 18.21 & 20.80 & 22.39 \\
\hline & Minimum & 0.96 & 0.60 & 1.56 & 1.41 & 0.99 & 5.03 & 7.70 & 9.33 \\
\hline \multirow{3}{*}{$\begin{array}{l}\text { Fault mode } \\
\text { PFCV open }\end{array}$} & Average & 0.96 & 0.62 & 1.58 & 1.41 & 1.99 & 10.89 & 14.29 & 15.87 \\
\hline & Maximum & 0.96 & 0.65 & 1.60 & 1.42 & 2.04 & 18.14 & 21.53 & 23.12 \\
\hline & Minimum & 0.96 & 0.60 & 1.56 & 1.40 & 1.95 & 5.59 & 8.99 & 10.56 \\
\hline \multirow{3}{*}{$\begin{array}{l}\text { EOL } \\
\text { pressures }\end{array}$} & Average & 0.96 & 0.65 & 1.60 & 1.41 & 1.91 & 4.90 & 8.22 & 9.83 \\
\hline & Maximum & 0.96 & 0.65 & 1.61 & 1.41 & 1.93 & 5.04 & 8.37 & 9.98 \\
\hline & Minimum & 0.96 & 0.64 & 1.60 & 1.41 & 1.90 & 4.78 & 8.08 & 9.68 \\
\hline
\end{tabular}




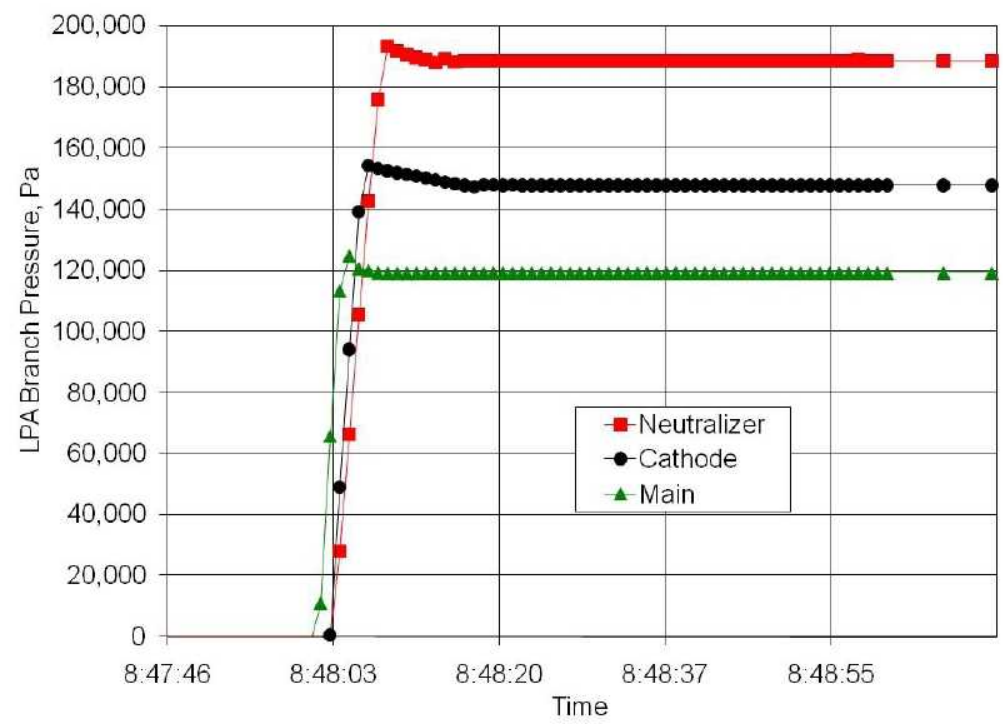

Figure 48.-LPA branch pressures as a function of time during flow initiation.

During these PMS integration tests, it was found that whenever an LPA or HPA PFCV driver circuit was commanded to regulate to a different pressure, the driver circuit always overshot the new commanded pressure. This is demonstrated in Figure 48 for the LPA PFCVs, however, this was also found to occur with the HPA PFCV as well. A later review of prior PMS test data showed that these pressure overshoots had always occurred. In addition, the amount of pressure overshoot was found to be a function of the inlet pressure. This behavior was attributed to an improper tuning of the proportionalintegral-derivative loop within the PFCV driver circuit. Although this improper tuning had no impact on the tests conducted, there was concern that fault mode testing with a HPA PFCV failed open presented a risk to the LPA. If the pressure overshoot was large enough, it could damage the LPA pressure transducers or latch valves. As a result, fault mode testing with a HPA PFCV failed open was skipped.

\section{Propulsion System Functionality and Fault Handling Without Thruster Operation}

A large number of tests were conducted throughout the SSIT to demonstrate propulsion system functionality and fault handling. This section will discuss the results of PMS flow throttling tests and PPU regulation across full power supply range and interlock tests. During all tests described in this section, the PM1R thruster was not operated, although the PMS was still connected to it. The DCIU Simulator controlled both the PMS and PPU, as well as the XFSE. The flow path and valve positions for the PMS and XFSE are identical to that used in the PM1R-PMS integration test, as shown in Figure 27. As with prior tests, measurements were made in $5 \mathrm{~s}$ intervals for $5 \mathrm{~min}$ and averaged to reduce mass flow controller measurement error. The PPU was configured as shown in Figure 13, except that it was connected to a resistive load so that the full power supply regulation range could be demonstrated. The PPU was under vacuum and the baseplate temperature was maintained at $25^{\circ} \mathrm{C}$. The following sections will separately discuss the results of PMS and PPU tests.

\section{PMS Results}

To demonstrate that the PMS could throttle the flow rate within the $300 \mathrm{~s}$ requirement, the PMS was throttled over a total of 11 different sets of flow rates, as shown in Table 16. These flow rate sets included the maximum and minimum branch flow rate requirements (i.e., test points 1 to 9) as well as the high and low power flow rates (i.e., test points 10 and 11, respectively). Demonstration of throttling times included 26 variations of throttling between the test points in Table 16. The flow rate throttling time was defined as 
the time required to reach 5 percent of the next commanded set of flow rates. The overall maximum flow rate throttling transition time was measured to be $155 \mathrm{~s}$. Not surprisingly, this time was that required to decrease the cathode flow rate from $6.00 \mathrm{sccm}$ to $2.00 \mathrm{sccm}$. Throttling times for branch flow rate increases are controlled by the PFCV and its driver circuit and were always within $11 \mathrm{~s}$. Throttling times for branch flow rate decreases, however, are a function of the volume being drained and the flow restriction. The cathode branch had one of the highest flow restrictions and the largest internal volume. The maximum flow rate throttling transition time from high to low power flow rates and from low to high power flow rates was 43 and $11 \mathrm{~s}$, respectively. These durations were all within the $300 \mathrm{~s}$ requirement.

TABLE 16- - LPA FLOW RATE COMBINATIONS USED
TO DEMONSTRATE PMS THROTTLING TIMES
\begin{tabular}{|c|c|c|c|}
\hline \multicolumn{2}{c}{ Main flow rate, } & Cathode flow rate, & Neutralizer flow rate, \\
sccm & sccm & sccm \\
\hline 1 & 50.0 & 6.00 & 6.00 \\
2 & 50.0 & 2.00 & 6.00 \\
3 & 50.0 & 6.00 & 2.50 \\
4 & 50.0 & 2.00 & 2.50 \\
5 & 12.0 & 6.00 & 6.00 \\
6 & 12.0 & 2.00 & 6.00 \\
7 & 12.0 & 6.00 & 2.50 \\
8 & 12.0 & 2.00 & 2.50 \\
9 & 0.00 & 0.00 & 0.00 \\
10 & 49.6 & 4.87 & 4.01 \\
11 & 12.3 & 3.52 & 3.00 \\
\hline Required flow rate range & $12.0-50.0$ & $2.00-6.00$ & $2.50-6.00$ \\
\hline
\end{tabular}

\section{PPU Results}

The results of PPU power supply regulation range tests on a resistive load are given in Table 17 and Table 18. In some cases, the full power supply range was not demonstrated because the proper resistance was not available for the test. In most cases, though, these resistive load tests demonstrated that the PPU power supplies satisfied their required output current and voltage ranges. In addition to this, the accelerator power supply demonstrated a surge current capability of 0.9 A, satisfying the 0.6 A minimum requirement.

TABLE 17.-POWER PROCESSOR POWER SUPPLY REGULATION RANGE TESTS FOR THE NEUTRALIZER HEATER, DISCHARGE HEATER, AND NEUTRALIZER KEEPER POWER SUPPLIES

[Italicized values indicate that the full range was not demonstrated because the proper resistance was not available]

\begin{tabular}{|c|c|c|c|c|c|c|c|c|c|c|}
\hline \multicolumn{2}{|c|}{ Power supply } & \multicolumn{3}{|c|}{ Neutralizer heater } & \multicolumn{3}{|c|}{ Discharge heater } & \multicolumn{3}{|c|}{ Neutralizer keeper } \\
\hline $\mathrm{HPB}=80 \mathrm{~V}$ & Voltage, V & 6.85 & 12.30 & 14.04 & 4.56 & 10.91 & 24.71 & 3.71 & 11.01 & 35.35 \\
\hline & Current, A & 3.50 & 8.51 & 5.70 & 3.51 & 8.51 & 4.65 & 1.00 & 2.99 & 2.24 \\
\hline $\mathrm{HPB}=160 \mathrm{~V}$ & Voltage, V & 6.84 & 12.26 & 16.87 & 4.55 & 10.89 & 29.56 & 3.71 & 11.01 & 35.91 \\
\hline & Current, A & 3.50 & 8.51 & 6.83 & 3.51 & 8.52 & 5.58 & 1.00 & 2.99 & 2.28 \\
\hline Requirement & $\begin{array}{l}\text { Voltage, V } \\
\text { Current, A }\end{array}$ & \multicolumn{3}{|c|}{$\begin{array}{c}3-12 \\
3.5-8.5\end{array}$} & \multicolumn{3}{|c|}{$\begin{array}{c}3-24 \\
3.5-8.5\end{array}$} & \multicolumn{3}{|c|}{$\begin{array}{c}8-32 \\
1-3\end{array}$} \\
\hline
\end{tabular}

TABLE 18.-POWER PROCESSOR POWER SUPPLY REGULATION RANGE TESTS

FOR THE DISCHARGE, ACCELERATOR, AND BEAM POWER SUPPLIES

[Italicized values indicate that the full range was not demonstrated because the proper resistance was not available]

\begin{tabular}{|c|l|r|r|r|r|r|r|r|r|}
\hline \multicolumn{2}{|c|}{ Power Supply } & \multicolumn{4}{|c|}{ Discharge } & \multicolumn{3}{|c|}{ Accelerator } & \multicolumn{2}{c|}{ Beam } \\
\hline $\mathrm{HPB}=80 \mathrm{~V}$ & Voltage, V & 13.07 & 26.11 & 36.97 & 27.62 & 102.1 & 527.0 & 276.3 & 1803 \\
& Current, A & 4.05 & 8.03 & 3.72 & 22.46 & 0.0065 & 0.032 & 0.82 & 3.51 \\
\hline $\mathrm{HPB}=160 \mathrm{~V}$ & Voltage, V & 13.11 & 26.26 & 49.15 & 27.65 & 102.1 & 527.0 & 275.9 & 1802 \\
& Current, A & 4.04 & 8.03 & 3.03 & 22.47 & 0.0065 & 0.032 & 0.82 & 3.51 \\
\hline Requirement & Voltage, V & \multicolumn{4}{|c|}{$15-35$} & \multicolumn{2}{|c|}{$115-525$} & $275-1800$ \\
& Current, A & \multicolumn{4}{|c|}{$4-24$} & & $0.00-0.04$ & $1.00-3.52$ \\
\hline
\end{tabular}

The results of PPU interlock tests on a resistive load are given in Table 19. All tests were conducted at a low PPU output power level. High power bus voltage tests were conducted at a $28 \mathrm{~V}$ low power bus voltage. The low power bus voltage test was conducted at a $100 \mathrm{~V}$ high power bus voltage. In all cases, 
the interlocks properly safed the PPU. However, the table shows that the neutralizer and discharge current interlocks were set $0.8 \mathrm{~A}$ and $0.2 \mathrm{~A}$ too low, respectively. While this does not present a significant issue, these interlocks can easily be reworked to yield the desired interlock value.

TABLE 19.-POWER PROCESSOR INTERNAL INTERLOCKS. [Italicized values indicate that the measured value did not satisfy the requirement]

\begin{tabular}{|l|c|c|}
\hline \multicolumn{1}{|c|}{ PPU interlocks } & Measured value & Requirement \\
\hline HPB overvoltage & $166.9 \mathrm{~V}$ & $>165 \mathrm{~V}$ \\
HPB undervoltage & $74.9 \mathrm{~V}$ & $<75 \mathrm{~V}$ \\
LPB undervoltage & $21.8 \mathrm{~V}$ & $<23.5 \mathrm{~V}$ \\
Neutralizer current & $1.20 \mathrm{~A}$ & $2 \mathrm{~A}$ \\
Discharge current & $3.42 \mathrm{~A}$ & $3.6 \mathrm{~A}$ \\
\hline
\end{tabular}

\section{Conclusions}

As a critical part of the NEXT test validation process, a single string integration test was performed on the NEXT propulsion system. The objectives of this test were to verify that an integrated system of major NEXT propulsion system elements meets project requirements, to demonstrate that the integrated system is functional across the entire power processor and propellant management system input ranges, and to demonstrate to potential users that the NEXT propulsion system is ready for transition to flight. Propulsion system elements included in this system integration test were: 1) an engineering model ion thruster, labeled PM1R, that has successfully completed environmental testing at qualification levels; 2) an engineering model propellant management system that has successfully completed environmental testing at qualification levels; 3) an engineering model power processor unit; and 4) a breadboard DCIU Simulator that acted as a test console. Project requirements that were verified during this system integration test included individual element requirements, integrated system requirements, and fault handling.

A detailed test plan was developed for the system integration test for verification of project requirements. It was divided into three major test types that included propulsion system demonstrations of performance, functionality, and fault handling. Propulsion system demonstrations of performance included measurements of system performance at standard input conditions and over the full range of PPU and PMS input conditions. Propulsion system demonstrations of functionality were essentially acceptance testing of the PPU, PMS, and DCIU Simulator in a system configuration and a demonstration of PMS ability to operate at the lowest possible PMS inlet pressures. Propulsion system demonstrations of fault handling included PMS fault mode operation, PPU fault and interlock testing on a resistive load, and DCIU fault handling tests. Other tests included PPU risk reduction tests on a resistive load, a PM1R reperformance acceptance test to establish a baseline thruster performance, a risk-reduction PMS-thruster integration test, and PMS calibration checks.

During the PM1R thruster RePAT, mass flow controllers were used to provide flow to the thruster and a power console made of commercially available power supplies provided power. All PM1R RePAT results were compared to those of the PAT test performed in the summer of 2007. The RePAT demonstrated that PM1R thruster operation and subassembly performance had not changed significantly since the past PAT test and environmental tests, and also established a baseline set of data for comparisons with the remaining tests.

Propellant management system calibrations were checked before and after all tests involving the PMS. Calibration checks were performed on individual LPA branches by comparing them to mass flow controller indicated flow rates. Two PMS shortcomings were uncovered during initial checks included a PFCV driver circuit inability maintain commanded flow rates when flowing gas through more than one LPA branch, and an insufficient amount of calibration data was obtained prior to the integration test to fully demonstrate fault mode capability. Calibration errors were low and were almost always $<3$ percent except for the lowest main flow rate during normal operation, but this was due to an improperly determined calibration equation. 
During the PM1R-PMS integration test, the thruster was operated with the PMS and a power console. The sum of the LPA indicated branch flow rates measured during the PM1R-PMS integration test were found to be within 3 percent of the mass flow controller flow rates. All PM1R-PMS integration test results were compared to those of the RePAT. Results demonstrated that PMS could successfully interface with and operate a NEXT ion thruster with no anomalous thruster behavior.

Propulsion system demonstrations of performance were included tests over the full range of PPU input conditions with the PPU baseplate temperature maintained at 25 and $50{ }^{\circ} \mathrm{C}$. All thruster performance results obtained during the two propulsion system performance tests were compared to those of the RePAT and the test results demonstrated that PPU and PMS could successfully interface with and operate a NEXT ion thruster with no anomalous thruster behavior. The sum of the indicated LPA branch flow rates were found to be within 3.25 percent of the mass flow controller flow rates. Average PMS power consumption at a $28 \mathrm{~V}$ low power bus voltage was $9.52 \mathrm{~W}$, with the LPA consuming $7.9 \mathrm{~W}$. The thermal throttle heaters consumed up to 49 percent of the total PMS power. The maximum measured LPA power consumption during normal mode operation was $8.35 \mathrm{~W}$, which was less than the $15 \mathrm{~W}$ maximum requirement. The maximum measured HPA power consumption during normal mode operation was $1.83 \mathrm{~W}$, which was also less than the $5 \mathrm{~W}$ maximum requirement.

The PPU successfully satisfied all power efficiency requirements against which it was tested, achieving a peak power efficiency of 0.954 . Power processor efficiencies were typically lower at a $50{ }^{\circ} \mathrm{C}$ baseplate temperature due to increased resistive losses, but they were still typically within 0.01 of the $25^{\circ} \mathrm{C}$ baseplate temperature efficiencies. The PPU functioned nominally over the low power bus voltage range of 22 to $34 \mathrm{~V}$ and peak housekeeping power was $28.1 \mathrm{~W}$. The PPU typically recycled the thruster successfully, however, continuous recycling caused by the PPU was found to occur during operation at elevated PPU internal temperatures. The PPU completed almost all of the planned propulsion system performance tests, but failed during full power thruster operation at a baseplate temperature of $50{ }^{\circ} \mathrm{C}$ due to faulty diodes in a beam module output rectifier stage. Following replacement of the diodes, a stacked ceramic capacitor on the input filter of a beam module failed. Root cause determination was still in progress at the time of this writing.

Because the PPU was not available for further testing, the remaining PMS-related integration tests were conducted using a power console. These tests included operation at a PMS inlet pressure of $6,200 \mathrm{kPa}(900 \mathrm{psia})$, demonstrations of PMS fault handling, and PMS operation at end-of-life inlet pressures. All thruster performance results obtained during the remaining three PMS integration tests were compared to those of the RePAT, and results from the PMS integration tests demonstrated that for the range of PMS operating modes tested, PMS could successfully interface with and operate a NEXT ion thruster with no anomalous thruster or PMS behavior. The sum of the indicated LPA branch flow rates measured during the all PMS integration test were found to be within 2.9 percent of the mass flow controller flow rates. For PMS fault mode operation, PMS power consumption was measured to be as high as $22.39 \mathrm{~W}$. The maximum PMS fault mode measured LPA power consumption was $21.53 \mathrm{~W}$, which is less than the $25 \mathrm{~W}$ maximum requirement and the maximum measured HPA power consumption was $1.63 \mathrm{~W}$, which is less than the $5 \mathrm{~W}$ maximum requirement. For normal PMS operation, PMS power consumption was within 4 percent that of the system performance test. Propellant management system testing at end-of-life inlet pressures showed that the PMS could drain the propellant tank to a 0.45 percent residual propellant mass.

A number of PPU and PMS functionality and fault handling tests were conducted without thruster operation. To demonstrate that the PMS flow throttling capability, the PMS was throttled over a total of 11 different sets of flow rates, and the maximum flow rate throttling transition time was measured to be $155 \mathrm{~s}$ which was within the $300 \mathrm{~s}$ requirement.

The results of PPU power supply regulation range tests on a resistive load demonstrated that the PPU power supplies satisfied most of their required output current and voltage ranges against which they were tested. Although the neutralizer and discharge current interlocks were set 0.8 and $0.2 \mathrm{~A}$ too low, respectively, results of PPU interlock tests on a resistive load showed that in all cases, the interlocks properly safed the PPU. 
As a result of the PPU component failures, a number of propulsion system demonstrations of functionality and fault handling could not be completed. And because of the recycling issue at elevated internal temperatures, recycle tests during propulsion system demonstrations of performance could not be completed over the entire range of input conditions. These remaining demonstration tests will, therefore, require further system testing and will be completed following the repair of the PPU.

The system integration tests that were successfully completed, however, demonstrated much of the propulsion system's performance, functionality, and fault handling capabilities. Following the successful repair and retest of the PPU, the NEXT ion propulsion system will be shown to be ready for transition to flight.

\section{References}

1. Patterson, M.J. and Benson, S.W., "NEXT Ion Propulsion System Development Status and Performance," AIAA-2007-5199, July 2007.

2. Polk, J.E., et al., "Demonstration of the NSTAR Ion Propulsion System on the Deep Space One Mission," IEPC Paper 01-075, Oct. 2001.

3. Brophy, J. R., Garner, C.E., and Mikes, S., "Development Dawn Ion Propulsion System - Initial Checkout after Launch," AIAA-2008-4917, July 2006.

4. Benson, S.W. and Patterson, M.J., "NEXT Ion Propulsion System Progress Towards Technology Readiness," AIAA-2008-5285, July 2008.

5. Patterson, M.J., et al., "NEXT Ion Propulsion System: Single-string Integration Test Results," JANNAF Proceedings, May 2004.

6. "NASA Research and Technology Program and Project Management Requirements," NPR 7120.8, February 2008.

7. Hoskins, W.A., et al., "Development of a Prototype Model Ion Thruster for the NEXT System," AIAA-2004-4111, July 2004.

8. Snyder, J.S., et al., "Environmental Testing of the NEXT PM1R Ion Engine," IEPC Paper 2007-276, September 2007.

9. Aadland, R.S., et al., "Development Results of the NEXT Propellant Management System," JANNAF Proceedings, Dec. 2005.

10. Hoskins, W.A., et al., "Overview of the NEXT Ion Propulsion System Program at Aerojet," AIAA2005-3885, July 2005.

11. Pinero, L.R., et al., "Performance of the NEXT Engineering Model Power Processor Unit," AIAA2007-5214, July 2007.

12. Soulas, G.C., Domonkos, M.T., and Patterson, M.J., "Performance Evaluation of the NEXT Ion Engine," AIAA-2003-5278, July 2003.

13. Herman, D.A., Soulas, G.C., and Patterson, M.J., "Performance Evaluation of the Prototype-model NEXT Ion Thruster," AIAA-2007-5212, July 2007.

14. J. S. Snyder, J.R., et al., "Environmental Testing of the NEXT PM1 Ion Engine," AIAA-2007-5275, July 2007.

15. Vaughn, D.A., "Gimbal Development for the NEXT Ion propulsion System," AIAA-2005-3865, July 2005.

16. Aadland, et al., "Development Results of the NEXT Propellant Management System," JANNAF Proceedings, Dec. 2005.

17. Aadland, R.S. and Talerico, L., "NEXT Propellant Management System (PMS) Thermal Vacuum Cycle Test Report," Aerojet Internal Report 2007-R-2948, Aug. 14, 2007.

18. Patterson, M.J., et al., "NEXT Multi-Thruster Array Test-Engineering Demonstration," AIAA2006-5180, July 2006.

19. Soulas, G.C. and Patterson, M.J., "NEXT Ion Thruster Performance Dispersion Analyses," AIAA2007-5213, July 2007. 


\begin{tabular}{|c|c|c|}
\hline \multicolumn{2}{|c|}{ REPORT DOCUMENTATION PAGE } & $\begin{array}{l}\text { Form Approved } \\
\text { OMB No. } 0704-0188\end{array}$ \\
\hline \multicolumn{3}{|c|}{$\begin{array}{l}\text { The public reporting burden for this collection of information is estimated to average } 1 \text { hour per response, including the time for reviewing instructions, searching existing data sources, gathering and maintaining the } \\
\text { data needed, and completing and reviewing the collection of information. Send comments regarding this burden estimate or any other aspect of this collection of information, including suggestions for reducing this } \\
\text { burden, to Department of Defense, Washington Headquarters Services, Directorate for Information Operations and Reports (0704-018), } 1215 \text { Jefferson Davis Highway, Suite } 1224 \text {, Allington, VA } 222202-4302 \text {. } \\
\text { Respondents should be aware that notwithstanding any other provision of law, no person shall be subject to any penalty for failing to comply with a collection of information if it does not display a currently valid OMB } \\
\text { control number. } \\
\text { PLEASE DO NOT RETURN YOUR FORM TO THE ABOVE ADDRESS. }\end{array}$} \\
\hline $\begin{array}{l}\text { 1. REPORT DATE (DD-MM-YYYY) } \\
01-02-2010\end{array}$ & $\begin{array}{l}\text { 2. REPORT TYPE } \\
\text { Technical Memorandum }\end{array}$ & 3. DATES COVERED (From - To) \\
\hline \multirow{3}{*}{\multicolumn{2}{|c|}{$\begin{array}{l}\text { 4. TITLE AND SUBTITLE } \\
\text { NEXT Single String Integration Test Results }\end{array}$}} & 5a. CONTRACT NUMBER \\
\hline & & 5b. GRANT NUMBER \\
\hline & & 5c. PROGRAM ELEMENT NUMBER \\
\hline \multirow{3}{*}{\multicolumn{2}{|c|}{$\begin{array}{l}\text { 6. AUTHOR(S) } \\
\text { Soulas, George, C.; Patterson, Michael, J.; Pinero, Luis; Herman, Daniel, A.; Snyder, John, } \\
\text { Steven }\end{array}$}} & 5d. PROJECT NUMBER \\
\hline & & 5e. TASK NUMBER \\
\hline & & $\begin{array}{l}\text { 5f. WORK UNIT NUMBER } \\
\text { WBS } 346620.04 .05 .03 .11\end{array}$ \\
\hline \multicolumn{2}{|c|}{$\begin{array}{l}\text { 7. PERFORMING ORGANIZATION NAME(S) AND ADDRESS(ES) } \\
\text { National Aeronautics and Space Administration } \\
\text { John H. Glenn Research Center at Lewis Field } \\
\text { Cleveland, Ohio 44135-3191 }\end{array}$} & $\begin{array}{l}\text { 8. PERFORMING ORGANIZATION } \\
\text { REPORT NUMBER } \\
\text { E-17131 }\end{array}$ \\
\hline \multirow{2}{*}{\multicolumn{2}{|c|}{$\begin{array}{l}\text { 9. SPONSORING/MONITORING AGENCY NAME(S) AND ADDRESS(ES) } \\
\text { National Aeronautics and Space Administration } \\
\text { Washington, DC 20546-0001 }\end{array}$}} & $\begin{array}{l}\text { 10. SPONSORING/MONITOR'S } \\
\text { ACRONYM(S) } \\
\text { NASA }\end{array}$ \\
\hline & & $\begin{array}{l}\text { 11. SPONSORING/MONITORING } \\
\text { REPORT NUMBER } \\
\text { NASA/TM-2010-216087 }\end{array}$ \\
\hline \multicolumn{3}{|c|}{$\begin{array}{l}\text { 12. DISTRIBUTION/AVAILABILITY STATEMENT } \\
\text { Unclassified-Unlimited } \\
\text { Subject Category: } 20 \\
\text { Available electronically at http://gltrs.grc.nasa.gov } \\
\text { This publication is available from the NASA Center for AeroSpace Information, 443-757-5802 }\end{array}$} \\
\hline
\end{tabular}

\section{SUPPLEMENTARY NOTES}

\section{ABSTRACT}

As a critical part of NASA's Evolutionary Xenon Thruster (NEXT) test validation process, a single string integration test was performed on the NEXT ion propulsion system. The objectives of this test were to verify that an integrated system of major NEXT ion propulsion system elements meets project requirements, to demonstrate that the integrated system is functional across the entire power processor and xenon propellant management system input ranges, and to demonstrate to potential users that the NEXT propulsion system is ready for transition to flight. Propulsion system elements included in this system integration test were an engineering model ion thruster, an engineering model propellant management system, an engineering model power processor unit, and a digital control interface unit simulator that acted as a test console. Project requirements that were verified during this system integration test included individual element requirements, integrated system requirements, and fault handling. This paper will present the results of these tests, which include: integrated ion propulsion system demonstrations of performance, functionality and fault handling; a thruster re-performance acceptance test to establish baseline performance; a risk-reduction PMS-thruster integration test; and propellant management system calibration checks.

\section{SUBJECT TERMS}

Ion thruster; Ion engine; Ion propulsion

\begin{tabular}{|c|c|c|c|c|c|}
\hline \multicolumn{3}{|c|}{ 16. SECURITY CLASSIFICATION OF: } & \multirow{2}{*}{$\begin{array}{l}\text { 17. LIMITATION OF } \\
\text { ABSTRACT } \\
\text { UU }\end{array}$} & \multirow{2}{*}{$\begin{array}{l}\text { 18. NUMBER } \\
\text { OF } \\
\text { PAGES } \\
54\end{array}$} & \multirow{2}{*}{$\begin{array}{l}\text { 19a. NAME OF RESPONSIBLE PERSON } \\
\text { STI Help Desk (email:help@sti.nasa.gov) } \\
\text { 19b. TELEPHONE NUMBER (include area code) } \\
\text { 443-757-5802 }\end{array}$} \\
\hline $\begin{array}{l}\text { a. REPORT } \\
\text { U }\end{array}$ & $\begin{array}{l}\text { b. ABSTRACT } \\
\text { U }\end{array}$ & $\begin{array}{l}\text { c. THIS } \\
\text { PAGE } \\
\text { U }\end{array}$ & & & \\
\hline
\end{tabular}



